\title{
Centro de Monitoreo del Aprendizaje \\ a lo Largo de la Vida para Todos
}

Alba Luz Muñoz Restrepo Anabela Villa Saavedra Nora Elena Gil Ramírez 



\section{Centro de Monitoreo del Aprendizaje a lo Largo de la Vida para Todos}

Alba Luz Muñoz Restrepo Anabela Villa Saavedra Nora Elena Gil Ramírez 


\section{¿Cómo citar este libro? / How to cite this book?}

Muñoz Restrepo, A. L., Villa Saavedra, A. y Gil Ramírez, N. E. (2021). Centro de Monitoreo del Aprendizaje a lo Largo de la Vida para Todos (Working papers N. ${ }^{\circ} 3$ ). Ediciones Universidad Cooperativa de Colombia. DOI: https://dx.doi.org/10.16925/wpgp.05 


\section{Resumen}

En el marco del Proyecto Educativo Institucional de la Universidad Cooperativa de Colombia y, específicamente, desde su Modelo Educativo Crítico con Enfoque de Competencias, surge la necesidad de monitorear el "Aprendizaje a lo largo de toda la Vida". De esta manera, el centro de monitoreo se entiende como el proceso sistemático de recolectar, analizar y utilizar información para hacer seguimiento y medición permanente a las variables e indicadores que intervienen en el desarrollo del modelo educativo y el aprendizaje del estudiante. Esto va a permitir evidenciar la calidad del Proyecto Educativo Institucional, puesto que facilita estimar la variación en el desarrollo de las competencias de los estudiantes, desde el momento de ingreso a la universidad y hasta que se integran a la vida laboral como profesionales. En la parte inicial, se presentan experiencias que otras instituciones han tenido alrededor del seguimiento al rendimiento académico del estudiante, así como experiencias que muestran cómo la Universidad Cooperativa de Colombia desarrolla su propia estrategia de monitoreo al estudiante. Esta primera parte finaliza con la revisión conceptual acerca del aprendizaje a lo largo de la vida y la importancia de la evaluación. En seguida, se explica cómo se gestiona el Centro de Monitoreo del Aprendizaje a lo largo de la Vida para Todos en cada una de sus fases (antes, durante y después), mediante algunos indicadores que evidencian los resultados alcanzados entre 2015 y 2020.

Palabras clave: aprendizaje, evaluación, indicadores, modelo educativo, monitoreo, rendimiento, resultados de aprendizaje. 



\section{Centro de Monitoreo del Aprendizaje a lo Largo de la Vida para Todos}

Alba Luz Muñoz Restrepo

Anabela Villa Saavedra

Nora Elena Gil Ramírez 



\section{Acerca de las autoras}

\section{Alba Luz Muñoz Restrepo}

Magíster en Epidemiología. Vicerrectora Académica,

Universidad Cooperativa de Colombia.

Correo electrónico: alba.munoz@ucc.edu.co

\section{Anabela Villa Saavedra}

Magíster en Educación. Directora de Gestión de Proyectos Especiales,

Universidad Cooperativa de Colombia.

Correo electrónico: anabela.villa@ucc.edu.co

\section{Nora Elena Gil Ramírez}

Magíster en Investigación Psicoanalítica. Investigadora externa.

Correo electrónico: noraelenagilr@gmail.com 


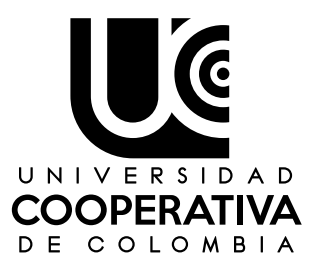

COOPERATIVA

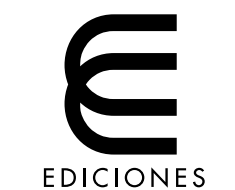

iversidad Cooperativa de Colombia

\section{GREEN PAPERS}

Centro de Monitoreo del Aprendizaje a lo Largo de la Vida para Todos

(c) Ediciones Universidad Cooperativa de Colombia,

Bogotá, noviembre de 2021

(c) Alba Luz Muñoz Restrepo, Anabela Villa Saavedra, Nora Elena Gil Ramírez

\section{Colección Green Papers}

DOI: https://dx.doi.org/10.16925/wpgp.05

\section{Fondo Editorial}

DIRECTOR NACIONAL EDITORIAL

Julián Pacheco Martínez

ESPECIALISTA EN GESTIÓN EDITORIAL

Daniel Urquijo Molina

ESPECIALISTA EN PRODUCCIÓN EDITORIAL (LIBROS)

Camilo Moncada Morales

ESPECIALISTA EN PRODUCCIÓN EDITORIAL (REVISTAS)

Andrés Felipe Andrade Cañón

ANALISTA EDITORIAL

Claudia Carolina Caicedo Baquero

\section{Proceso editorial}

CORRECCIÓN DE ESTILO

Guiovana Camila Suárez

DIAGRAMACIÓN Y DISEÑO DE PORTADA

Juan Pablo Rátiva

Impreso en Bogotá, Colombia. Depósito legal según

el Decreto 460 de 1995 


\section{Contenido}

$\begin{array}{ll}\text { Introducción } & 13\end{array}$

$\begin{array}{ll}\text { Marco de referencia } & 16\end{array}$

$\begin{array}{ll}\text { Antecedentes } & 17\end{array}$

$\begin{array}{ll}\text { Marco conceptual } & 22\end{array}$

Gestión del Centro de Monitoreo del Aprendizaje a lo Largo

de la Vida para Todos en la Universidad Cooperativa de Colombia 32

Gestión en el antes 33

$\begin{array}{ll}\text { Gestión en el durante } & 39\end{array}$

Gestión en el después $\quad 68$

$\begin{array}{ll}\text { Conclusiones } & 72\end{array}$

$\begin{array}{ll}\text { Glosario } & 76\end{array}$

$\begin{array}{lc}\text { Referencias } & 88\end{array}$ 



\section{Introducción}

\section{A lgunos países han definido la importancia y la}

centralidad que tiene para los sistemas de aseguramiento de la calidad la evaluación de los aprendizajes; no tiene mucha validez que un sistema de aseguramiento de la calidad busque garantizar la calidad de la educación cuando los estudiantes no logran niveles de competencia mínimos para ejercer una profesión; hay una incoherencia entre fines y medios en lo que respecta a tener una educación de calidad, en este caso profesionales competentes, y un sistema que pasa por alto la necesidad de evaluar el proceso de escolarización en una IEs determinada. (Celis Giraldo, 2013, p. 21)

Por su parte, la Organización para la Cooperación y el Desarrollo Económicos (OCDE) plantea que, dentro de los retos de la Educación, se encuentra:

Desarrollar una visión del sistema educativo como un continuo con expectativas claras de aprendizaje en cada etapa. Un marco curricular nacional haría que las transiciones fuesen más fáciles para los estudiantes, ayudaría a los profesores en el aula y permitiría al país subir el nivel y responder mejor a los objetivos socioeconómicos nacionales. (OCDE, 2016, p. 5)

A nivel europeo, en el marco del pacto de Bolonia, el establecimiento de sistemas de reconocimiento y validación de todas las formas de aprendizaje se ha convertido en uno de los temas centrales en los sectores de la educación y la formación. En este contexto, se ha hecho necesario permitir que los logros de aprendizaje sean reconocidos y validados, independientemente de donde se 
lleven a cabo las formas de aprendizaje permanente (EURYDICE, 2013). Ahora bien, entra en la consideración otro componente determinante en el aprendizaje: el "Aprendizaje Universal”. El Ministerio de Educación Nacional (MEN) expresa la importancia y necesidad de contar con un Diseño Universal para el Aprendizaje (DUA) y lo define como "un conjunto de principios y estrategias que incrementan las posibilidades de aprendizaje y orientan al maestro en la formulación de metodologías flexibles teniendo en cuenta la diversidad en el aula" (MEN, s. f., p. 3).

La enseñanza requiere considerar múltiples elementos para lograr un aprendizaje efectivo en el estudiante, eliminando las barreras: utilizar diversidad de materiales, técnicas y estrategias para llegar al estudiante; aplicar la estrategia psicológica para entender mejor a los estudiantes y buscar adaptar sus experiencias de aprendizaje. Esto es fundamental en una educación inclusiva.

Atendiendo a estas tendencias, la Universidad Cooperativa de Colombia (UCC), a través del Centro de Monitoreo del Aprendizaje a lo Largo de la Vida para Todos, obtendrá información que permita establecer la conexión entre las vías formales, no formales e informales de aprendizaje, mediante resultados de evaluación provenientes del sector educativo, la formación profesional, la formación en las empresas y la experiencia laboral de las personas. Resultados de aprendizaje que comprendan diversos niveles y jerarquías educativos, con el fin de hacer un reconocimiento formal a una persona que ha alcanzado los resultados de aprendizaje, de acuerdo con los niveles determinados por la Universidad. Su objetivo es servir como

herramienta de medición permanente a las variables e indicadores cuantitativos y cualitativos, que intervienen en el desarrollo del modelo educativo, la evolución y desempeño académico de los estudiantes, generando alarmas tempranas para la toma de decisiones oportunas y efectivas a nivel institucional. (UCC, 2017, p. 10) 



\section{- 606 - - ERA.}

15. $\frac{d+10}{10}$

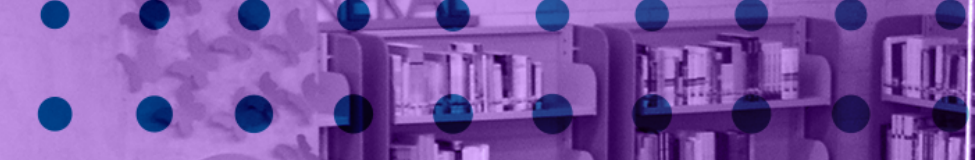

ind IIt 00

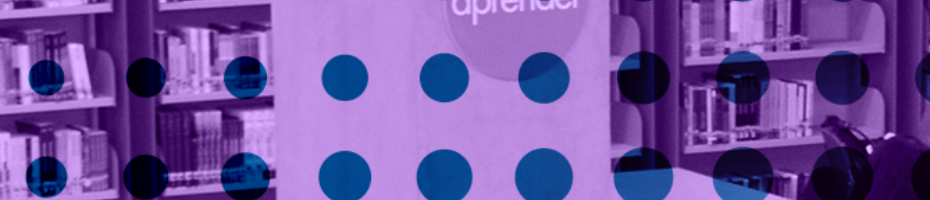

2.1. 4 -

वे

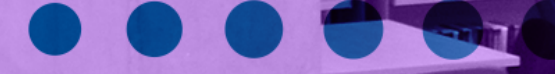

00000

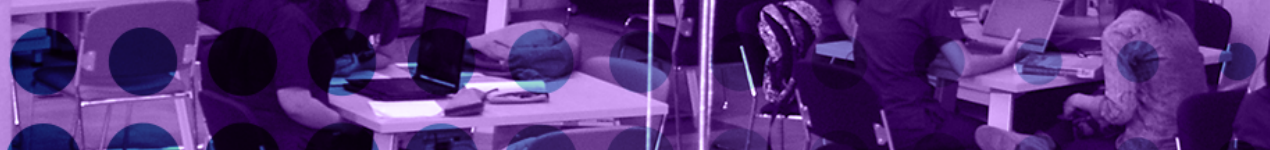

a)

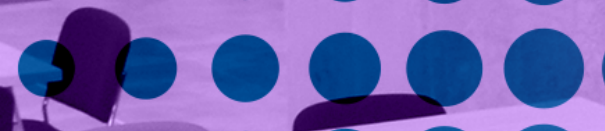

dेe

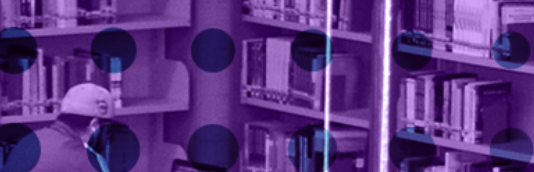

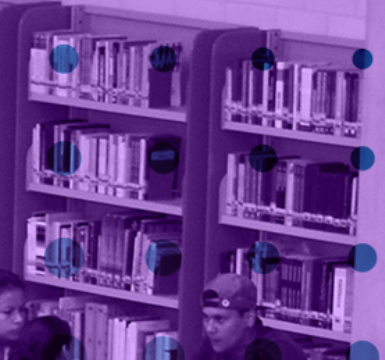

8000020

e.

(2)

-

5

$>1$

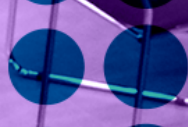

\section{$\triangle$ MARCO DE REFERENCIA \\ 4)}

$\gamma<$

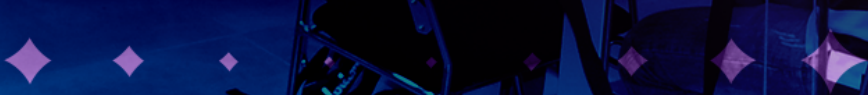

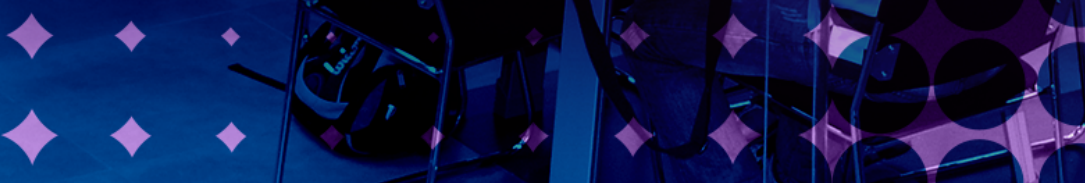

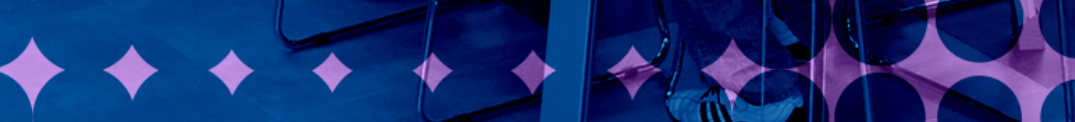

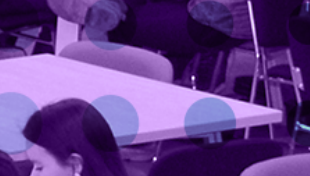




\section{Antecedentes}

T a Organización de las Naciones Unidas para la Educación, la Ciencia y la

Cultura (UNESCO, 2019) establece que un plan de monitoreo eficaz debe responder a varias preguntas: ¿qué indicadores se requieren para medir efectividad del proceso? ¿Quién va a recolectar los datos y cómo se recolectarán? ¿Quién comprobará la calidad de los datos? ¿Cómo se gestionarán los datos y quién tendrá acceso a ellos? Partiendo de esto, se estructura cómo será el desarrollo, gestión y seguimiento del plan o programa del centro de monitoreo.

En Latinoamérica se encuentra la experiencia de la Universidad Diego Portales (UDP) que, en 2008, inició "el diseño e implementación de un sistema de aseguramiento de la calidad, con estrategias de evaluación y seguimiento planificadas y sistemáticas" (Valenzuela y Pérez, 2012, p. 225). Su propósito se orientó a "asegurar y mejorar la calidad de la oferta académica de las unidades, sus académicos y docentes, y la progresión de los estudiantes en sus programas de estudio" (Valenzuela y Pérez, 2012, p. 225).

Sin embargo, desde 2004, ya contaba con una serie de instrumentos y reportes de resultados difundidos internamente sobre los resultados de aprendizaje de sus estudiantes. El Sistema de Seguimiento de Estudiantes y Titulados, se inició en 2008 con el "desarrollo de un sistema de información para el monitoreo de la calidad" (Valenzuela y Pérez, 2012, p. 226), contando con tres herramientas principales: 
1. Informe de Calidad UDP (informe anual que sistematiza y analiza las principales áreas del quehacer de la universidad, principalmente por medio de indicadores cuantitativos).

2. Sistema de Indicadores de Calidad en internet (información académica vigente e histórica de un conjunto de indicadores, mediante el acceso a una plataforma en línea).

3. Sistema de Seguimiento de Estudiantes y Titulados (Valenzuela y Pérez, 2012).

Este último sistema o estrategia empleada por la UDP se trabaja a través de un conjunto de encuestas aplicadas a los estudiantes en distintos momentos de su trayectoria académica y a titulados de pregrado. La información generada incluye los tiempos en que el estudiante ingresa a la universidad, cuando deserta o en el transcurso de su carrera y cuando está en proceso de obtener su título.

Su objetivo general es monitorear su percepción respecto a diversos aspectos de sus carreras y la universidad; caracterizar a los estudiantes que ingresan, indagar en las causales de deserción, y evaluar la calidad de la inserción laboral temprana de los titulados, entre otros aspectos, lo que permite informar la toma de decisiones de las unidades académicas y administrativas de la universidad. (Valenzuela y Pérez, 2012, p. 228)

En Colombia, existen algunas experiencias en instituciones de educación superior en cuanto a la creación de un centro para monitorear el aprendizaje del estudiante o también la elaboración de un tablero de indicadores para ello.

En la Universidad del Norte (UnINORTE), desde 2011, se creó el Centro de Recursos para el Éxito Estudiantil (CREE) con el propósito de generar una estrategia institucional de fomento a la permanencia y graduación, lideradas por pares estudiantiles, profesores y profesionales expertos en aprendizaje. El 
despliegue de su operación se realiza a los siguientes frentes: apoyo en asignaturas para los estudiantes, tutorías y orientación académica.

Por su parte, la Pontificia Universidad Javeriana, sede Bogotá, ha desarrollado el proyecto de Seguimiento a los Aprendizajes Estudiantiles cuyo objetivo es "identificar los factores que promueven el aprendizaje y el éxito académico de los estudiantes" (Pontificia Universidad Javeriana, s. f.). Este se centra en la generación de un plan de desarrollo estudiantil, entregando información que orientará la toma de decisiones para el mejoramiento continuo de la calidad de los aprendizajes de los estudiantes y la permanencia estudiantil; esto permitirá la generación de acciones preventivas frente al fracaso académico y la deserción del estudiante.

Se parte de considerar los siguientes elementos en su proyecto:

1. Definición de la variable dependiente: éxito académico. En estas consideran algunos elementos como: calificaciones de los cursos, promedio acumulado, Saber Pro, tasa de graduación, tasa de retención, desempeño laboral (status, salario de enganche).

2. Definición de las variables independientes: factores asociados al éxito académico. En estas consideran algunos elementos como aspectos familiares, logros individuales previos, recursos financieros.

En el marco del Proyecto Educativo Institucional de la Universidad Cooperativa de Colombia (UCC) y, específicamente, desde su Modelo Educativo Crítico con Enfoque de Competencias, surge la necesidad de monitorear el "aprendizaje a lo largo de toda la vida". Es así como, desde 2016, se inicia el proyecto que permite contar con una herramienta o sistema que consolide y disponga de la información relacionada con las trayectorias e indicadores asociados con el desempeño de los estudiantes, con el propósito de identificar 
aspectos de fortaleza y críticos, que requieran la generación de estrategias de intervención especial y oportuna en relación con el proceso formativo del estudiante. De esta manera, es posible obtener elementos de análisis para la toma de decisiones acerca del estado de la calidad educativa y la promesa de valor académica planteada por los programas y la institución a sus estudiantes, las familias y a la sociedad en general. En esta línea, el Centro de Monitoreo del Aprendizaje a lo Largo de Toda la Vida se define de la siguiente manera:

Se entiende por "centro de monitoreo", el proceso sistemático de recolectar, analizar y utilizar información para hacer seguimiento y medición permanente a las variables e indicadores, que intervienen en el desarrollo del modelo educativo y la calidad del Proyecto Institucional, puesto que permite estimar la variación en el desarrollo de las competencias de los estudiantes, entre el momento de ingreso a la universidad y hasta que ingresan a la vida laboral como profesionales. (UCC, 2017b)

Partiendo de esta definición, el Centro de Monitoreo del Aprendizaje a lo Largo de Toda la Vida debe contemplar: entrada-insumos, procesos y salidaresultados, permitiendo realizar un análisis de datos tanto en el nivel individual (estudiante) como en el sistémico (institución), así como en varios momentos del aprendizaje del estudiante: antes de iniciar su formación, durante esta y, después de culminarla para, con ello, abarcar el aprendizaje durante toda la vida y generar diferentes itinerarios, posibilidades y rutas de formación e intervención para el logro de los resultados o competencias esperadas. Además, de acuerdo con el Ministerio de Educación Nacional (MEN), el aprendizaje a lo largo de toda la vida es el proceso que potencia el desarrollo de conocimientos, destrezas y actitudes, a lo largo del ciclo vital de la persona.

En 2016, la UCC comenzó a estructurar la creación del Centro de monitoreo del aprendizaje, hoy denominado Centro de Monitoreo del Aprendizaje a lo Largo de la Vida para Todos. Su objetivo fue constituirse como una estrategia 
que aporte a mejorar la calidad educativa vista este desde el aprendizaje del estudiante y sus resultados, ya que a partir del seguimiento de una batería de indicadores establecidos se podría monitorear dichos resultados tanto a nivel de estudiantes como de los programas académicos y, con ello, establecer acciones correctivas y de mejora.

El Centro de Monitoreo del Aprendizaje a lo Largo de la Vida para Todos provee información de carácter estratégico, tanto para el personal académico administrativo, como para el profesor y el estudiante. Es un motor de cambio que implica a todos los actores del proceso educativo, promoviendo la pertinencia de la oferta educativa, el mejoramiento y calidad de los procesos. Permite generar alarmas e información para la toma de decisiones y formulación de estrategias que estabilicen o mejoren los resultados esperados. Suministra información sobre el valor agregado, aporte relativo y la transformación de los estudiantes durante su proceso educativo en la universidad, valorando cómo en el transcurso de los años que están vinculados a la institución desarrollan las competencias establecidas en los Proyectos Educativos de los Programas (PEP), pero igual, reconociendo cómo llega el estudiante al momento de ingreso a la universidad y cómo se realiza el seguimiento y acompañamiento posterior a su graduación. Su objetivo es:

Asegurar la calidad de los resultados de aprendizaje, mediante información que permita generar alertas tempranas en el desarrollo de las competencias, a partir de la implementación de sistemas de evaluación diagnóstica, formativa, prescriptiva, sumativa, predictiva y certificativa. (UCC, 2021, art. 1)

Esta generación de información permite elaborar analíticas e indicadores sobre los procesos de enseñanza y aprendizaje en tiempo real, para poder tomar decisiones pertinentes y oportunas relacionadas, considerando tres momentos en la vida del estudiante: antes, durante y después (art. 3): 
- En el Antes, se trabajarán con indicadores previos y una evaluación diagnóstica, tomando referente la Prueba Saber 11 y la caracterización del estudiante.

- En el Durante, se trabajarán indicadores de proceso, con una evaluación formativa y prescriptiva.

- En el Después, se trabajarán indicadores de desempeño para el egresado y, para ello, se contará con la información de la Prueba de Saber Pro, valor agregado y aporte relativo, configurando una evaluación sumativa, predictiva y certificativa, dando paso al reconocimiento de competencias previas.

\section{Marco conceptual}

De acuerdo con la Organización de Estados Iberoamericanos para la Educación, la Ciencia y la Cultura (OEI):

Se puede decir que las ideas sobre aprendizaje a lo largo de la vida han acompañado la historia de la educación. Desde Platón (427 a 348 a J.C.) que ya sostenía que la educación debía prolongarse a la edad adulta, a Comenio (1592-1670) que afirmaba que la educación no es únicamente la formación de los niños en la escuela o en las familias "es un proceso que afecta a toda la vida de las personas y sus múltiples adaptaciones sociales" y, más cercano en el tiempo, Condorcet (17431794) responsable del Informe presentado ante la Asamblea Nacional Francesa en 1792 en el que afirma que "la instrucción debería abarcar todas las edades, no hay ninguna en la que no sea útil y posible de aprender" En el siglo XX, el informe "Aprender a ser: el nuevo mundo de la educación de hoy y de mañana" encargado por la UNESCO a una comisión internacional presidida por Pierre. (OEI, 2017)

En el siglo xx, el término "educación a lo largo de la vida" es

acuñado por la UNESCO en la década de los setenta y ochenta. Sin embargo, en 1996 la Organización de Cooperación y Desarrollo Económico (OCDE) así como 
el informe Delors enfatizaron nuevamente la importancia del aprendizaje, por lo que la unESCO retomó el término de aprendizaje a lo largo de la vida y hoy bajo ese nombre se le denomina en la mayoría de los países. (Unesco, s. f., p. 1)

El concepto de "aprendizaje a lo largo de toda la vida" (ALTV) proviene del informe de la UNESCO elaborado por la comisión Faure en 1972: "Aprender a ser". El informe se centra en el aprendizaje, entendido como un proceso que va más allá de la educación y de la enseñanza. La educación y la enseñanza se conciben allí, como dimensiones que están subordinadas al proceso de aprendizaje.

Asimismo, las actividades escolares y extraescolares (formales, no formales e informales) se examinan sin distinción jerárquica y la importancia de la educación básica para todos, se asume como una premisa: el aprendizaje es un proceso de toda la vida, tanto en su duración como en su diversidad:

Aprender a vivir, aprender a aprender, de forma que se puedan ir adquiriendo nuevos conocimientos a lo largo de toda una vida; aprender a pensar de forma libre y critica, aprender a amar el mundo y a hacerlo más humano, aprender a realizarse en y mediante el trabajo creador. (Faure et al., 1972, p. 132)

La comisión Faure no consideró que el aprendizaje a lo largo de toda la vida fuese un proceso de escolarización permanente, de educación de adultos o de formación profesional continua. No lo consideró como un sistema educativo ni como un ámbito pedagógico, sino como un principio organizativo de todas las formas de educación (formal, no formal e informal) con componentes mejor integrados e interrelacionados.

Desde esta perspectiva, el aprendizaje no está confinado a un periodo específico de la vida, sino que va "de la cuna a la tumba" (sentido horizontal). El aprendizaje se da en todos los contextos en los que conviven las personas como familia, comunidad, trabajo, estudio, ocio (sentido vertical). El apren- 
dizaje "supone valores humanísticos y democráticos como la emancipación y la inclusión (sentido profundo). Enfatiza el aseguramiento de los aprendizajes relevantes (y no sólo la educación) más allá del sistema escolar" (UNESCo, s. f., p. 2). La educación debe ser impartida y adquirida a través de una multiplicidad de medios. Lo importante no es el camino que un individuo ha seguido, es lo que ha aprendido o adquirido en ese recorrido (Faure et al., 1972).

\section{8}

Declaración de los Derechos Humanos

Derecho humano de segunda generación

\section{6}

Pacto Internacional de los Derechos Económicos, Sociales y Culturales (PIDESC)

Década de 1960: Paulo Freile, Iván Illich, Evertt Reimer

La educación encierra un tesoro de Jacques Delors

\section{2}

Aprender a ser: la educación del futuro de Edgar Faure

\section{6}

Los siete saberes necesarios para la educación del futuro de Edgar Morin

\section{9}

Replantear la educación: ¿'hacia un bien común mundial? de la UNESCO

\section{5}

Los futuros de la educación: aprender a transformarse de la UNESCO (cuarto objetivo de desarrollo sostenible)

El ALTV no se organiza a partir de la edad, el espacio y el tiempo. Es una resignificación de la forma como ofrecemos el servicio educativo.

Figura 1. Línea de tiempo en la evolución del concepto de aprendizaje a lo largo de la vida. Elaboración propia con base en información suministrada por la Vicerrectoría Académica (2021). 
El aprendizaje a lo largo de toda la vida (ALTV) no se organiza a partir de la edad, el espacio y el tiempo. Es una resignificación de la forma en que se ofrece el servicio educativo.
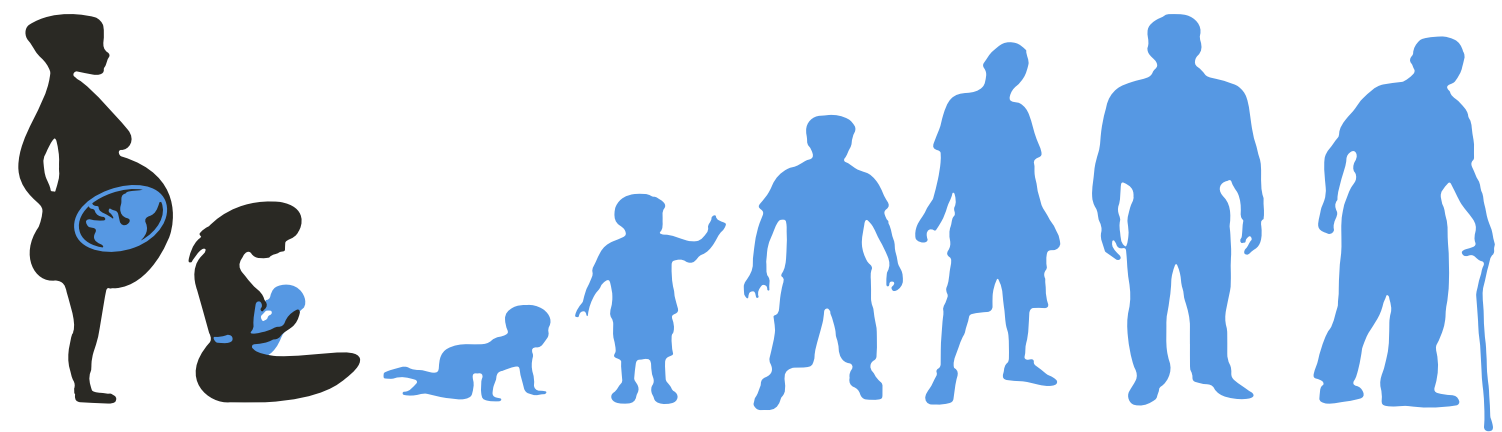

Figura 2. Curva de tiempo para el aprendizaje a lo largo de toda la vida. Elaboración propia con base en información suministrada por la Vicerrectoría Académica, 2021.

Según el MEN, el aprendizaje a lo largo de la vida es un proceso que potencia el desarrollo de conocimientos, destrezas y actitudes a lo largo del ciclo vital de la persona; de esta manera, se materializa lo que Figel (2009) afirma: "El aprendizaje permanente es una necesidad" (párr. 1).

Ahora bien, el aprendizaje debe ser valorado o evaluado en todo momento, sea antes de iniciar un proceso de formación, durante el mismo o después de culminado. La unesco (s. f.) señala que "la evaluación del aprendizaje es un elemento esencial en todo plan de monitoreo de cualquier sector educativo" (párr. 1) y considera que existen diferentes formas de evaluar.

Se considera que la evaluación es un "proceso de recogida y tratamiento de informaciones pertinentes, válidas y fiables para permitir, a los actores interesados, tomar las decisiones que se impongan para mejorar las acciones y los resultados" (Sarria, s. f., p. 2). Además, para la UNESCo, la evaluación puede ser:

- En el aula, de tipo formativo o sumativo, dependiendo de cómo y cuándo se empleen los resultados de la evaluación: 
- Evaluaciones formativas: son diagnósticas y le permiten conocer al profesor y al estudiante si está logrando avances con la enseñanza y el aprendizaje.

- Evaluaciones sumativas: miden y valoran el aprendizaje con el fin de certificarlo, asignar calificaciones, determinar promociones, verificar resultados. Se realiza al término de una etapa de los procesos de enseñanzaaprendizaje.

- Evaluaciones públicas, que se suelen utilizar para certificar que una persona haya alcanzado un nivel determinado en sus estudios y como método de selección para la siguiente etapa educativa. Por otra parte, constituyen un soporte para que las instituciones educativas analicen y evalúen la coherencia entre el currículo y el proceso de enseñanza.

- Evaluaciones gran escala que pueden ser nacionales, regionales o internacionales: estas se pueden emplear para valorar los resultados de un sistema educativo mediante instrumentos que proporcionan evidencias sobre los niveles de rendimiento del estudiante.

Sobre evaluaciones formativas, Santiago et al. (2017) señalan que son aquellas acompañan el proceso de aprendizaje del alumno y lo hace progresivo. Se dan en la etapa de formación:

La etapa del DURANTE para conocer el punto exacto del progreso del estudiante y con ellas se busca conocer las posibles dificultades con las que cada estudiante se encuentra antes de seguir avanzando. Pueden ser formativas, pero también sumativas, con calificación o sin ella. (p. 8)

Estas evaluaciones a gran escala se definen como aquellas que: constituyen una clase de prueba estandarizada a escala nacional o transnacional que ofrece una visión general acerca de los resultados de aprendizaje alcanzados por un grupo de estudiantes en un año concreto y en un determinado número de ámbitos de aprendizaje (UNESCO, s. f.). 
Dichas pruebas han incrementado en frecuencia y cobertura en gran parte de los países del mundo, además de la medición de las competencias de "lectura y matemáticas, se miden las aptitudes digitales, las competencias informáticas y de información, las habilidades socioemocionales o la comprensión de conceptos y cuestiones relacionadas con el civismo y la ciudadanía" (Santiago et al., 2017, p. 11).

Los resultados de la evaluación deben ser compilados y analizados para que, a partir de estos, se tomen las acciones necesarias para mejorar el aprendizaje en los estudiantes. Esto es lo que se conoce como analíticas de aprendizaje. Santiago et al. (2017) expresan que pueden emplearse "para identificar a los estudiantes, tanto para analizar su nivel de partida, como el de progreso y el de finalización, también para que los profesores, tutores, y los propios estudiantes pueden tomar las medidas necesarias para garantizar el mejor aprendizaje" (p. 6). Se compone de cuatro niveles: descriptivo, en que se analiza lo que ha ocurrido; diagnóstico, en que se analiza por qué ocurrió; predictivo, que analiza qué ocurrirá, y prescriptivo, que revisa lo que se debería hacer.

Si la evaluación como parte del monitoreo del aprendizaje del estudiante, este se convierte en una estrategia que permitirá mejorar los resultados de aprendizaje y la calidad de la educación desarrollada a nivel institucional. En igual medida, en un sistema de aseguramiento de la calidad de una institución educativa, la evaluación de los aprendizajes se convierte en un componente esencial, que permite evidenciar el cumplimiento y la calidad de sus procesos de enseñanza-aprendizaje.

De esta manera, monitoreo y evaluación son dos procesos conectados, que confluyen para generar alertas tempranas en el aprendizaje del estudiante; por ello, contar con una estrategia o programa que permita monitorear el avance y logro del aprendizaje, promueve en la institución una educación equitativa 
y de calidad; de acuerdo con esto, "para mejorar con el tiempo los resultados del aprendizaje y la calidad de la educación se necesita una estrategia de monitoreo del aprendizaje" (UNESCO, 2019).

En Colombia, el MEN ha venido señalando la importancia que tiene para el sector de la Educación Superior evaluar los aprendizajes de los estudiantes como una manera de rendir cuentas a la sociedad sobre una de las funciones más importantes que toda institución de educación superior debe cumplir: desarrollar en los estudiantes las competencias y habilidades necesarias para hacer avanzar la sociedad por la senda del conocimiento.

El Plan Nacional de Desarrollo (PND) 2018-2022, "Pacto por Colombia, pacto por la equidad", armonizado con el Plan Nacional Decenal de Educación 2016-2026, dispone que el reconocimiento de aprendizajes previos para la certificación de competencias, con el fin de promover las rutas de aprendizaje, las relaciones con el sector productivo y el aprendizaje a lo largo de la vida (Congreso de la República de Colombia, 2019, art. 194). Lo anterior está soportado en el Sistema Nacional de Cualificaciones (SNC), que fue creado por el Gobierno colombiano como un instrumento que aporta a la disminución de las brechas existentes entre el sector productivo y académico, buscando fortalecer el capital humano del país a través de una oferta educativa y formativa pertinente y de calidad. El PND lo define como:

Conjunto de políticas, instrumentos, componentes y procesos necesarios para alinear la educación y formación a las necesidades sociales y productivas del país y que promueve el reconocimiento de aprendizajes, el desarrollo personal y profesional de los ciudadanos, la inserción o reinserción laboral y el desarrollo productivo del país. (Congreso de la República de Colombia, 2019, art. 194)

Las nuevas condiciones que rigen el sistema educativo colombiano giran en torno al aseguramiento de la calidad en las IEs, que establece un conjunto 
de normas. El Ministerio de Educación Nacional (MEN, 2019) entiende la calidad como el "conjunto de atributos articulados, interdependientes, dinámicos, construidos por la comunidad académica como referentes y que responden a las demandas sociales, culturales y ambientales" (art. 2.5.3.2.2.1). Esto exige que las IES realicen un seguimiento a todos los actores que intervienen en el proceso educativo: estudiantes, profesores, egresados, comunidad académico-administrativa para evaluar el cumplimiento de este compromiso de calidad.

De esta manera, por un lado, las IEs deben contar con políticas, estrategias, procesos e indicadores que faciliten a los estudiantes la permanencia y graduación en condiciones de calidad, que deberán ser coherentes y consistentes con su naturaleza jurídica, tipología, identidad y misión institucional. Y, por otra parte, deben establecer mecanismos que propendan por el aprendizaje a lo largo de la vida, de tal forma que involucre la experiencia del egresado en la dinámica institucional (MEN, 2019).

Por su parte, la Resolución 015224 de 2020 establece las condiciones de calidad institucional y señala que dentro de la normativa institucional se debe contemplar la homologación y reconocimiento de aprendizajes entre programas de la misma institución o de otras instituciones (art. 8). Además, deberán, mediante evidencias e indicadores, soportar los procesos de homologación, reconocimientos de aprendizajes previos, información cualitativa y cuantitativa para mejorar la permanencia y la graduación y estudios que permitan implementar acciones frente a la deserción por cohorte y por periodo (MEN, 2020a, art. 13).

A su vez, para soportar el aprendizaje del egresado a lo largo de la vida, se deben establecer mecanismos que propendan por la oferta de programas de formación en diferentes dimensiones del desarrollo personal y profesional 
para la actualización de sus egresados, de acuerdo con las necesidades del entorno (MEN, 2020a, art. 34). Para los egresados, se establece que la IEs debe contar con una descripción de la oferta de programas de formación en diferentes dimensiones del desarrollo personal y profesional de sus egresados (MEN, 2020a, art. 36).

Esta resolución, adicionalmente, establece los parámetros de calidad para los programas académicos. Señala que las IEs deberán definir los niveles de aprendizaje del estudiante desde que ingresa hasta cuando termina sus estudios y establecer los posibles reconocimientos de aprendizaje durante su proceso formativo (MEN, 2020a, art. 12). En la misma medida, deberán presentar los resultados de aprendizaje de los estudiantes y la descripción de cómo se articulan estos con los planes de estudio del programa académico (MEN, 2020a, art. 13). Y, también, señala que los programas académicos deberán estar en armonía con el Marco Nacional de Cualificaciones (MEN, 2020a, art. 6).

La UCC (2017a), mediante el Acuerdo Superior 312 de 2017, define la política de reconocimiento de competencias previas, señalando que el programa establece los procesos, procedimientos, instrumentos y criterios para evaluar las competencias previas de los aspirantes o estudiantes activos y de trasferencia que, por conocimiento o experiencia, ya hayan desarrollado competencias que exigen los planes de estudio de la Universidad. Hasta el momento, se ha definido, a través del Acuerdo Superior 459 de 2019, la política para el reconocimiento de competencias en el estudiante dentro del programa de formación de Open Lingua (competencia en inglés), lineamiento que rige para los exámenes de suficiencia, clasificación, validación, homologación y Pruebas de Estado Saber 11 a nivel de pregrado (UCC, 2019, art. 3). Para nivel de posgrado, el reconocimiento de competencia del idioma inglés se aplicará mediante un examen de suficiencia realizado de forma interna o externa (UCC, 2019, art. 35). De esta manera, hoy la Universidad favorece y reconoce 
competencias ya adquiridas por los estudiantes, lo que revela un aspecto que promueve la movilidad, la excelencia y permanencia en el estudiante, que se enmarca, también, en reconocer el aprendizaje a lo largo de la vida. 


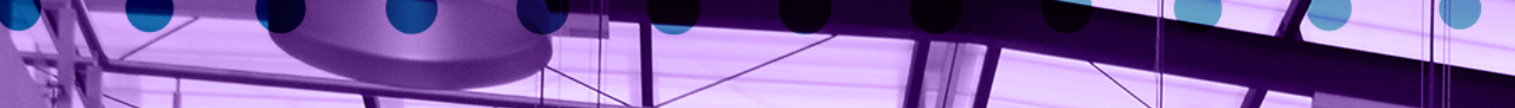

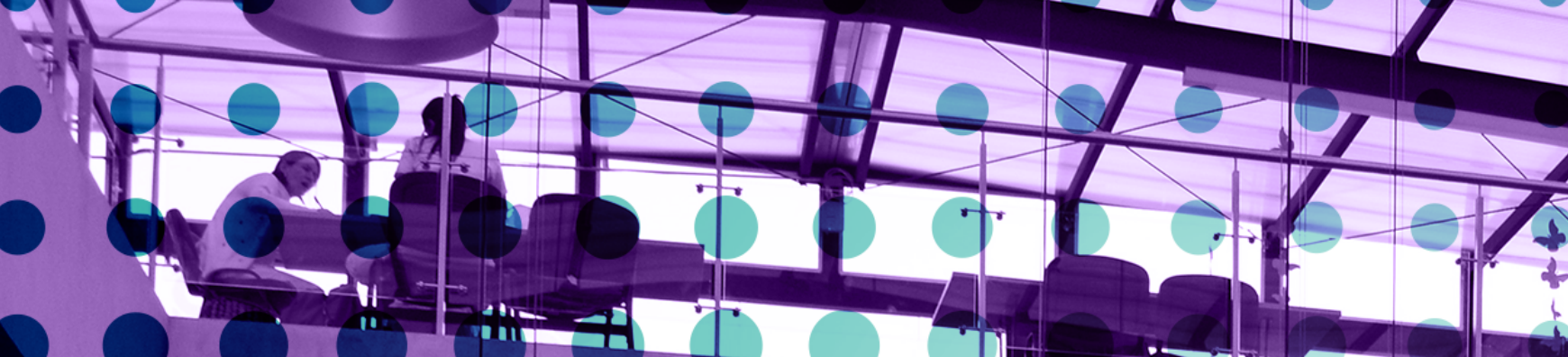
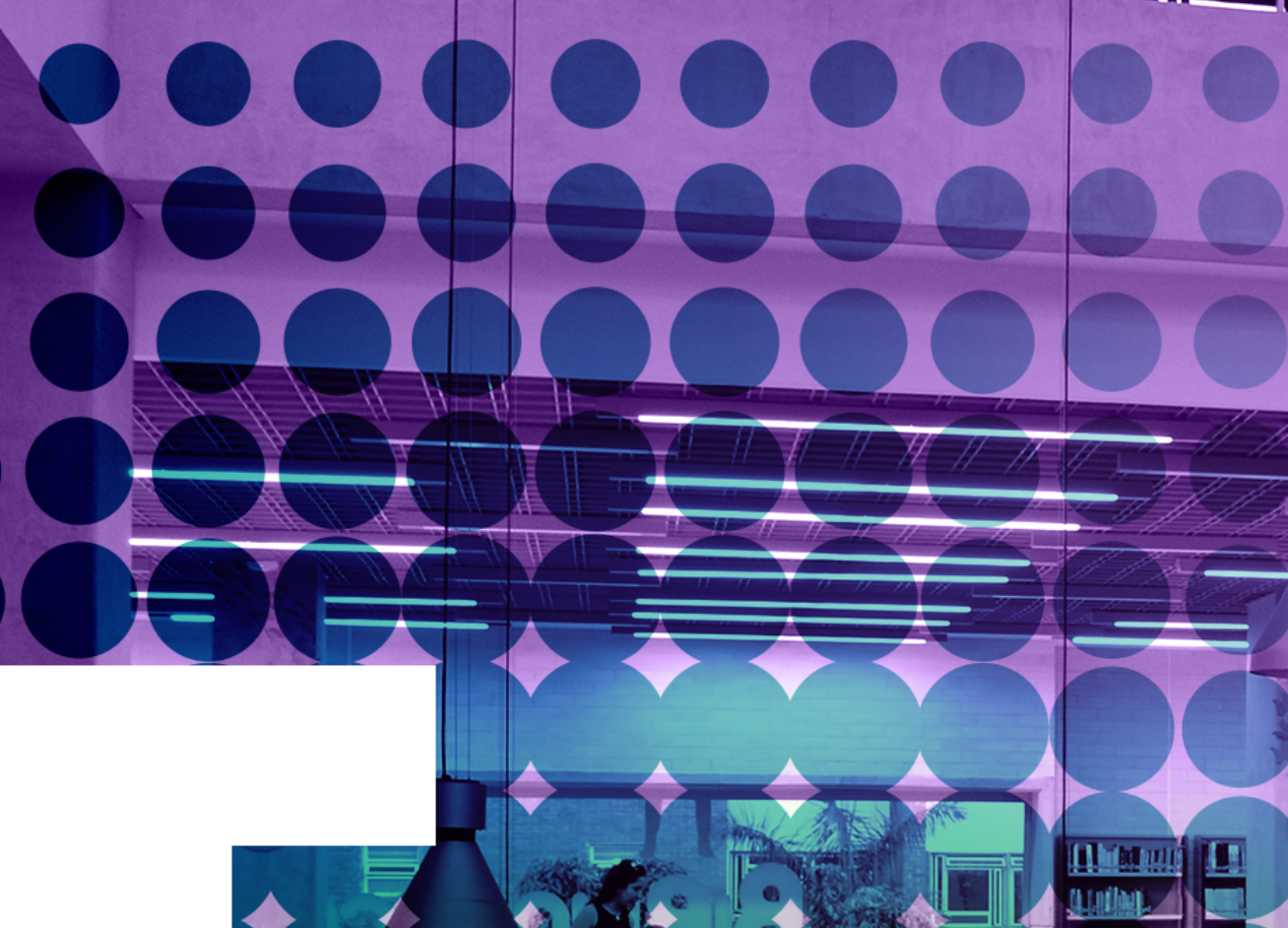

$+3$

GESTION DEL CENTRO DE : MONITOREO DEL APRENDIZAJE

- ALO LARGO DE LAVIDA SA PARA TODOS EN LA UCC 
$\mathbf{M}$ onitorear la calidad académica del estudiante desde que inicia hasta que finaliza sus estudios no solo es una manera de validar la eficiencia y efectividad del Modelo Educativo, sino también es una herramienta que le brinda elementos y alertas a la institución y, en especial, al programa académico y al profesorado, para responder a las exigencias y demandas educativas en un contexto inclusivo, pero también, altamente competitivo. Esto permite, finalmente, determinar la coherencia y pertinencia del plan de estudios de un programa académico, verificar la gestión del currículo para así poder entablar acciones de mejoramiento. Este es uno de los mecanismos más importantes en el aseguramiento de la calidad institucional. La Universidad se apoya en diferentes programas y estrategias para realizar dicho monitoreo y posterior análisis en cada una de las etapas que estructuran al Centro de monitoreo del aprendizaje a lo largo de la vida para todos.

A continuación, se detalla la estructura y los componentes que han sido considerados para llevar a cabo el monitoreo del aprendizaje en los estudiantes (figura 3).

\section{Gestión en el antes}

Todo aspirante, que inicia su proceso de admisión a la Universidad, presenta los resultados de su prueba de Estado Saber 11. Este es un indicador de entrada para poder analizar los resultados de las competencias evaluadas en dicha prueba y establecer si el aspirante es admitido. En este análisis, también, es importante conocer los datos de caracterización del estudiante en términos de aspectos sociodemográficos, familiares, económicos, entre otros. Igual es el momento, por parte de la UCC dar paso al reconocimiento de aprendizajes previos y, en particular, para la competencia en segunda lengua, inglés. A continuación, se presenta una descripción de cómo el campus Medellín, lleva su proceso en esta etapa. 


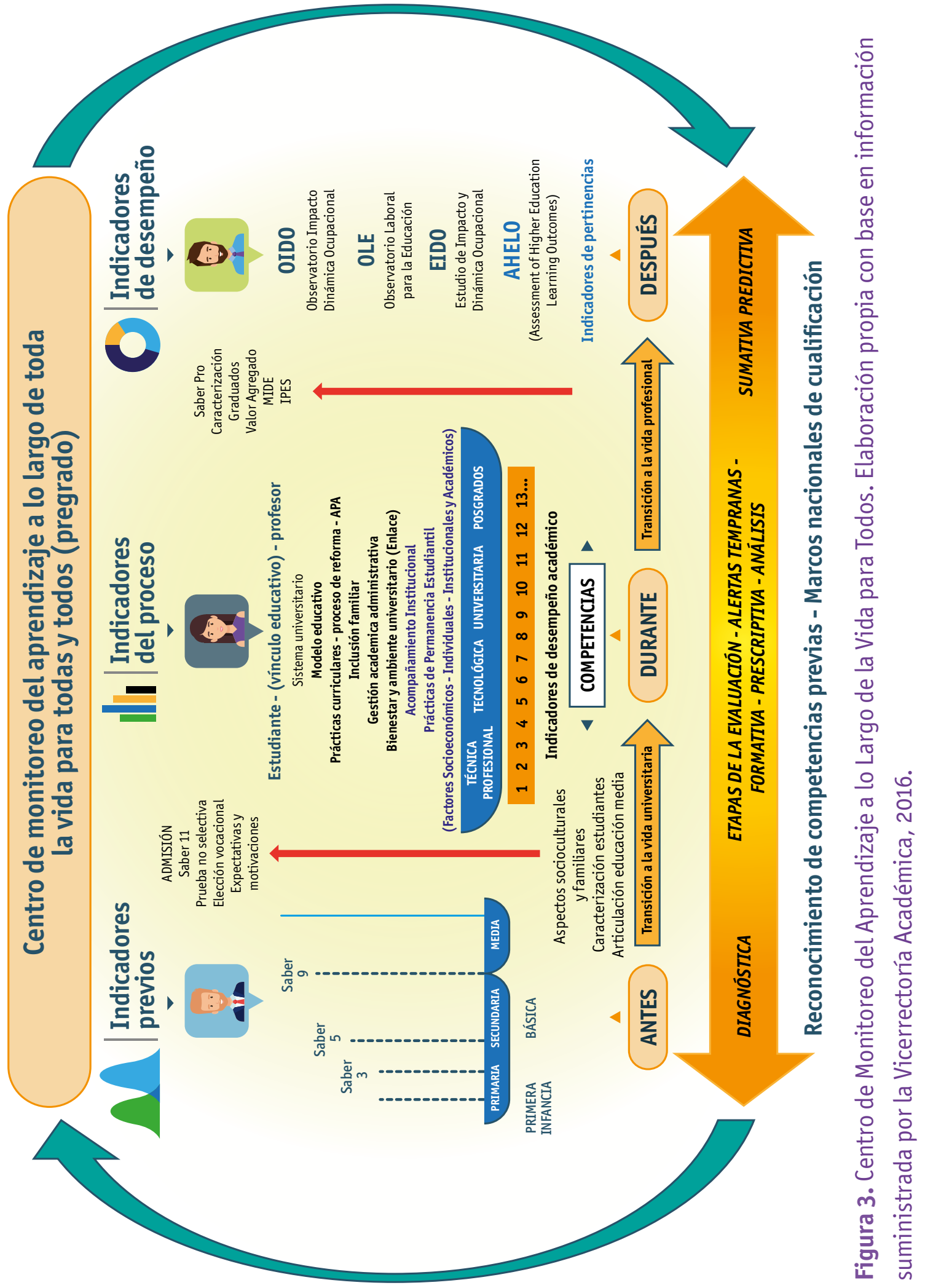




\section{Descripción de las estrategias adelantadas} por el campus Medellin

Proceso de admisión: durante los últimos cinco años, la seccional ha tenido un promedio de 4200 estudiantes matriculados en programas de educación para el trabajo y el desarrollo humano (ETDH), de pregrado, posgrado y formación continua. La figura 4 muestra el histórico del total de estudiantes matriculados en cursos de extensión, ETDH, pregrado y posgrado en el periodo 2015-2020.

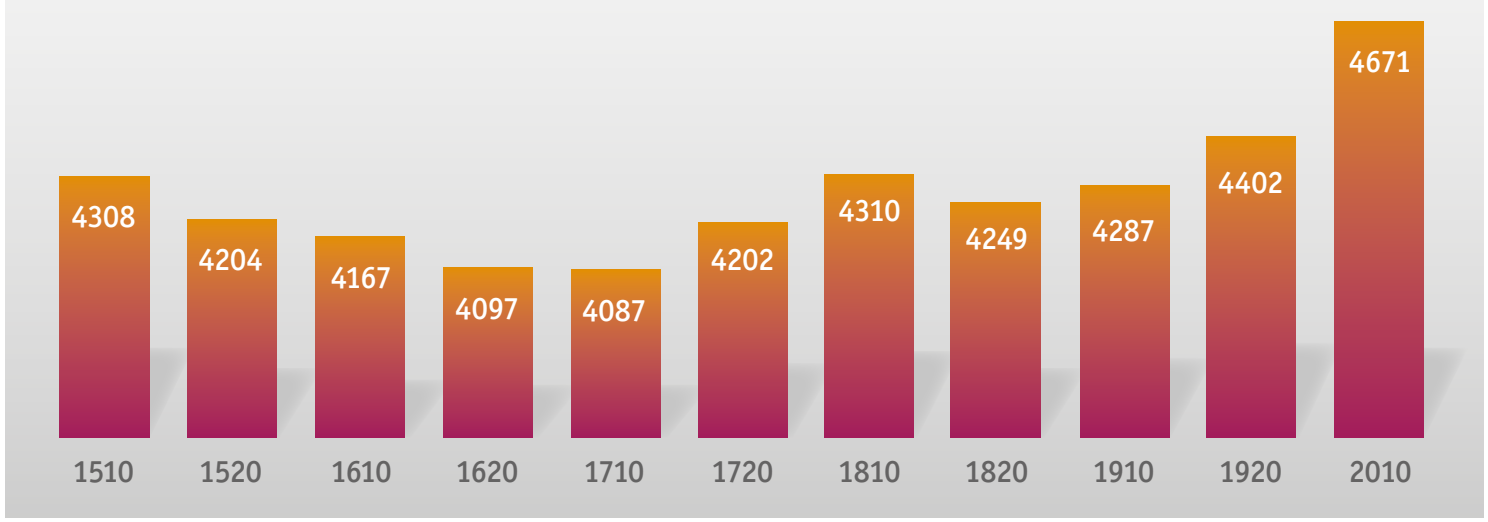

Figura 4. Histórico del número de estudiantes matriculados, seccional Medellín.

Elaboración propia con base en información suministrada por el Sistema de información Oracle People Soft (OPS), ucc.

Mediante los procesos de flexibilidad académico-administrativa como homologaciones, suficiencias, reconocimiento de saberes previos, se ha posibilitado el acceso, la movilidad y la continuidad de estudios superiores y posgraduales. Entre 2015-2020, en el campus se han realizado 1418 validaciones, 348 suficiencias y 504 homologaciones. En el mismo periodo, por transferencias internas provenientes de otros campus, se han admitido 360 estudiantes y por transferencias externas 470 estudiantes.

Caracterización de estudiantes nuevos: una de las acciones del Centro de Monitoreo del Aprendizaje a lo Largo de Toda la Vida es la caracterización 
sociodemográfica de los estudiantes. En el caso de los estudiantes del campus Medellín, encontramos que en un $80 \%$ de estos provienen de estratos socioeconómicos 1, 2 y 3 y el $20 \%$ restante de estratos 4, 5 y 6 . El 52\% estudia con recursos de los padres, un $20 \%$ con recursos propios o de familiares, un $25 \%$ requiere financiación, y un 3\% tiene becas. El 62\% de la población estudiantil son mujeres y el 38\% hombres. El 75\% tiene una edad entre los 15 y 20 años, el $21 \%$ entre 21 y 30 años, el 3\% tiene entre 31 y 40 años, y el 1\% tiene más de 41 años. El 78\% de los estudiantes de la Seccional Medellín provienen de municipios de Antioquia y el 22\% restante de otros departamentos del país. Estos rasgos de la población estudiantil exigen el desarrollo y fortalecimiento permanente del acompañamiento financiero, académico y psicosocial, temas que se profundizarán en el ítem de Bienestar Universitario.

Con respecto a la caracterización de acuerdo con el promedio de las pruebas Saber 11, los estudiantes admitidos en el periodo 2015-2020, tienen un promedio global en concordancia con lo que muestra la figura 5.

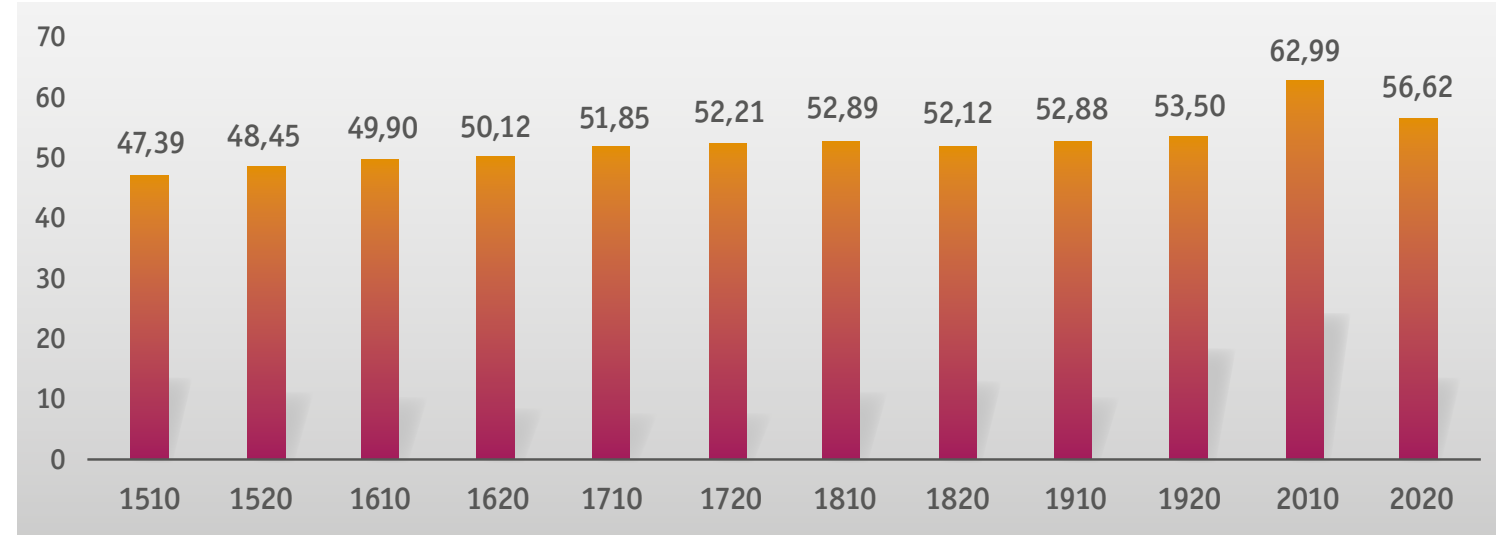

Figura 5. Promedio global de las pruebas Saber 11 de estudiantes nuevos 2015-2020, Campus Medellín. Elaboración propia.

El análisis realizado en el Consejo Académico de la Seccional en relación con las pruebas Saber 11 de estudiantes admitidos, permite identificar los valores que servirán de guía para el apoyo y la preparación, que tendrá por objetivo 
asegurar el éxito del estudiante en su aprendizaje. Por esta razón, el análisis de las pruebas Saber 11 es un insumo básico para el cálculo del valor académico agregado, que permite aislar lo aprendido en la institución, de las condiciones iniciales con el fin de medir de forma más precisa el aporte institucional al aprendizaje del estudiante y la calidad en la formación académica.

Se resalta que, desde el programa Open Lingua, se "reconoce la validez de las pruebas de Estado Saber 11, o la que haga sus veces, realizada por el Instituto Colombiano para la Evaluación de la Educación (ICFES), como medio para acreditar competencias previas en los niveles de desempeño del idioma inglés" (ucc, 2019, art. 6). Como resultado de esta nueva disposición, se ha realizado reconocimiento previo a saberes en inglés al $41 \%$ del total de estudiantes matriculados en el periodo académico 2010 (tabla 1).

Tabla 1. Reconocimiento competencias en segunda lengua estudiantes admitidos 2020-I

\begin{tabular}{|c|c|c|c|}
\hline Descripción & $\begin{array}{c}\mathbf{N}^{\circ}{ }^{\circ} \text { de } \\
\text { matriculados }\end{array}$ & $\begin{array}{c}\mathbf{N} .^{\circ} \text { de } \\
\text { reconocimientos }\end{array}$ & Total \\
\hline Estudiantes nuevos & 355 & 142 & $40 \%$ \\
\hline Estudiantes de transferencia externa & 33 & 19 & $58 \%$ \\
\hline Total de estudiantes & 388 & 161 & $41 \%$ \\
\hline
\end{tabular}

Fuente: elaboración propia con base en información suministrada por la Subdirección de Multilingüismo OPS, 2020.

Los anteriores indicadores permiten evidenciar el compromiso institucional con la democratización de la educación superior y con el reconocimiento de saberes y del aprendizaje a lo largo de toda la vida. Dentro de las acciones que se han implementado para el mejoramiento del nivel de las competencias genéricas de los admitidos están:

- Inclusión, mediante la reforma curricular de los planes de estudio, de tres cursos de formación humanística cuyas competencias se enfocan en el desa- 
rrollo de la lectura crítica, la escritura y el razonamiento cuantitativo. Inclusión de al menos cuatro niveles de inglés para el desarrollo de competencias en segunda lengua.

- Mediante la biblioteca activa, se desarrollan actividades de promoción de la lectura y la escritura.

- A través del programa Enlace, se realizan talleres y acompañamientos, que logró, en el primer semestre de 2020, la participación de 5736 estudiantes, 153 profesores, 398 administrativos, 116 egresados en diversas actividades, como:

- Asesoría académica

- Taller métodos y técnicas de estudio

- Taller inmersión vida universitaria

- Talleres seguimiento semestre especial

- Talleres lectura crítica

- Talleres refuerzo lectura y escritura

- Talleres refuerzo razonamiento cuantitativo

- Talleres refuerzo competencias ciudadanas

- Taller estilos de aprendizaje: test cuadrantes cerebrales

- Taller formación integral basada en la evidencia

- Taller formación integral: inteligencia financiera

- Taller métodos y hábitos de estudio: manejo del tiempo

- Taller formación integral: inteligencia emocional 


\section{Gestión en el durante}

La UCC, desde 2016, adelanta estrategias de seguimiento al desempeño y rendimiento académico de los estudiantes. Su propósito es analizar cómo se comportan algunas variables de este nivel en el estudiante. Estos resultados son un insumo importante que brinda elementos para realizar seguimiento al desempeño estudiantil y, en consecuencia, permiten definir estrategias de corto y mediano plazo para mejorar su aprendizaje y mejorar los niveles de retención estudiantil de cada programa académico. Pero, más allá de la evaluación y su mejora, permite identificar a aquellos estudiantes que tienen dificultades y apoyarlos en su proceso formativo y para, de esta forma, asegurar el desempeño para una futura contribución al desarrollo económico, productivo y social que aporte a una mejor sociedad. Para ello, la Universidad ha dispuesto los siguientes programas e indicadores de proceso:

- La Consejería: es un programa de orientación que se realiza al estudiante cuando se encuentre ante dificultades académicas, psicosociales o financieras, brindando asesoría en: orientación, en métodos y hábitos de estudio, formulación y realización de proyecto de vida, asesoría en financiación para el pago de la matrícula y seguimiento de calificaciones. Se atiende, asimismo, la dimensión humana, contemplando las dificultades de interacción, emocionales, afectivas, familiares y de adaptación sociocultural que puedan estar afectando al estudiante. De esta forma, se apoyan los procesos pedagógicos, trabajando en forma conjunta con estudiantes, monitores, docentes, administrativos y directivos (UCC, s. f., párr. 2).

- La Tutoría académica individual o grupal: busca aclarar dudas sobre los contenidos de los cursos, trabajos o actividades en particular. La tutoría obedece al desarrollo de un plan estructurado, entre tutor y tutorado, de manera sistemática bajo los lineamientos de un programa determinado (UCC, s. f., párr. 1). 
- Módulo mis asesorados: es una funcionalidad del sistema de información académica de la UCC, que permite a los estudiantes solicitar asesorías con el fin reforzar los conocimientos en los que considere que tiene falencias. Además, facilita a los profesores el seguimiento de los estudiantes, para así identificar situaciones relacionadas con el rendimiento académico, lo cual permite un mejoramiento continuo en los procesos (sistema de información ops).

- Polaris - Experiencia del estudiante: se enfoca en la permanencia del estudiante y será la estrategia que sistematizará al Centro de Monitoreo del Aprendizaje a lo Largo de la Vida para Todos.

- Indicadores de proceso: mediante la generación de reportes ejecutivos de consulta que se obtienen a través del sistema de información ops, los académicos (Vicerrectoría Académica, subdirectores académicos, decanos, jefes de programa, entre otros) obtienen información del comportamiento de algunas variables de rendimiento académico del estudiante.

A continuación, se describe cómo el campus Medellín lleva a cabo el monitoreo al estudiante mediante diferentes estrategias e indicadores.

Descripción de las estrategias adelantadas por el campus Medellin

Permanencia: el programa acceso, permanencia y fomento a la graduación, Enlace, se ha venido desarrollando en el campus Medellín desde su creación en 2013 y se ha ejecutado desde 2014, impactando de manera importante el acceso, la permanencia y graduación de los estudiantes. El promedio anual de matrículas de estudiantes nuevos en los últimos cinco años es de 788.

Las estrategias para el fomento de la permanencia han permitido los anteriores indicadores de graduación, especialmente, las acciones de acompañamiento académico, que buscan propender por el buen desempeño de los 
estudiantes a partir del desarrollo de las competencias requeridas a nivel disciplinar. En el campus Medellín se ha contado con las siguientes:

- Evaluación flexible y articulada al Sistema Institucional de Evaluación por Competencias (SIEC).

- Sistema bibliográfico integral/Bibliotecas activas.

- Ambientes Prácticos de Aprendizaje (APA).

- Semilleros de investigación.

- Intercambios académicos.

- Acciones de apoyo académico para estudiantes: consejerías, tutorías virtuales y presenciales, prácticas en laboratorio autónomas y dirigidas, grupos de estudio, talleres específicos enfocados en el desarrollo de competencias para el aprendizaje, exposiciones de trabajo de curso, "Olimpiadas Saber Pro" el reto es contigo, nivelación de competencias matemáticas para la educación (desarrollo del pensamiento crítico; razonamiento cuantitativo y matemático).

- Sistema Integrado de Desempeño Profesoral (sIDP): contempla el proceso de selección de profesores según los perfiles definidos institucionalmente; su cualificación sustentada en la oferta de la Escuela para la Excelencia Educativa y el fortalecimiento de espacios de aprendizaje colaborativo y en red (Rizoma); la evaluación de profesores, cuyo objetivo es mejorar sus competencias pedagógicas.

- Espacio para el aprendizaje desde el servicio (programas de voluntariado por la permanencia).

- Inducción a estudiantes nuevos (taller de inmersión a la vida universitaria).

- Asesoría, orientación y acompañamiento psicosocial: implementación módulo Mis asesorados para registro de consejerías, tutorías y acompañamiento académico. Se han realizado 3496 procesos de tutorías, asesorías, consejerías, que han fortalecido el acompañamiento y soporte a los estudiantes, impactando de manera positiva su desempeño académico y permanencia. 
Se realizan actividades individuales y grupales, en las que se busca favorecer la expresión y el reconocimiento del impacto emocional al que pueda enfrentarse el estudiante por diferentes factores personales, familiares, sociales y de discriminación. Esto se logra a partir de asesorías, orientación y acompañamiento en pro del restablecimiento de lazos sociales y familiares, permitiendo el desarrollo de potencialidades individuales, colectivas y, como resultado derivado, el buen desempeño académico. En esta se destacan las siguientes acciones:

- Estudio Construyendo Futuro, relacionado con índices de salud mental de la población estudiantil.

- Estudio de resiliencia.

- Asesoría y acompañamiento con profesionales de psicología y el desarrollo de talleres liderados desde el programa de Psicología, soportado en los estudiantes en práctica extramural.

Mediante el Programa Enlace, se ha logrado la participación de 6403 estudiantes, profesores, administrativos y egresados en 2020-1, para acompañamiento académico, psicosocial, financiero, salud mental positiva, adaptación procesos de cuarentena y modalidad de docencia remota, entre otros, relacionados con el fortalecimiento de la permanencia. Como uno de los logros más significativos de esta estrategia, está la disminución en el 75\% del número de estudiantes en condición de semestre especial durante los últimos cinco años (figura 6).

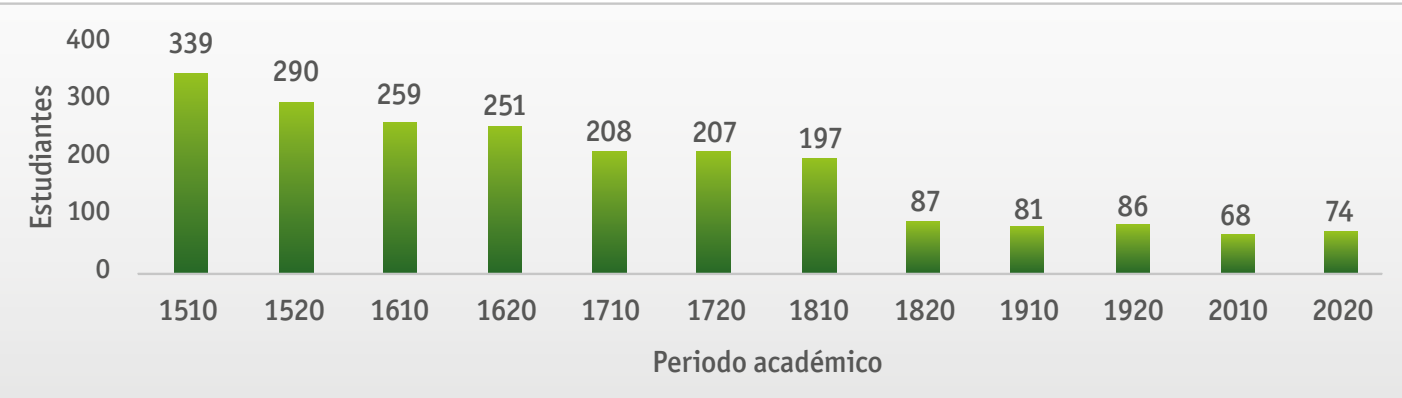

Figura 6. Estudiantes en semestre especial 2015-2020, Campus Medellín. Elaboración propia con base en información suministrada por el Sistema de información OPS, UCC. 
La estrategia de asesoría, orientación y acompañamiento financiero se soporta en el "Sistema de servicios y apoyo financiero a estudiantes". Este sistema evidencia diferentes alianzas con entidades financieras, que han facilitado el acceso de estudiantes a la institución, algunas de ellas son: Cooperativa Comuna, Banco Pichincha, Banco BBva, Bancoomeva, Sufí, Fondo Nacional del Ahorro, Bancolombia, Cotrafa, fomento de los Fondos Especiales del Icetex, Fondo Comuna para la Educación Superior comuna y otros convenios institucionales.

Entre 2014 y 2020, se han beneficiado de los estímulos y beneficios con los que la Universidad cuenta, un número de 11522 estudiantes (figura 7). Estos beneficios equivalen a un total de \$ 4870941520 pesos, por los siguientes conceptos: convenios y programas de extensión, monitorias, bono solidario, grupo familiar, promedio académico, solicitud directa, descuento institucional, sindicatos, docente y empleados.

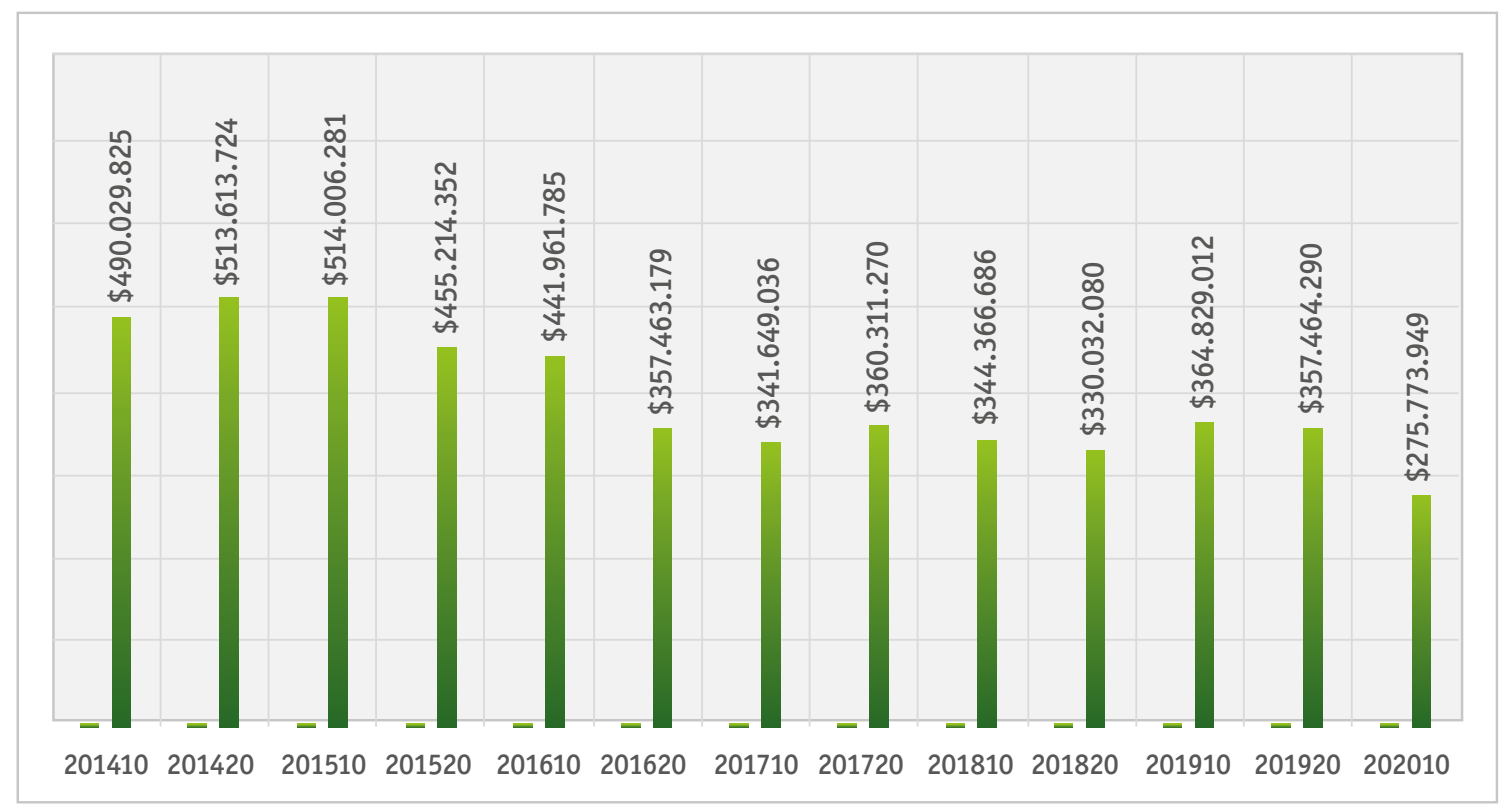

Figura 7. Estímulos y beneficios de la comunidad universitaria. Elaboración propia.

Deserción estudiantil: en el marco de la estrategia cultura de la información, se realizan procesos de reflexión y análisis de la información proporcio- 
nada por el Centro de Monitoreo del Aprendizaje a lo Largo de Toda la Vida, SPADIES y el Sistema Institucional de Evaluación de Competencias (SIEC), relacionada con los factores críticos para la permanencia (individuales, institucionales, financieros y académicos), resultados de las tasas de deserción, tasas de matrícula, tasas de graduación, índice de valor académico agregado, resultados de la medición del nivel de desarrollo de las competencias y, en general, información sobre el desempeño académico y la adaptación a la vida universitaria del estudiante; cabe destacar el análisis en torno a los cursos críticos, cancelaciones, repitencias y programas con mayor número de estudiantes en semestre especial, así como el monitoreo y análisis de la deserción por período y por cohorte (figuras 8 y 9).

La figura 8 muestra que la tasa de deserción por periodo de la seccional Medellín ha mostrado una tendencia por debajo de los indicadores a nivel nacional e institucional en los últimos cinco años. Así, por ejemplo, para el periodo 2018-2, la seccional tuvo una deserción de periodo 4.27 puntos por debajo de la nacional, según reportes del Sistema Nacional de Información de la Educación Superior (SNIES), lo cual es evidencia el impacto favorable de las acciones de acompañamiento y seguimiento mediante el programa Enlace.

Las cifras de deserción por cohorte, reportadas por el sPADIES, muestran, una tendencia por debajo de las cifras a nivel nacional e institucional, para la seccional Medellín (figura 9). Esto muestra la importancia la de continuar fortaleciendo las estrategias del programa Enlace, el acompañamiento académico, la transformación de la relación profesor-estudiante hacia un vínculo dialógico y de asesoría permanente, los cambios en la evaluación hacia una mayor evaluación formativa por encima de la sumativa han impactado de manera positiva en la permanencia del estudiante a lo largo de su proceso educativo. 


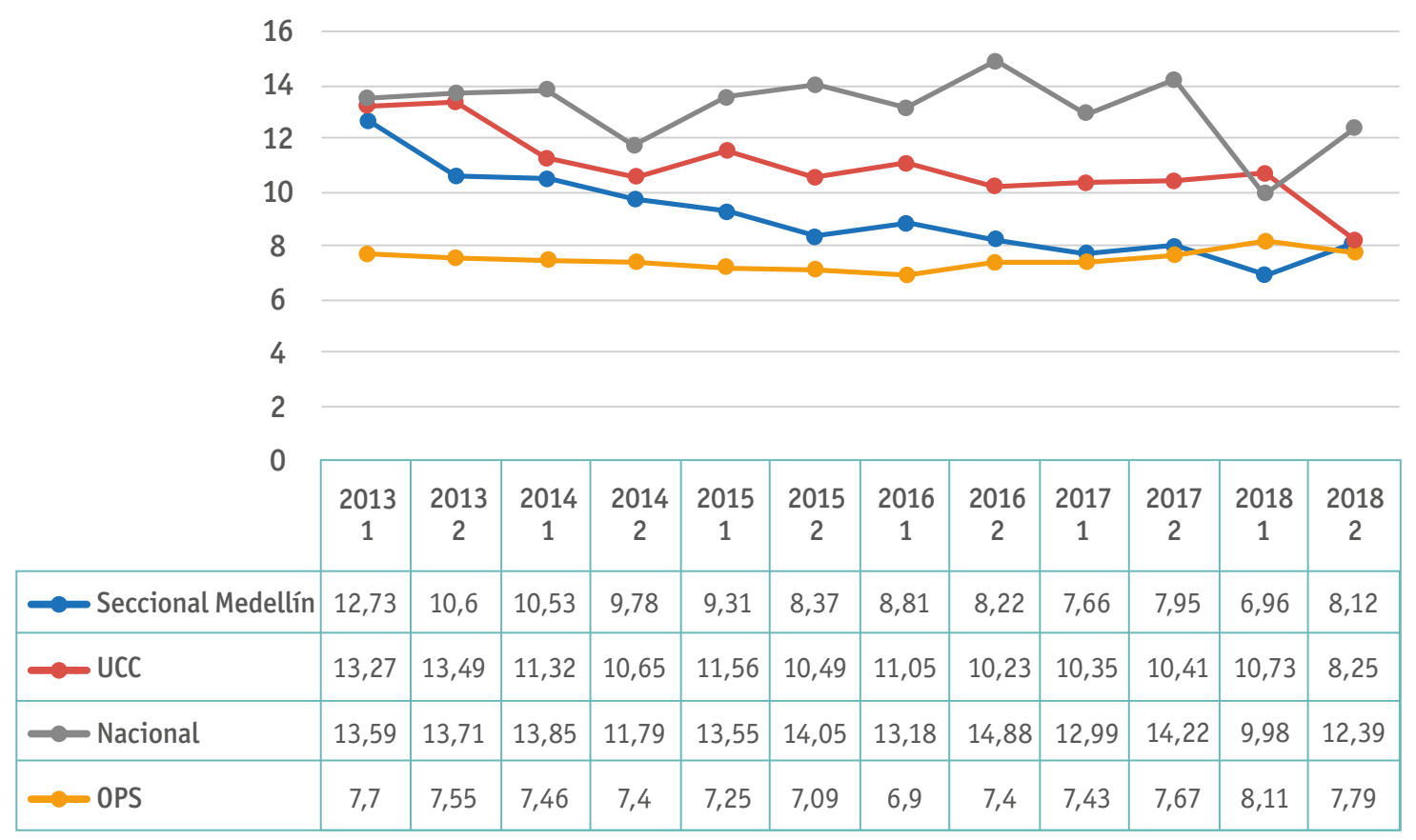

Figura 8. Comparativa de la tasa de deserción por periodo, seccional Medellín. Elaboración propia con base en datos de SPADIES.

\begin{tabular}{|l|c|c|c|c|c|c|c|c|c|c|c|c|}
\hline & \multicolumn{1}{c}{10} \\
\hline
\end{tabular}

Figura 9. Comparativa de la tasa de deserción por cohorte, seccional Medellín. Elaboración propia con base en datos de SPADIES. 
Guía de desempeño del estudiante y análisis de cursos críticos: dentro del monitoreo al desempeño académico de los estudiantes, por programa, se realiza el seguimiento a los siguientes indicadores: cancelaciones, porcentaje de aprobación y no aprobación de cursos, repitencia, estudiantes en condición de semestre especial, promedios académicos. Mediante la guía de desempeño del estudiante, se evalúa:

- Áreas de inscripción de los programas al ICFES, con el fin de fortalecer competencias específicas.

- Análisis de la pertinencia de los programas académicos.

- Capacitaciones y talleres con estudiantes para generar cultura de autoaprendizaje y fomento de las humanidades como mecanismo para el desarrollo de competencias genéricas.

- Análisis de los perfiles de los profesores y su coherencia con los cursos que orientan.

- Uso y efectividad de los APA y campus virtual. En la figura 10, se puede ver la forma en que se monitorea el uso del campus virtual por parte de los profesores a medida que avanza el periodo académico.

Análisis de los resultados de las pruebas Saber Pro: los promedios globales del desempeño de los estudiantes del campus en las pruebas Saber Pro durante el periodo comprendido entre 2016-2019 son similares a los promedios institucionales y nacionales si se tiene en cuenta que la actual escala de valoración del ICFEs habla que un promedio es similar a otro si su valor se encuentra en \pm 9 puntos, para la deviación estándar se habla que es similar si es \pm 6 puntos. El histórico de los promedios globales durante el periodo 2016-2019 se evidencia en la figura 11. 


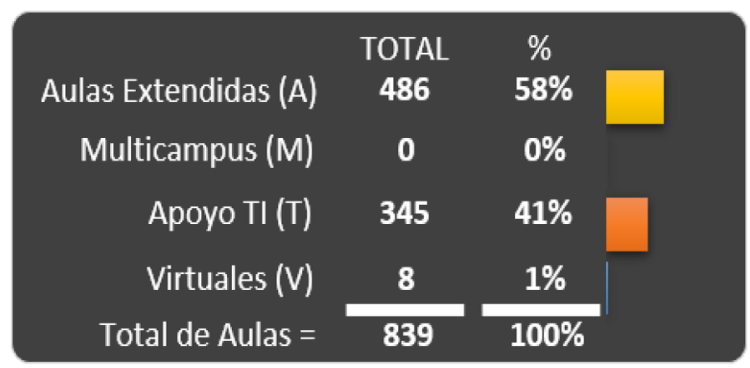

\begin{tabular}{|c|c|c|c|c|c|}
\hline Año $\forall=\nabla_{x}$ & Sede 決 $\nabla_{x}$ & \multicolumn{4}{|c|}{ Año_\#Informe (M-D) 泣 $\nabla_{x}$} \\
\hline 2020 & OONAL & \multicolumn{3}{|c|}{$2020[\operatorname{lnf} 18](5-21)$} & $\hat{\imath}$ \\
\hline 2018 & 05MED & \multicolumn{3}{|c|}{2020 [Inf 19] (5-26) } & \\
\hline 2019 & & \multicolumn{3}{|c|}{$2020[\operatorname{lnf} 21](6-4)$} & \\
\hline 2021 & & \multicolumn{3}{|c|}{$2020[\operatorname{lnf} 22](6-8)$} & \\
\hline Modo 決 $F_{x}$ & Facultad 決 & $\nabla_{x}$ & Programa & 決 & $\nabla_{x}$ \\
\hline A & COMSO & $\wedge$ & 05ADC & & $\hat{\imath}$ \\
\hline $\mathrm{T}$ & DEREC & & 05B02 & & \\
\hline v & FCAEC & & 05B06 & & \\
\hline M & FCCOM & $\checkmark$ & 05B10 & & $\checkmark$ \\
\hline
\end{tabular}

\section{ESTADÍSTICA DE USO DE HERRAMIENIAS POR PARTE DEL PROFESOR EN CAMPUS VIRTUAL}
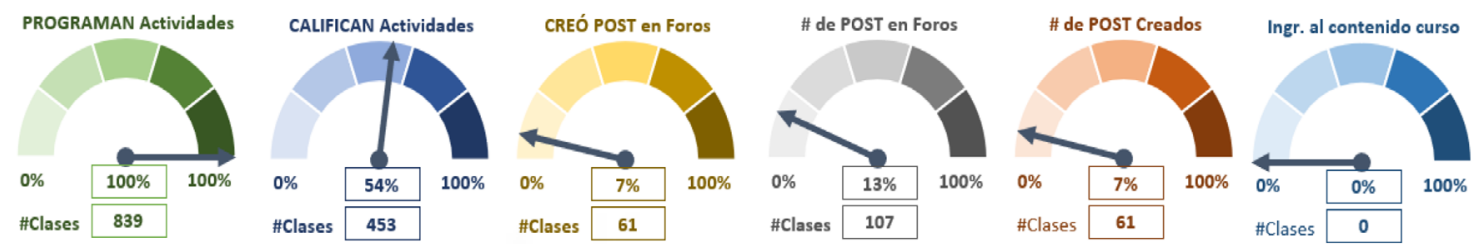

\section{ESTADÍSTICA DEL ÚLTIMO INGRESO POR PARTE DEL PROFESOR A LAS AULAS VIRTUALES}
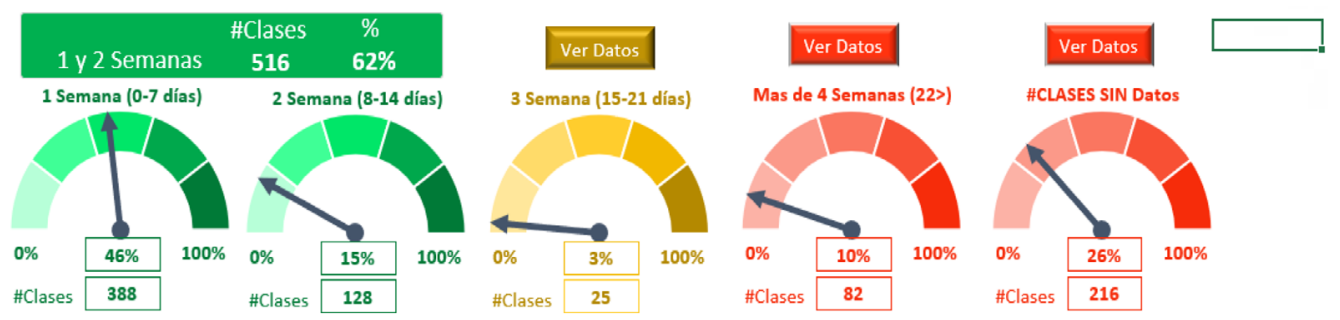

Figura 10. Estadísticas de uso del campus virtual por profesores, seccional Medellín.

Elaboración propia con base en información suministrada por la Coordinación E-Learning, campus Medellín, ucc. 
Uno de los objetivos del Modelo Educativo Crítico con Enfoque de Competencias es el logro del aprendizaje significativo y el desempeño exitoso de los estudiantes en diversos contextos. Los programas de Administración de Empresas e Ingeniería Civil ya empiezan a tener los primeros egresados del plan de estudios bajo dicho modelo educativo y al hacer un análisis comparado del desempeño académico de los estudiantes pertenecientes a los programas con enfoque de competencias, se evidencia un mejor desempeño de estos en las pruebas Saber Pro (figura 12).

En ambos programas, se aprecia un impacto positivo de la reforma curricular y del modelo educativo sobre el aprendizaje de los estudiantes, evidenciado en mejores resultados en las pruebas Saber Pro. Adicionalmente, de manera sistemática, se implementan acciones enfocadas en el logro de los aprendizajes, el desarrollo de las competencias y el rendimiento en las pruebas Saber Pro, por ejemplo:

- El Acuerdo Superior 366 de 2018 motiva a los estudiantes de Derecho que obtengan un desempeño en Saber Pro por encima del 80\% de los mejores promedios, a ser eximidos de la presentación de todos los preparatorios (UCC, 2018).

- Según la Resolución Rectoral 432 del 2013, “en el caso que el puntaje más alto de estas pruebas, en cualquier programa académico sea obtenido por un estudiante o egresado de esta Universidad, ésta le otorgará un 100\% de descuento en el valor de la matrícula para cursar un programa de posgrado en la institución" (UCC, 2013b).

Monitoreo y análisis de resultados del SIEC: en el campus Medellín, 3762 estudiantes han sido evaluados mediante las pruebas sIEC en el periodo comprendido entre 2016 y 2019. La aplicación periódica de las pruebas permite establecer alarmas para intervenir de manera oportuna el aprendizaje y el desarrollo de las competencias. En las figuras 13-16, se dan algunos ejemplos del comportamiento de estas variables en el campus Medellín. 


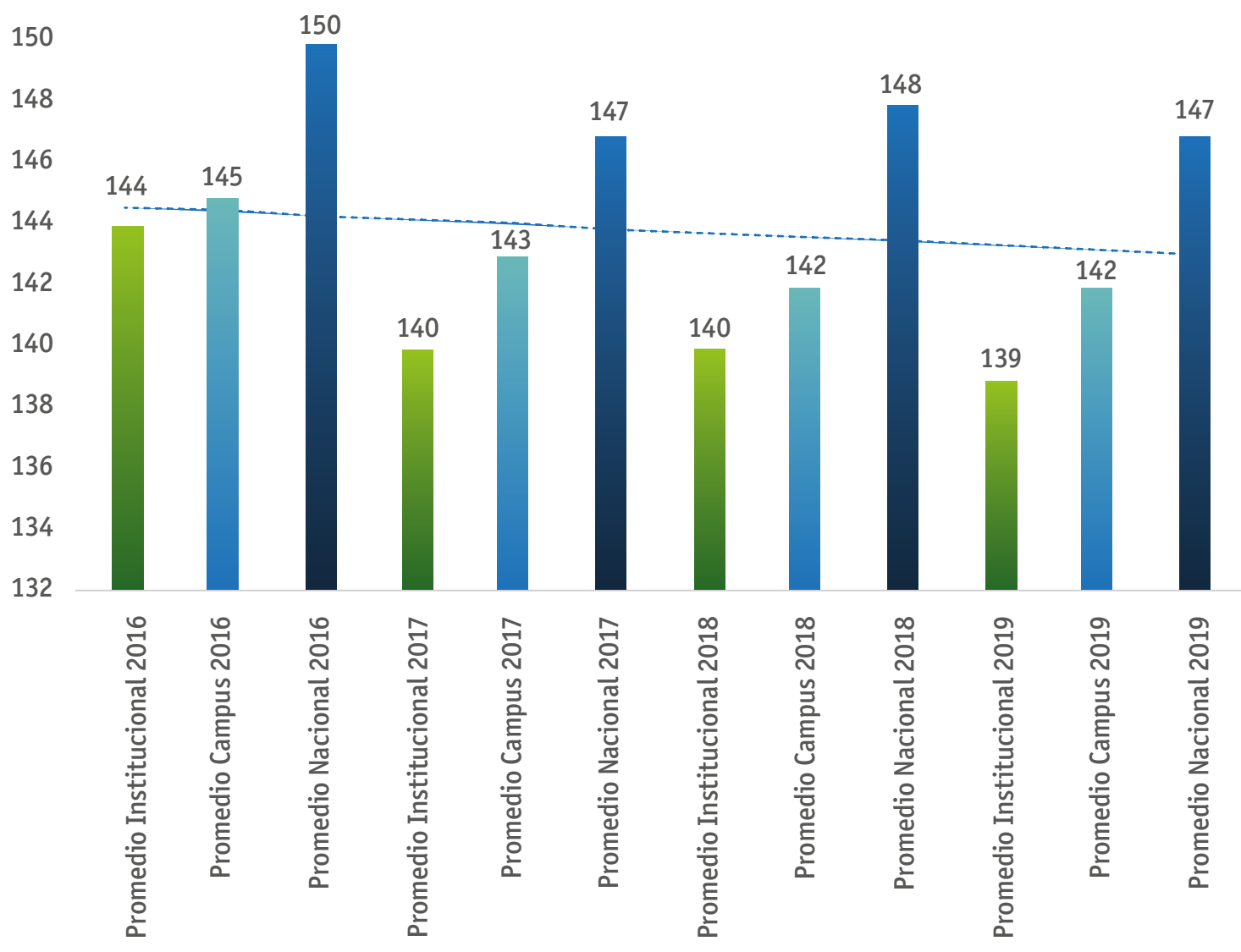

Figura 11. Histórico del promedio global del desempeño de estudiantes en Saber Pro 2016-2019. Elaboración propia con base en información suministrada por la Subdirección Académica, seccional Medellín, UCC, 2020.

150

145

140

135

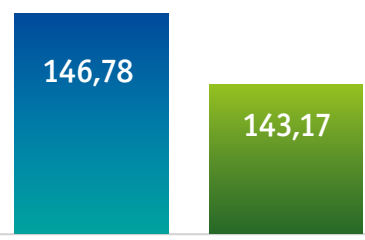

Ingeniería civil

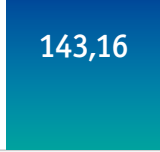

\section{1}

Administración de empresas

Promedio Global Saber Pro competencias

Promedio Global Saber Pro objetivos

Figura 12. Resultados del desempeño en Saber Pro: programas por objetivos-programas con enfoque de competencias. Elaboración propia. 

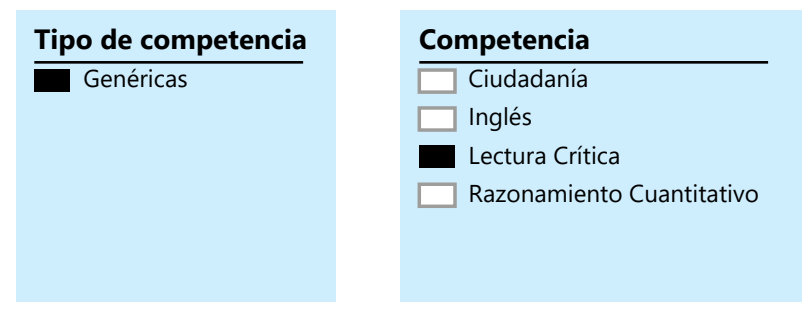

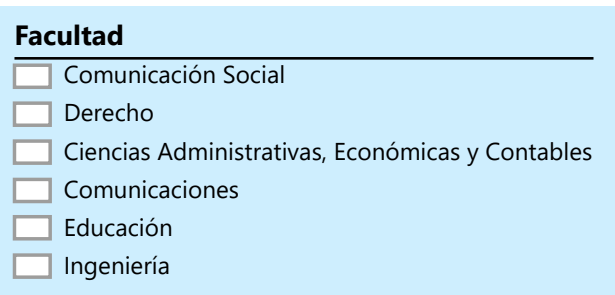

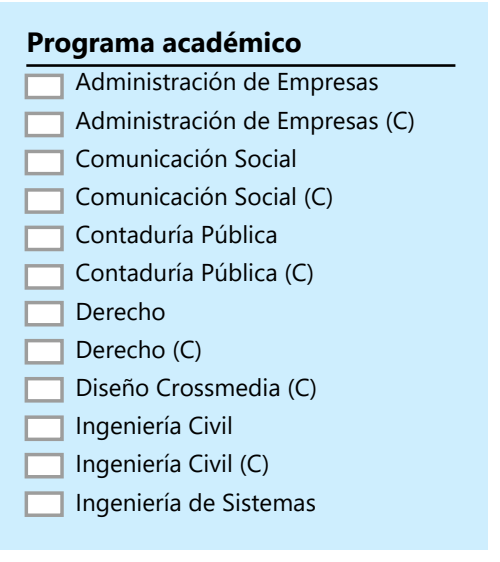

Estudiantes según nivel de desempeño

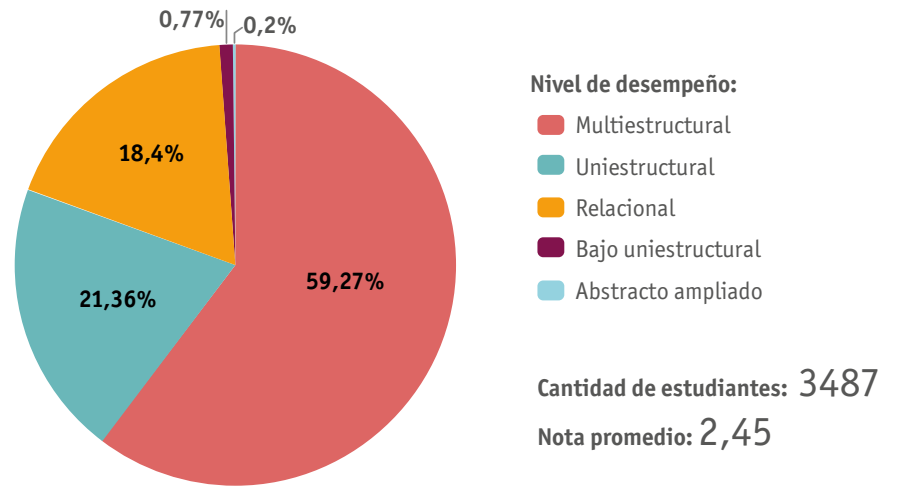

Cantidad de estudiantes y promedio de nota por aplicación y región de aprendizaje

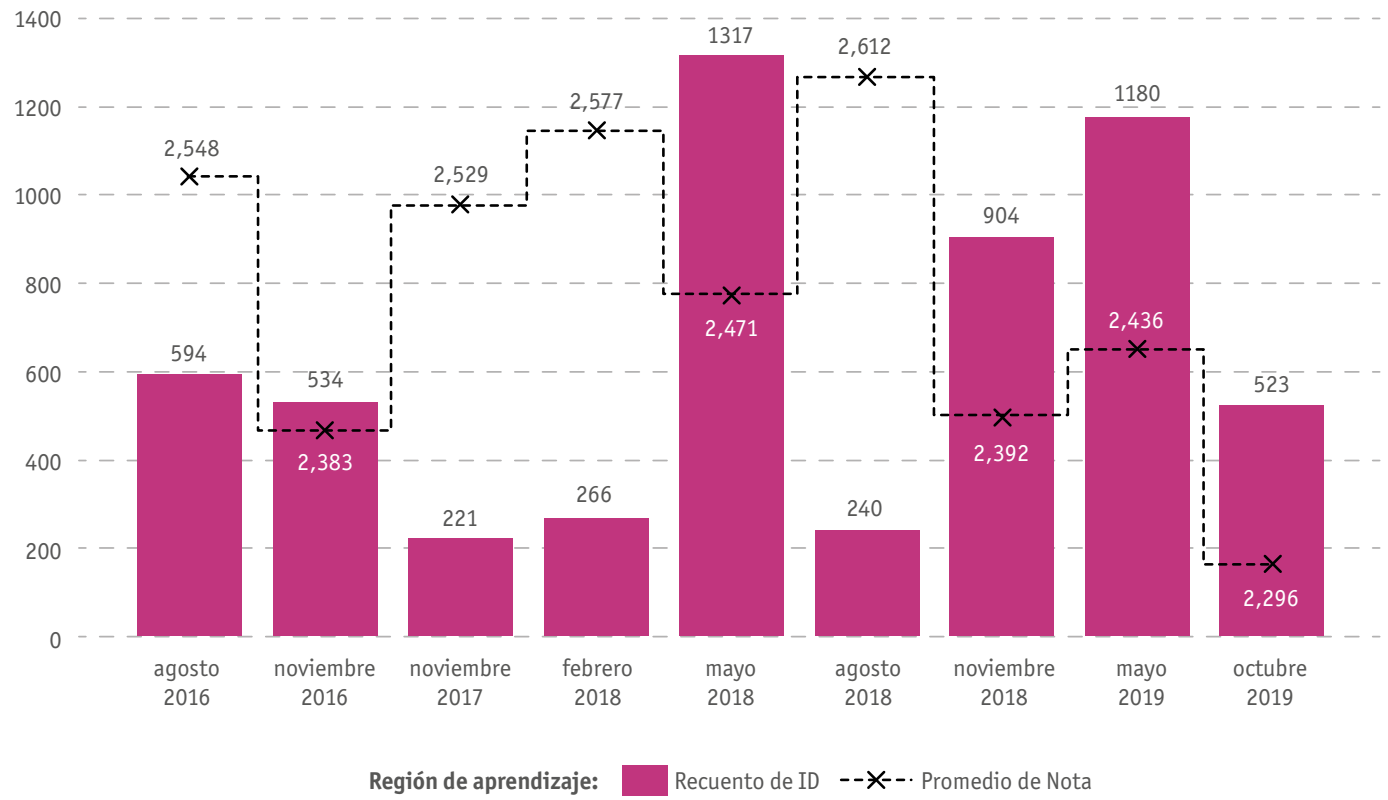

Figura 13. Resultados de las pruebas SIEC en competencias genéricas 2016-2019: lectura crítica, campus Medellín, 2018. Elaboración propia con base en información suministrada por el SIEC (2018). 

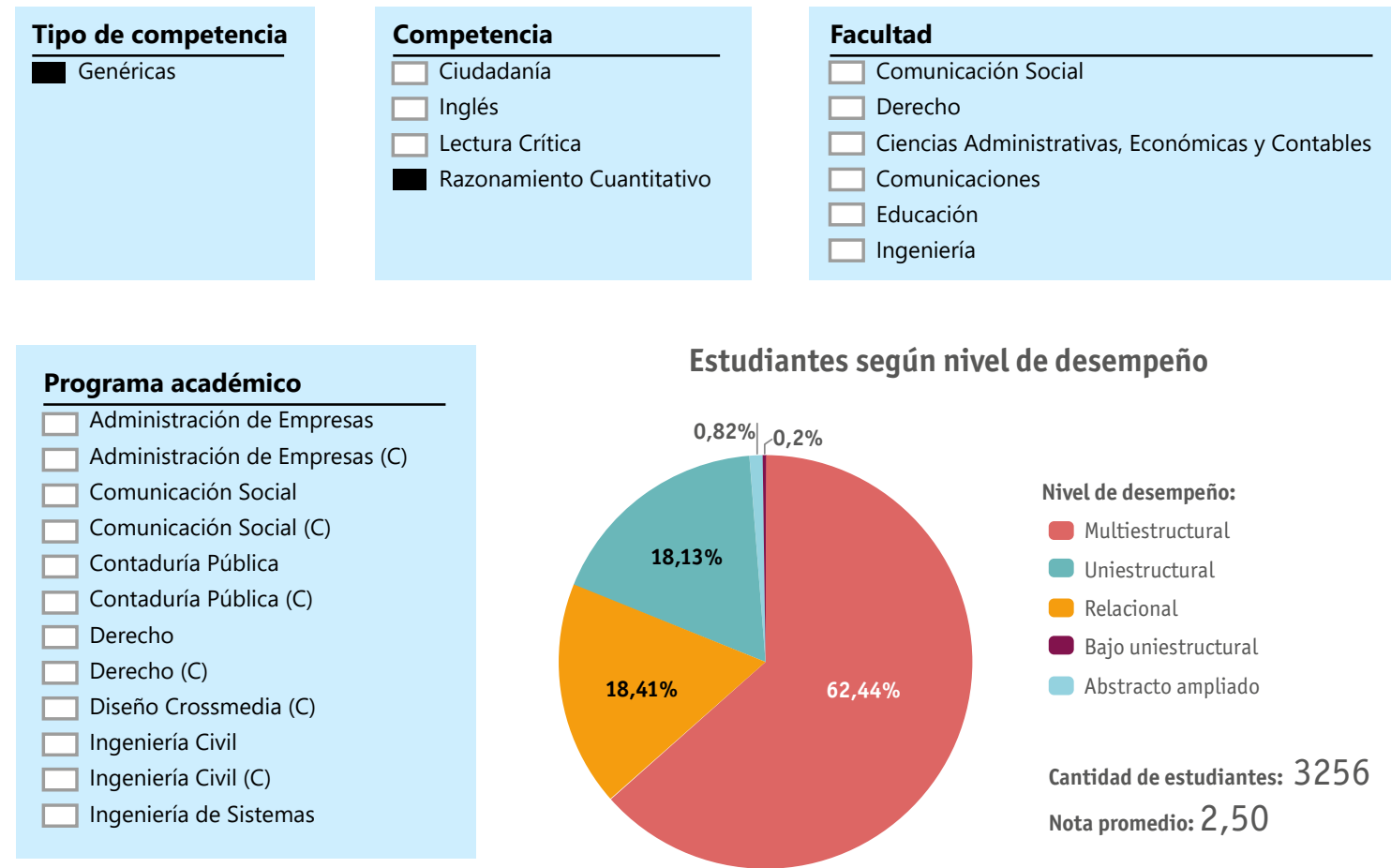

\section{Estudiantes según nivel de desempeño}

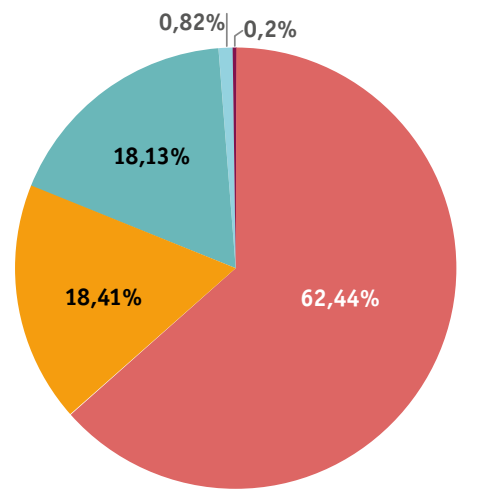

Nivel de desempeño:

Multiestructural

Uniestructural

Relacional

Bajo uniestructural

Abstracto ampliado

Cantidad de estudiantes: 3256

Nota promedio: 2,50

Cantidad de estudiantes y promedio de nota por aplicación y región de aprendizaje

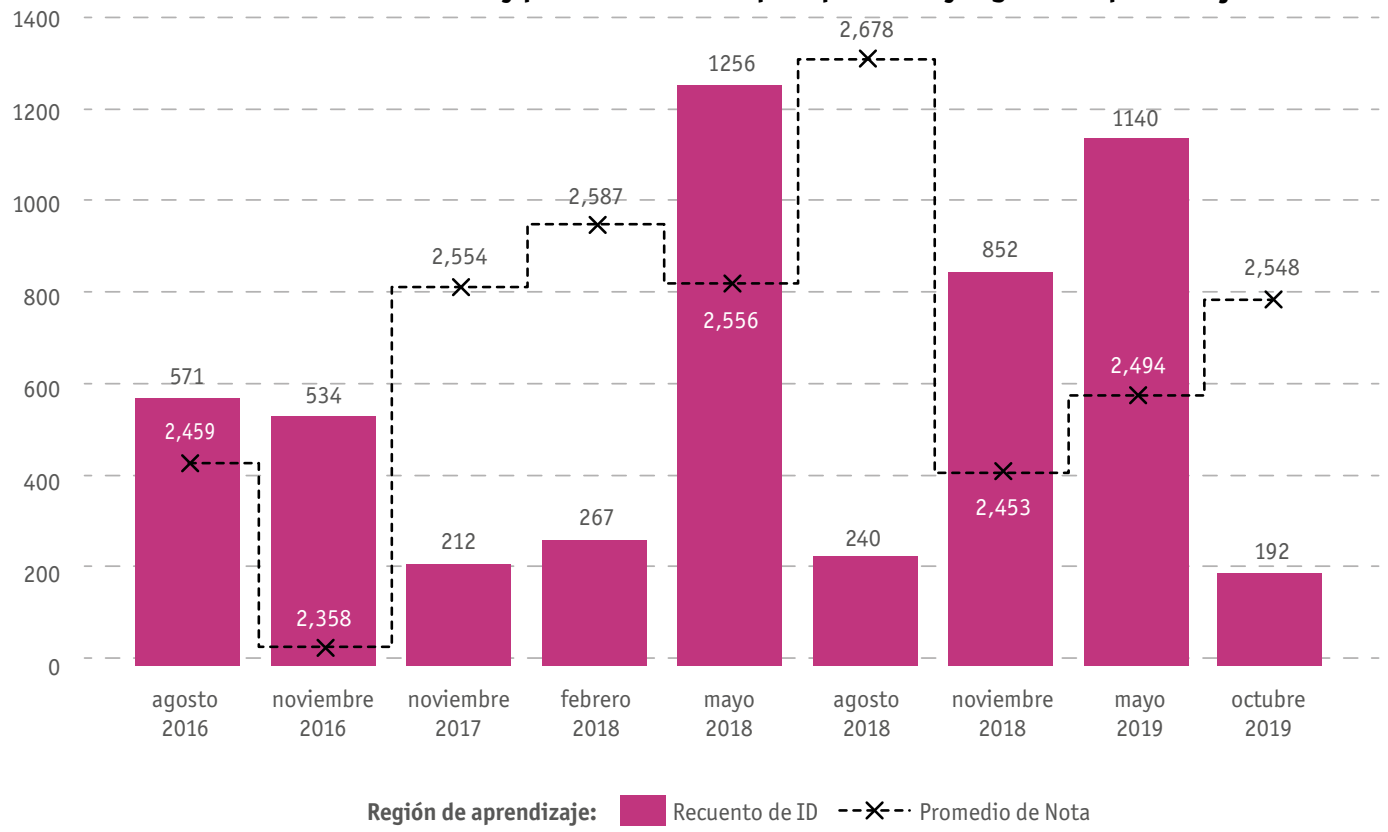

Figura 14. Resultados pruebas SIEC competencias genéricas 2016-2019: razonamiento cuantitativo, campus Medellín, 2018. Elaboración propia con base en información suministrada por el SIEC (2018). 

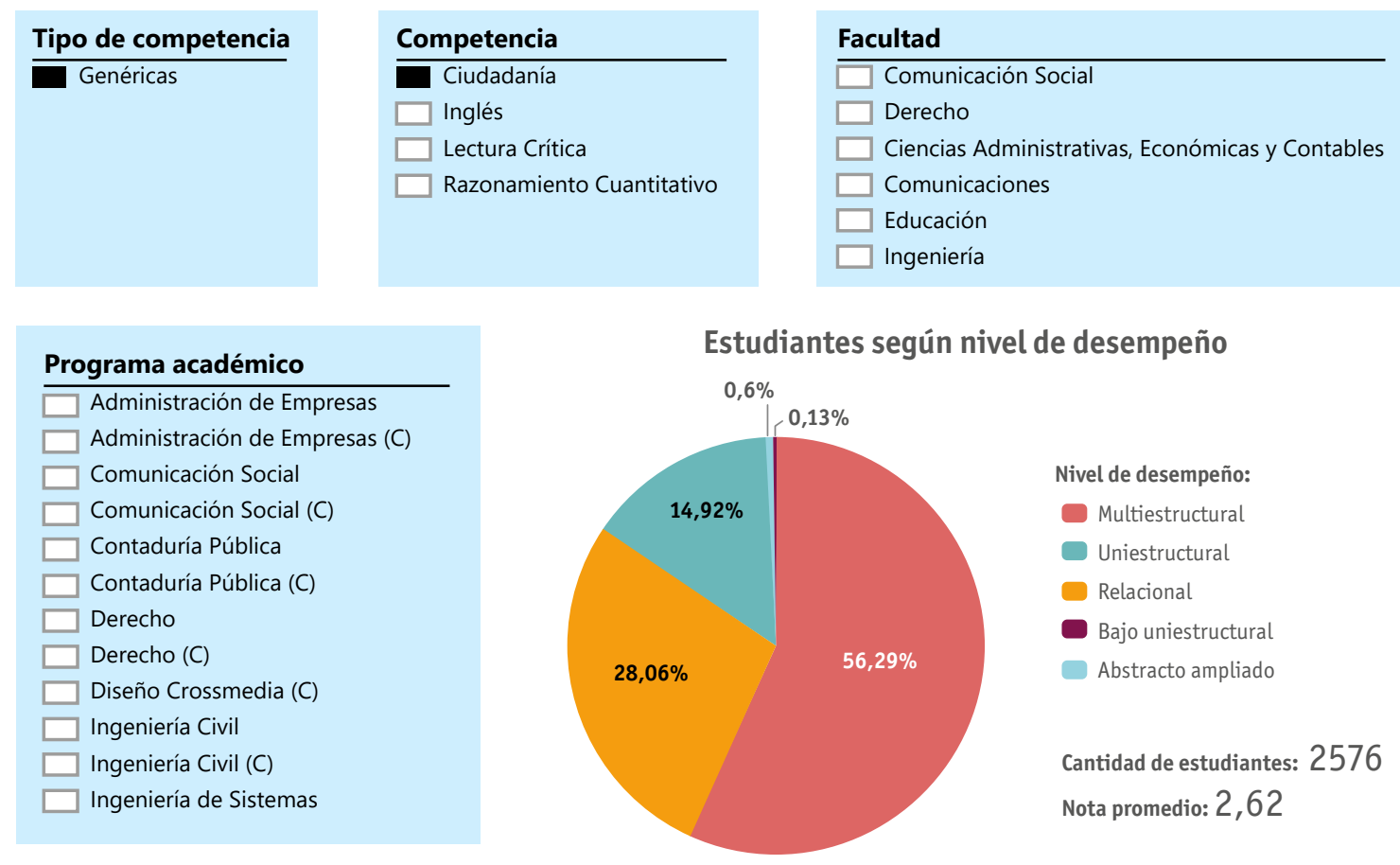

\section{Cantidad de estudiantes y promedio de nota por aplicación y región de aprendizaje}

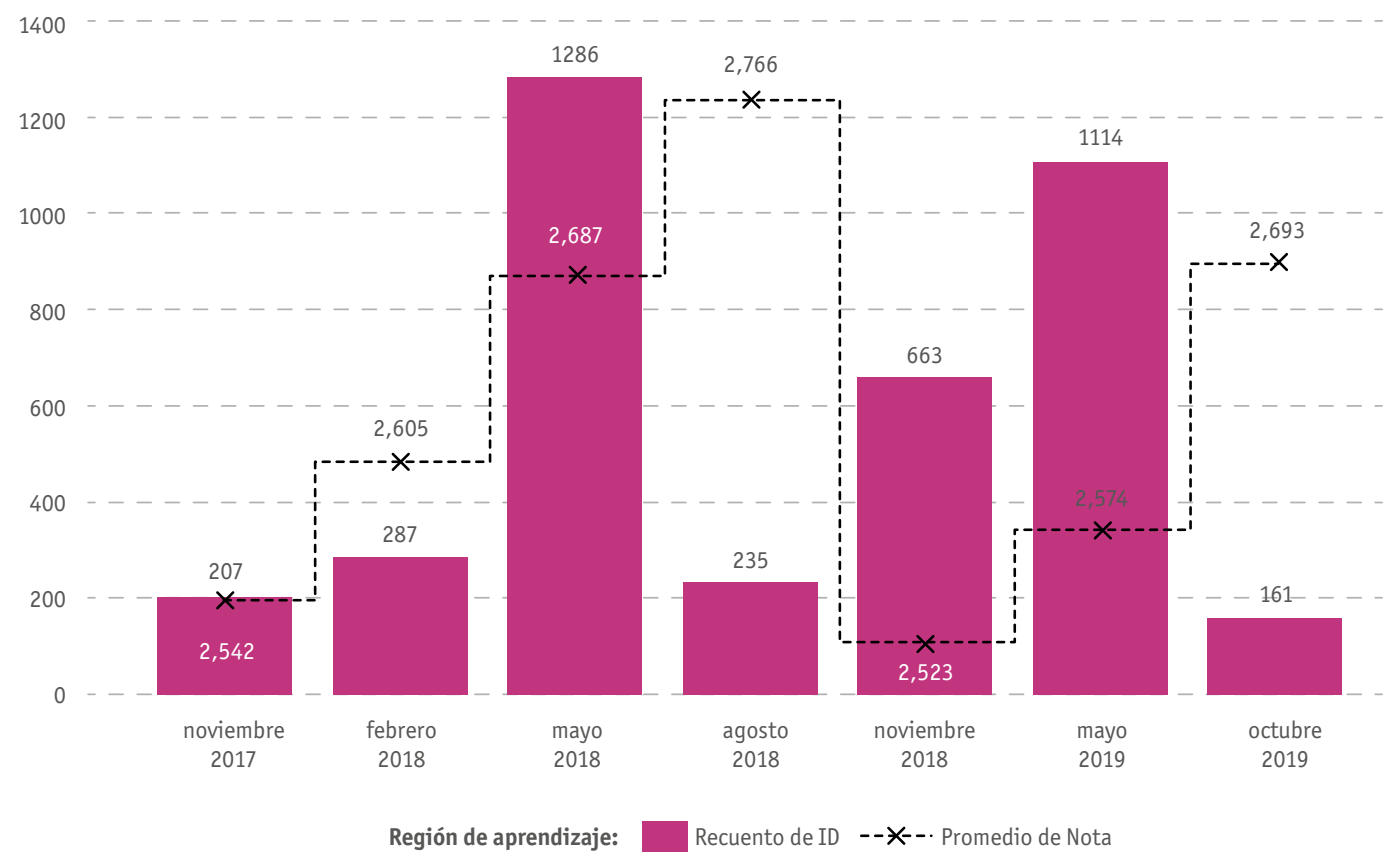

Figura 15. Resultados de las pruebas SIEC en competencias genéricas 2016-2019: competencias ciudadanas, campus Medellín, 2018. Elaboración propia con base en información suministrada por el SIEC (2018). 

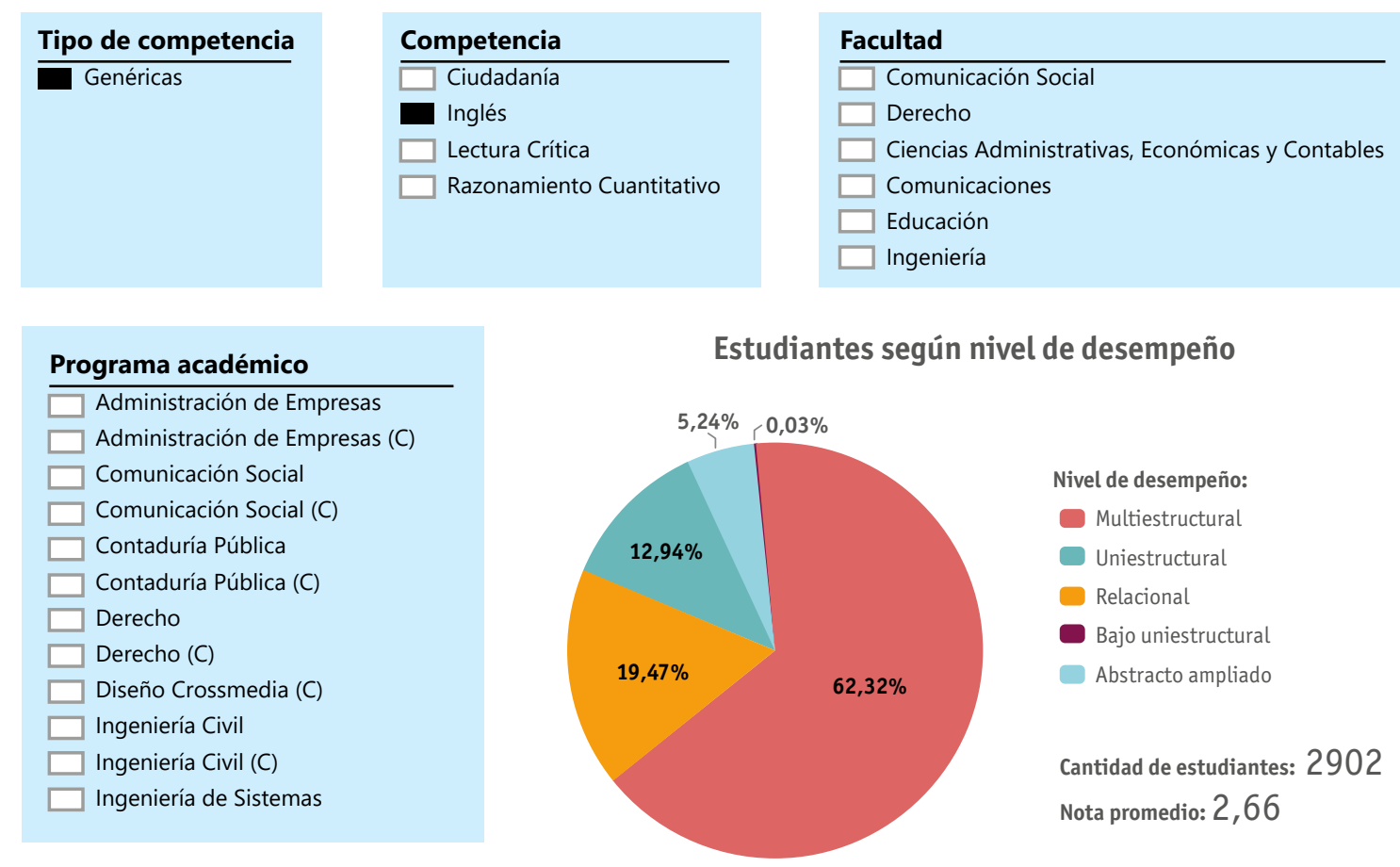

\section{Cantidad de estudiantes y promedio de nota por aplicación y región de aprendizaje}

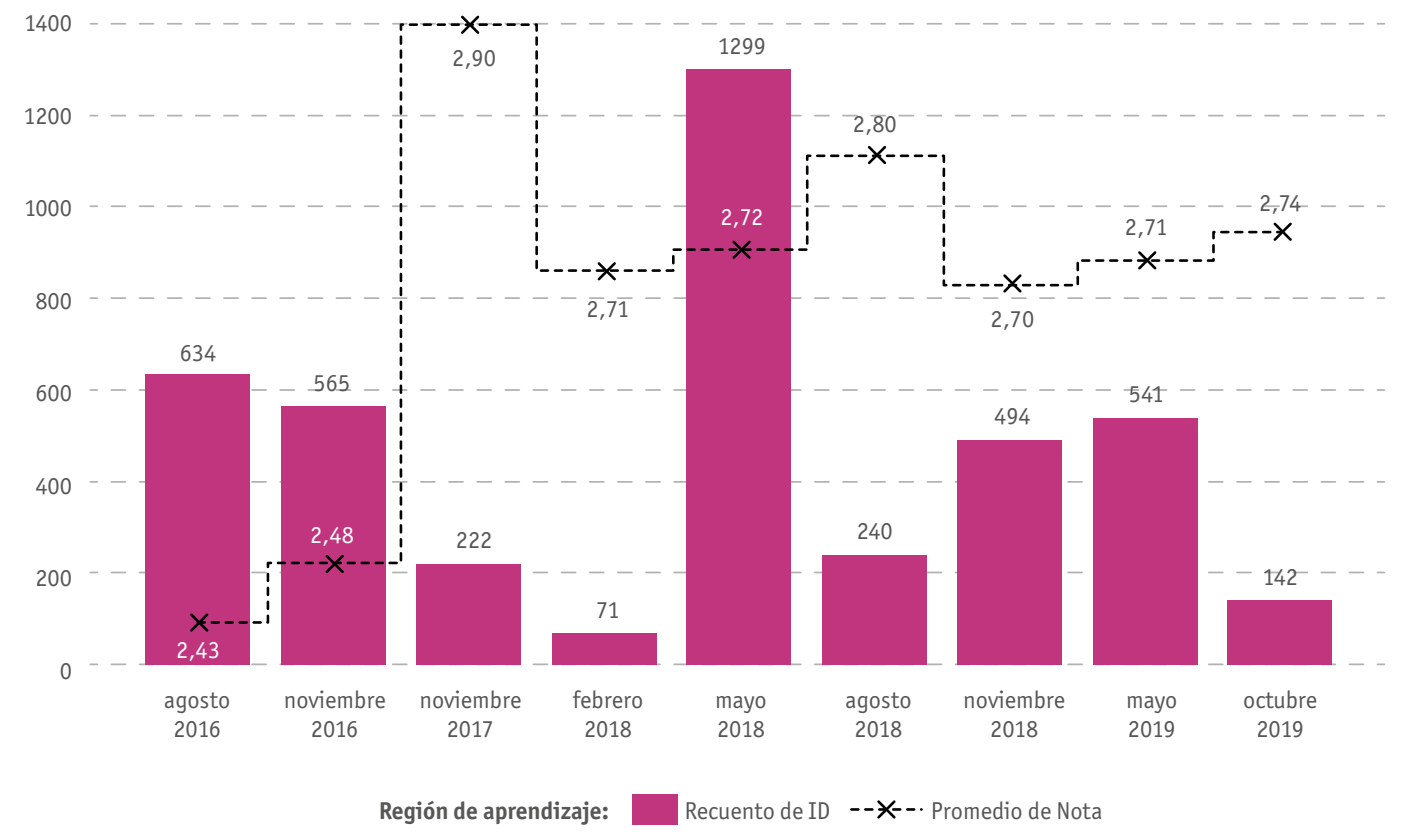

Figura 16. Resultados de las pruebas SIEC en competencias genéricas 2016-2019: inglés, campus Medellín, 2018. Elaboración propia con base en información suministrada por el $\operatorname{SIEC}(2018)$. 


\section{Algunas de las acciones derivadas de este proceso de evaluación y moni-} toreo son:

- Desde el centro de idiomas, se apoya la enseñanza y desarrollo de competencias en segunda lengua, con un promedio de 1270 estudiantes por periodo académico y 146 profesores que han accedido a cursos para el fortalecimiento de la competencia en segunda lengua. El uso de la plataforma Dexway ha permitido flexibilizar los tiempos para el aprendizaje y aportar al desarrollo de las competencias en segunda lengua de los estudiantes y profesores.

- Proyectos integradores y transversales a los planes de estudio para enfatizar en el desarrollo de las competencias genéricas.

- Énfasis en desarrollo de competencias genéricas en cursos de humanidades.

- Inclusión de cursos electivos con énfasis en áreas de evaluación específica de los programas.

- Implementación de agenda de actividades de desarrollo integral con énfasis en actividades culturales, para el fomento y desarrollo de competencias genéricas:

- Implementación de talleres de lectura.

- Implementación de talleres de escrituras creativas y científica.

- Promoción bilingüismo en los cursos, mediante lecturas en segunda lengua.

Monitoreo y análisis de valor académico agregado: a través del SIEC, se realiza el seguimiento al valor académico agregado. Este permite apreciar la calidad del proyecto educativo puesto que permite estimar la variación en el desarrollo cognitivo de los estudiantes, entre el momento inicial y el momento final del proceso educativo. Establece el cambio de estado que muestran los estudiantes como consecuencia de las prácticas de aula y del currículo. Para tal fin, compara los resultados de las Pruebas Saber 11 y de las Pruebas Saber Pro de cada estudiante (UCC, 2017a, art. 2). 
El valor académico de la seccional en el periodo comprendido entre 2014-2018 ha sido positivo. Para el cálculo de este, se toma como universo 81 universidades de Colombia, las cuales cumplen con el criterio de selección de la información, con un total de 69195 estudiantes, la Universidad cuenta, para este estudio, con un total de 2687 estudiantes, el campus de Medellín, particularmente, cuenta con 132 estudiantes, arrojando un valor agregado de 2,54 (figura 17).

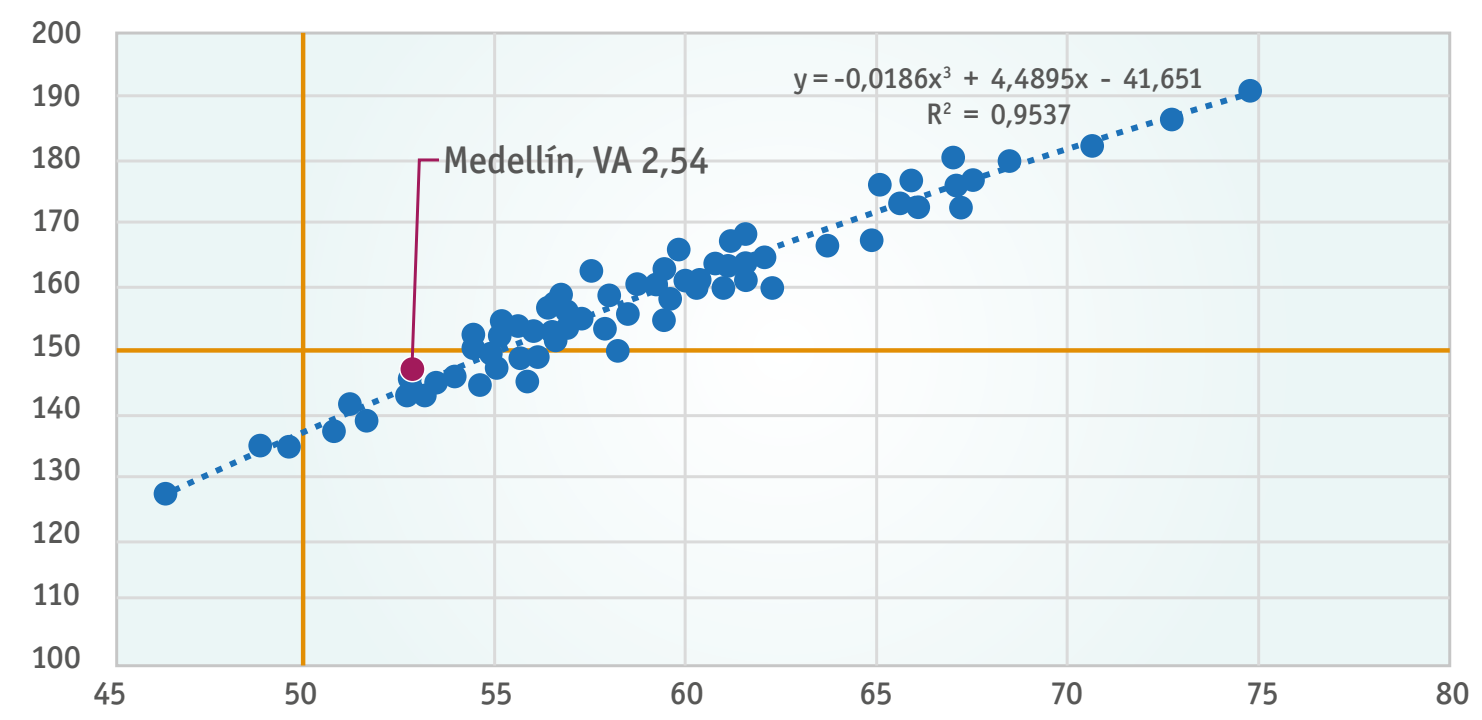

Figura 17. Valor académico agregado, campus Medellín, 2018. Elaboración propia con base en información suministrada por la Subdirección de Planeación Académica, 2019.

Es importante señalar el monitoreo que se realiza a cada programa del campus sobre el avance en el resultado del aprendizaje. En la figura 18, se presenta un ejemplo. Para su interpretación, es necesario tener en cuenta:

1. No siempre coincide el número de estudiantes con pruebas Saber 11 y Saber Pro.

2. La primera fila de datos corresponde a Saber Pro: promedio Global, desviación estándar, puntaje mínimo y puntaje máximo.

3. La segunda fila de datos corresponde a Saber 11: promedio Global, desviación estándar, puntaje mínimo y puntaje máximo. 
4. La tercera fila de datos corresponde a la equivalencia de puntajes de las pruebas Saber 11 a 300 puntos del Saber Pro, para poder hacer comparativos entre ambas pruebas: promedio global, desviación estándar, puntaje mínimo y puntaje máximo.

5. Para la lectura de los cuadrantes se debe hacer en sentido contrario a las manecillas del reloj.

\section{Cuadrante II \\ Son estudiantes o programas que presenta un Saber 11 por debajo de la media nacional, pero un Saber Pro por encima de la media nacional. \\ En el caso de la Universidad Cooperativa de Colombia que sus estudiantes suelen ingresar con un Saber 11 Por debajo de la media, este sería su cuadrante ideal. \\ Cuadrante III \\ Son estudiantes o programas que presentan resultados inferiores a la media nacional tanto en la prueba de Saber 11 como de Saber Pro, es importante aclarar que no significa que no se presenten un avance en el logro del aprendizaje.}

\section{Cuadrante I}

Son los estudiantes o programas que presenta resultados superiores a la media nacional, tanto para el Saber 11 como para el Saber Pro

Figura 18. Interpretación de los resultados del valor agregado. Elaboración propia.

Para el caso de Odontología, por ejemplo, el 54\% de la población estudiantil que presentó pruebas Saber Pro en el 2019 mostró un avance en el logro del aprendizaje, un 2\% se mantiene y el $44 \%$ restante no mostró avance de acuerdo con su desempeño en Saber Pro. Dentro de los análisis hechos a estos resultados, se encuentra que los estudiantes universitarios aun no le dan importancia al examen Saber Pro, por lo cual se han establecido mecanismos de sensibilización y preparación para presentar la prueba, de tal manera que los estudiantes asuman una actitud positiva frente a la misma y logren evidenciar su real nivel de aprendizaje (figura 19). 


\section{Puntajes Globales}

140,53

\begin{tabular}{|c|c|c|c|c|c|}
\hline \multicolumn{2}{|l|}{ Campus } & \multicolumn{2}{|l|}{ Programa } & \multicolumn{2}{|c|}{ Programa 0BJ y Com } \\
\hline MEDELLÍN & & ODONTOLOGÍA & & Todas & $\checkmark$ \\
\hline & & $\begin{array}{c}142,38 \\
\text { Prom. Saber Pro }\end{array}$ & $\begin{array}{l}16,92 \\
\text { Desv. Estandar Saber }\end{array}$ & $\begin{array}{l}93,00 \\
\text { Min. Saber Pro }\end{array}$ & $\underset{\text { Max. Saber Pro }}{184,00}$ \\
\hline $\begin{array}{c}99 \\
\text { № Estudiantes }\end{array}$ & $\begin{array}{c}74 \\
\text { № Estudiantes }\end{array}$ & $\begin{array}{l}47,00 \\
\text { Prom. Saber } 11\end{array}$ & $\begin{array}{c}5,87 \\
\text { Desv. Saber } 11\end{array}$ & $\begin{array}{l}34,64 \\
\text { Min. Saber } 11\end{array}$ & $\underset{\text { Max. Saber } 11}{62,80}$ \\
\hline $\begin{array}{l}\text { que presentan } \\
\text { Saber Pro }\end{array}$ & $\begin{array}{c}\text { con resultados } \\
\text { Saber } 11 \\
\text { Saber Pro }\end{array}$ & $\begin{array}{l}140,99 \\
\text { E. Prom. Saber } 11\end{array}$ & $\begin{array}{c}17,61 \\
\text { E. Desv. Saber } 11\end{array}$ & $\begin{array}{l}103,92 \\
\text { E. Min. Saber } 11\end{array}$ & $\begin{array}{c}188,40 \\
\text { E. Max. Saber } 11\end{array}$ \\
\hline
\end{tabular}

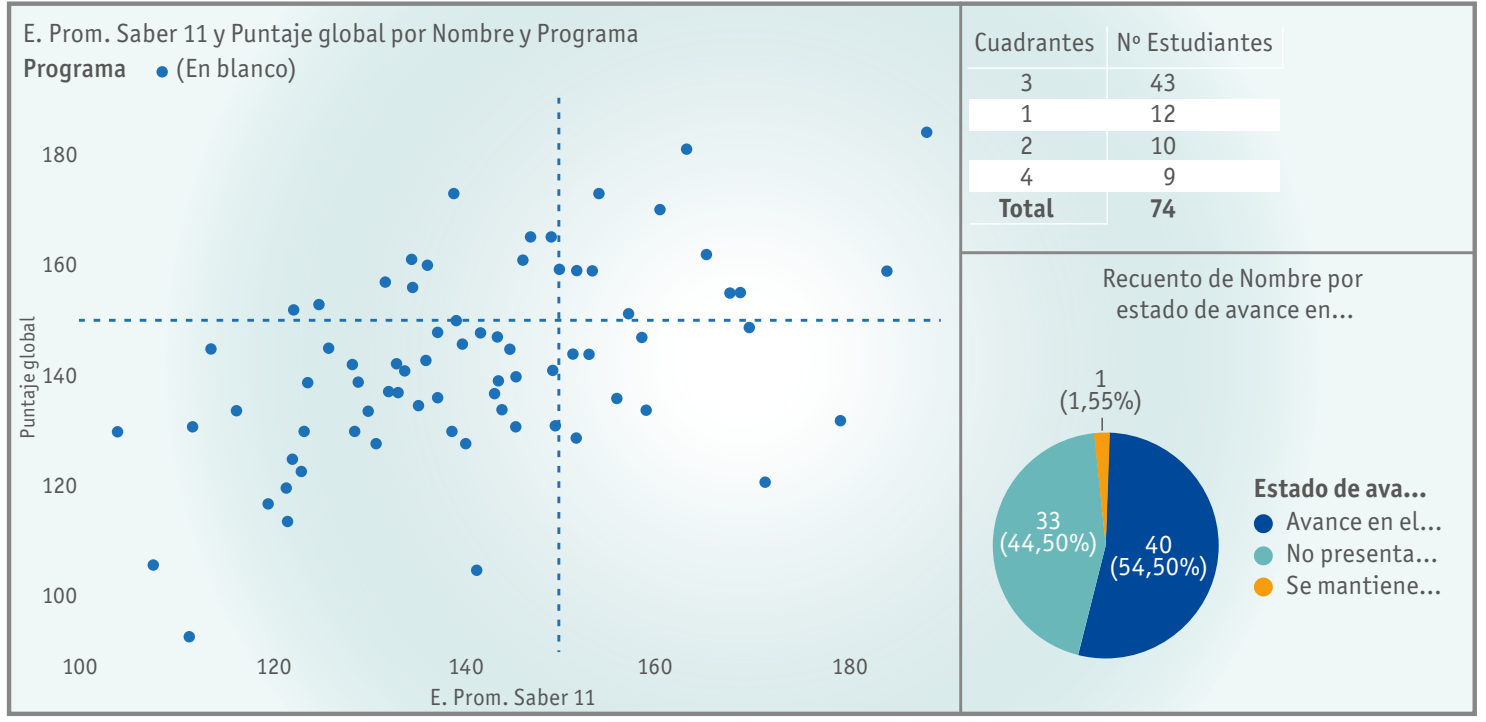

Figura 19. Avance en el resultado de aprendizaje, programa Odontología, campus Medellín, 2020. Elaboración propia con base en información suministrada por la Subdirección de Planeación Académica, 2020.

Teniendo en cuenta la importancia del vínculo pedagógico y de los procesos de enseñanza en el logro del aprendizaje, la evaluación profesoral hace parte del monitoreo permanente. Esta contempla la autoevaluación del profesor (15\%), evaluación de estudiantes (30\%) y la evaluación institucional (55\%). Para el caso de la evaluación realizada por los estudiantes y la autoevaluación, se contemplan las cinco dimensiones: estrategias de comunicación, estrategias de mediación cognitiva, gestión, estrategias evaluativas, didáctica. La calificación es de 0 a 4, en caso de obtener una evaluación de 3,2 para abajo en 
cualquiera de las dimensiones evaluadas, el profesor debe elaborar un plan de mejora. La figura 20 da cuenta de que en el 89\% de las clases evaluadas en el campus Medellín, los profesores obtuvieron, para el periodo académico 1920, una calificación promedio por encima de 3,2.

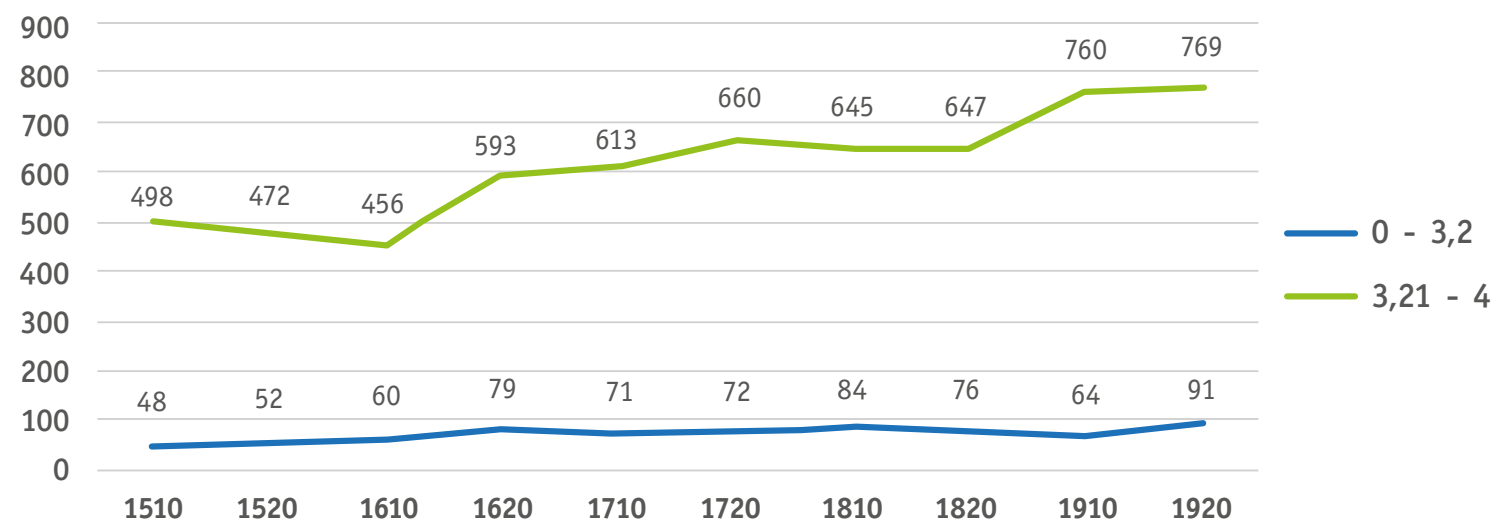

Figura 20. Clases evaluadas, campus Medellín, 2015-2019. Elaboración propia con base en información suministrada por la Subdirección Académica, campus Medellín, 2020.

La figura 20 evidencia un incremento en las evaluaciones de clase realizadas por parte de los estudiantes, como resultado de las acciones de mejora para incrementar la cultura de la evaluación de los profesores y sus clases, en 2015 se evaluaron 546 clases mientras que en el periodo 1920 se evaluaron 860 clases, lo que denota un incremento del $57,5 \%$ de clases evaluadas. También, se resalta que el número de profesores con planes de mejora ha disminuido, de tal manera que en el periodo 2016-2 el porcentaje de profesores con planes de mejora fue del 16,3\% mientras que en 2019-2 fue de 11,3\%. Otras de las acciones que se han implementado para avanzar en el logro del aprendizaje son:

Estrategia Rizoma, mediante el desarrollo de talleres virtuales y la consolidación de comunidades de aprendizaje de los profesores a nivel multicampus. Utilizando "Yammer" como herramienta de comunicación, se ha logrado avanzar en el empoderamiento del modelo educativo y el desarrollo de estrategias didácticas y evaluativas. 
A través de la Escuela para la Excelencia Educativa, se mantiene la cualificación profesoral para fortalecer prácticas pedagógicas y vínculo educativo.

Los profesores cuentan, en sus planes de trabajo, con horas destinadas para las asesorías y tutorías académicas, para garantizar el acompañamiento al proceso de aprendizaje. A través del módulo, Mis asesorados, se dispone de una herramienta del sistema de información que permite la sistematización de estas tutorías, con el propósito de evaluar los motivos más frecuentes de asesoría.

Otro soporte para este seguimiento se da a través de las variables de análisis consideradas por la Universidad para realizar el seguimiento en el estudiante, estas son:

- Matrículas estudiantiles

- Promedios académico semestral y acumulado

- Cursos repetidos

- Cursos aprobados y no aprobados

- Cancelaciones

- Reingresos

- Deserción

- Cursos vacacionales

A continuación, se hará una breve descripción del comportamiento de variables de rendimiento académicos como cursos cancelados, repetidos (tabla 2), para el campus Medellín durante el periodo de 2018-2 a 2020-2.

\section{Cursos repetidos}

Respecto a la información registrada en el sistema, para el análisis de cursos repetidos por áreas de conocimiento, se evidencia que el área de ciencias administrativas, económicas y contables es la que presenta mayor número de cursos repetidos (figuras 21 y 22; tabla 3). La tendencia para el último semestre es decreciente. 
Tabla 2. Comportamiento de los cursos repetidos por área de conocimiento, campus Medellín

\begin{tabular}{|c|c|c|c|c|c|c|}
\hline ÁREAS DE CONOCIMIENTO & 1810 & 1820 & 1910 & 1920 & 2010 & 2020 \\
\hline $\begin{array}{c}\text { Ciencias administrativas, } \\
\text { económicas, y contables }\end{array}$ & 22 & 25 & 27 & 33 & 33 & 18 \\
\hline Ciencias sociales y humanas & 91 & 108 & 87 & 85 & 82 & 51 \\
\hline Ingenierías & 49 & 57 & 55 & 74 & 72 & 42 \\
\hline Open Lingua & 7 & 5 & 6 & 7 & 5 & 0 \\
\hline Salud & 82 & 91 & 84 & 82 & 95 & 41 \\
\hline Total general & 251 & 286 & 259 & 281 & 287 & 152 \\
\hline
\end{tabular}

Fuente: elaboración propia con base en información suministrada por la Dirección de Gestión de Proyectos Especiales, ucc, 2021.
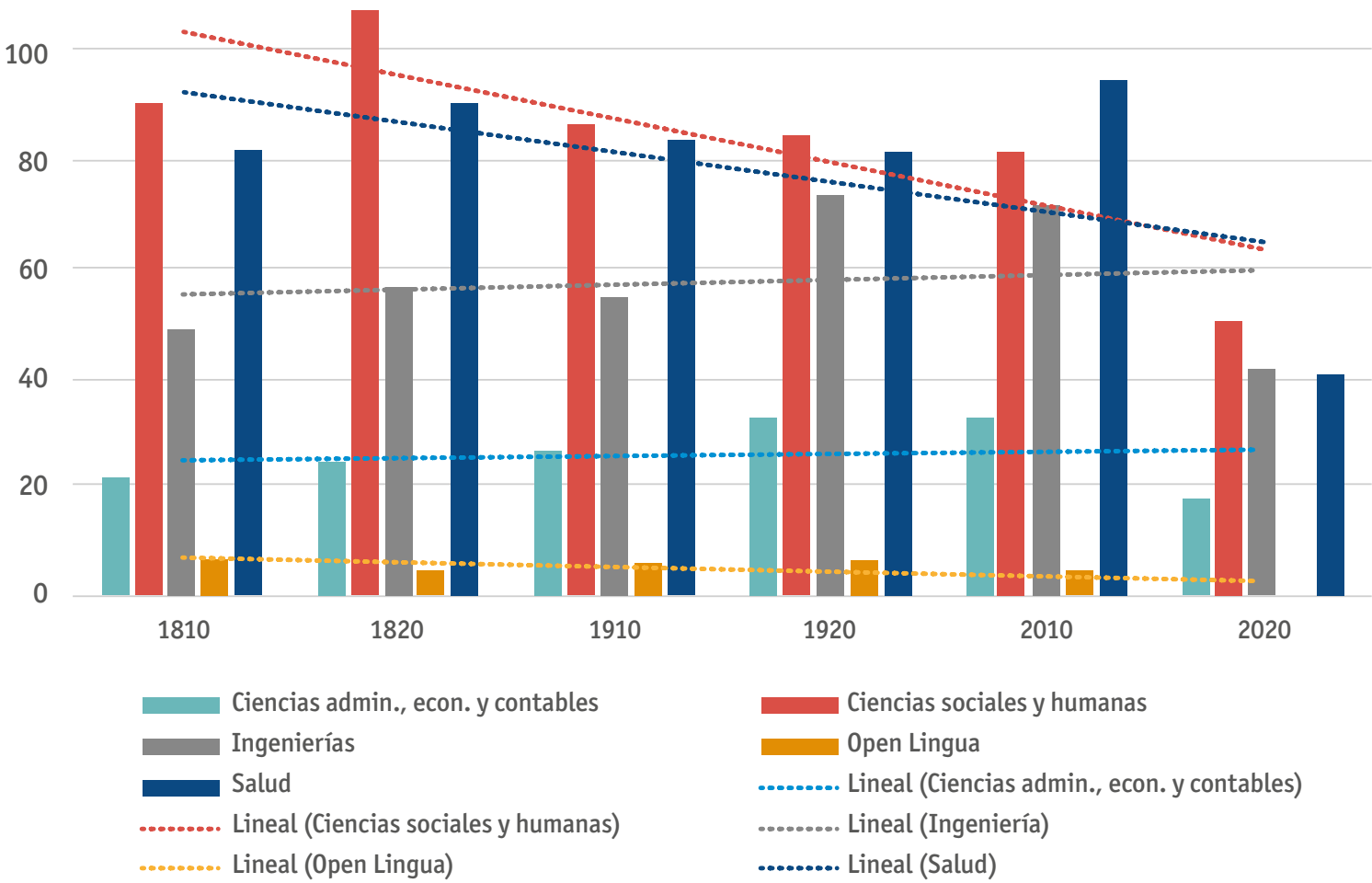

Figura 21. Comportamiento de los cursos repetidos, campus Medellín. Elaboración propia con base en información suministrada por la Dirección de Gestión de Proyectos Especiales, UCC, 2021. 


\begin{tabular}{|r|r|r|r|r|r|r|}
\hline \multicolumn{1}{|r|}{0} & 1810 & 1820 & 1910 & 1920 & 2010 & 2020 \\
\hline Series 1 & 251 & 286 & 259 & 281 & 287 & 152 \\
\hline
\end{tabular}

Figura 22. Tendencia de los cursos repetidos, campus Medellín. Elaboración propia con base en información suministrada por la Dirección de Gestión de Proyectos Especiales, Ucc, 2021.

Tabla 3. Comportamiento de las repitencias por programas académicos, campus Medellín

\begin{tabular}{|l|c|c|c|c|c|c|}
\hline \multicolumn{7}{|c}{ CURSOS QUE SE REPITEN } \\
\hline PROGRAMAS ACADÉMICOS & 1810 & 1820 & 1910 & 1920 & 2010 & 2020 \\
\hline Administración de Empresas & 6 & 1 & 4 & 2 & 1 & 2 \\
\hline Administración de Empresas (C) & 3 & 5 & 12 & 19 & 18 & 5 \\
\hline Comunicación Social & 10 & 14 & 5 & 7 & 6 & 6 \\
\hline Comunicación Social (C) & 1 & 0 & 0 & 0 & 0 & 0 \\
\hline Contaduría Pública & 13 & 16 & 8 & 7 & 5 & 1 \\
\hline Contaduría Pública (C) & 0 & 3 & 3 & 5 & 9 & 10 \\
\hline Derecho & 23 & 22 & 22 & 15 & 15 & 6 \\
\hline Derecho (C) & 9 & 14 & 10 & 15 & 18 & 15 \\
\hline Diseño Cross medía (C) & 1 & 0 & 1 & 8 & 9 & 4 \\
\hline Humanidades & 2 & 3 & 3 & 3 & 3 & 0 \\
\hline Ingeniería Civil & 25 & 26 & 28 & 31 & 28 & 4 \\
\hline Ingeniería Civil (C) & 18 & 23 & 22 & 28 & 29 & 30 \\
\hline
\end{tabular}




\begin{tabular}{|c|c|c|c|c|c|c|}
\hline \multicolumn{7}{|c|}{ CURSOS QUE SE REPITEN } \\
\hline PROGRAMAS ACADÉMICOS & 1810 & 1820 & 1910 & 1920 & 2010 & 2020 \\
\hline Ingeniería de Sistemas & 0 & 3 & 1 & 3 & 2 & 0 \\
\hline Ingeniería de Software (C) & 0 & 2 & 2 & 0 & 1 & 2 \\
\hline Ingeniería Mecánica (C) & 3 & 3 & 1 & 4 & 3 & 2 \\
\hline Lic. en Educ énfasis Tecno. IInforA & 1 & 2 & 1 & 0 & 0 & 0 \\
\hline Lic. Matemáticas e Informática & 14 & 18 & 20 & 17 & 10 & 7 \\
\hline Lic.edu.bas.Mat.Inf.Distancia & 4 & 3 & 0 & 1 & 0 & 0 \\
\hline Lic. en Tecnología e Informática & 1 & 0 & 0 & 0 & 0 & 0 \\
\hline Licenciatura en Matemática (C) & 0 & 0 & 0 & 0 & 0 & 0 \\
\hline Medicina & 34 & 32 & 21 & 19 & 29 & 10 \\
\hline Medicina $(\mathrm{C})$ & 12 & 17 & 18 & 20 & 23 & 16 \\
\hline Odontología & 25 & 26 & 21 & 19 & 14 & 2 \\
\hline Odontología (C) & 11 & 16 & 24 & 24 & 29 & 13 \\
\hline Open Lingua & 7 & 5 & 6 & 7 & 5 & 0 \\
\hline Psicología & 24 & 26 & 23 & 15 & 17 & 9 \\
\hline Psicología (C) & 2 & 6 & 3 & 12 & 13 & 8 \\
\hline Tecnología en Diseño Gráfico & 0 & 0 & 0 & 0 & 0 & 0 \\
\hline Tecnología en Sistemas & 2 & 0 & 0 & 0 & 0 & 0 \\
\hline Total general & 251 & 286 & 259 & 281 & 287 & 152 \\
\hline
\end{tabular}

Fuente: elaboración propia con base en información suministrada por la Dirección de Gestión de Proyectos Especiales, ucc, 2021.

Otro componente que permite realizar seguimiento al comportamiento y avance en los resultados académicos de los estudiantes es hacer el análisis, partiendo de los estudiantes con mayor repitencia, para conocer cuáles son los cursos que más repiten en cada uno de los programas académicos (tabla 4). Este es un resumen para el periodo entre el 2018-1 y 2020-2: 
Tabla 4. Comportamiento de los cursos repetidos por programas académicos, campus Medellín

\begin{tabular}{|c|c|c|c|c|c|c|}
\hline PROGRAMA ACADÉMICO REPITENCIA & 1810 & 1820 & 1910 & 1920 & 2010 & 2020 \\
\hline DERECHO (C) & 31 & 25 & 22 & 37 & 34 & 21 \\
\hline Derecho Civil General y Personas & 12 & 6 & 2 & 4 & 6 & 0 \\
\hline ING. CIVIL (C) & 77 & 106 & 113 & 125 & 174 & 92 \\
\hline Análisis Numérico & 5 & 2 & 5 & 6 & 14 & 2 \\
\hline Cálculo Diferencial & 7 & 12 & 4 & 5 & 10 & 8 \\
\hline Cálculo Integral & 6 & 8 & 8 & 8 & 8 & 5 \\
\hline Calculo Multivariado & 3 & 8 & 17 & 19 & 9 & 4 \\
\hline Estática & 3 & 5 & 6 & 12 & 13 & 4 \\
\hline Física Mecánica & 10 & 15 & 14 & 15 & 13 & 4 \\
\hline Mecánica de Fluidos & 1 & 1 & 1 & 2 & 6 & 10 \\
\hline Resistencia de Materiales & 1 & 3 & 0 & 3 & 10 & 3 \\
\hline ING. CIVIL & 93 & 82 & 92 & 82 & 89 & 8 \\
\hline Análisis Estructural II & 0 & 0 & 13 & 13 & 11 & \\
\hline Resistencia de Materiales & 6 & 13 & 11 & 3 & 6 & \\
\hline MEDICINA & 406 & 287 & 147 & 69 & 88 & 22 \\
\hline Bioquímica IV & 2 & 6 & 3 & 0 & 16 & 1 \\
\hline Clín. Mujer y Recién Nacido & 9 & 19 & 27 & 10 & 0 & 0 \\
\hline Farmacología & 150 & 87 & 45 & 12 & 8 & \\
\hline Inmunogénica & 63 & 63 & 4 & 8 & 6 & 0 \\
\hline MEDICINA (C) & 172 & 231 & 251 & 343 & 542 & 158 \\
\hline Bases de Embriog Histolg y palea. & 10 & 30 & 36 & 36 & 50 & 6 \\
\hline Farmacología Medica & 0 & 18 & 32 & 18 & 62 & 4 \\
\hline Microbiología Básica & 19 & 11 & 19 & 15 & 22 & 12 \\
\hline Procesos Bioquímicos & 27 & 44 & 36 & 46 & 44 & 15 \\
\hline Procesos Inmunológicos & 33 & 21 & 10 & 41 & 69 & 24 \\
\hline Sist.Musculo- Esquel y Tejido Hum & 27 & 31 & 35 & 35 & 18 & 3 \\
\hline Sistema Digestivo & 20 & 35 & 7 & 46 & 96 & 44 \\
\hline Sistema Respiratorio & 8 & 18 & 36 & 56 & 66 & 0 \\
\hline ODONTOLOGÍA (C) & 82 & 92 & 146 & 155 & 249 & 35 \\
\hline Bases de Biogenética & 14 & 7 & 18 & 18 & 24 & 1 \\
\hline Morfofisiología Cabeza y Cuello & 12 & 24 & 8 & 6 & 36 & 2 \\
\hline
\end{tabular}




\begin{tabular}{|c|c|c|c|c|c|c|}
\hline PROGRAMA ACADÉMICO REPITENCIA & $\mathbf{1 8 1 0}$ & $\mathbf{1 8 2 0}$ & $\mathbf{1 9 1 0}$ & $\mathbf{1 9 2 0}$ & $\mathbf{2 0 1 0}$ & $\mathbf{2 0 2 0}$ \\
\hline Morfología Dental Funcional & 31 & 19 & 14 & 30 & 24 & 0 \\
\hline Procesos Inmunológicos & 0 & 0 & 22 & 21 & 29 & 11 \\
\hline OPEN LINGUA & 56 & $\mathbf{6 4}$ & $\mathbf{3 2}$ & $\mathbf{5 1}$ & $\mathbf{5 8}$ & \\
\hline Inglés I & 37 & 13 & 8 & 15 & 16 & \\
\hline Inglés II & 7 & 22 & 8 & 6 & 18 & \\
\hline Inglés III & 8 & 20 & 11 & 18 & 16 & \\
\hline Inglés IV & 4 & 9 & 4 & 10 & 7 & \\
\hline Total general por semestres & 1284 & 1242 & 1096 & 1114 & $\mathbf{1 4 9 1}$ & $\mathbf{4 2 7}$ \\
\hline
\end{tabular}

Fuente: elaboración propia con base en información suministrada por la Dirección de Gestión de Proyectos Especiales, ucc, 2021.

\section{Cursos cancelados}

Para el análisis de esta variable, se observa que en cursos cancelados para el campus Medellín, la mayor incidencia está en Ciencias económicas, administrativas y contables; Ingenierías y Salud. No obstante, para el último semestre (2020-2), se observa menor proporción en las cancelaciones, excepto para el área de la salud (tablas 5 y 6; figuras 23 y 24).

Tabla 5. Comportamiento de los cursos cancelados por áreas de conocimiento, campus Medellín

\begin{tabular}{|l|c|c|c|c|c|c|}
\hline \multicolumn{1}{|c|}{ ÁREA DE CONOCIMIENTO } & 1810 & 1820 & 1910 & 1920 & 2010 & 2020 \\
\hline $\begin{array}{l}\text { Ciencias administrativas, } \\
\text { económicas y contables }\end{array}$ & 29 & 16 & 35 & 30 & 16 & 17 \\
\hline Ciencias sociales y humanas & 43 & 31 & 52 & 63 & 57 & 48 \\
\hline Ingenierías & 57 & 33 & 57 & 36 & 38 & 28 \\
\hline Open Lingua & 8 & 8 & 8 & 7 & 4 & 0 \\
\hline Salud & 56 & 65 & 68 & 53 & 52 & 66 \\
\hline Total general & 193 & 153 & 220 & 189 & 167 & 159 \\
\hline
\end{tabular}

Fuente: elaboración propia con base en información suministrada por la Dirección de Gestión de Proyectos Especiales, Ucc, 2021. 


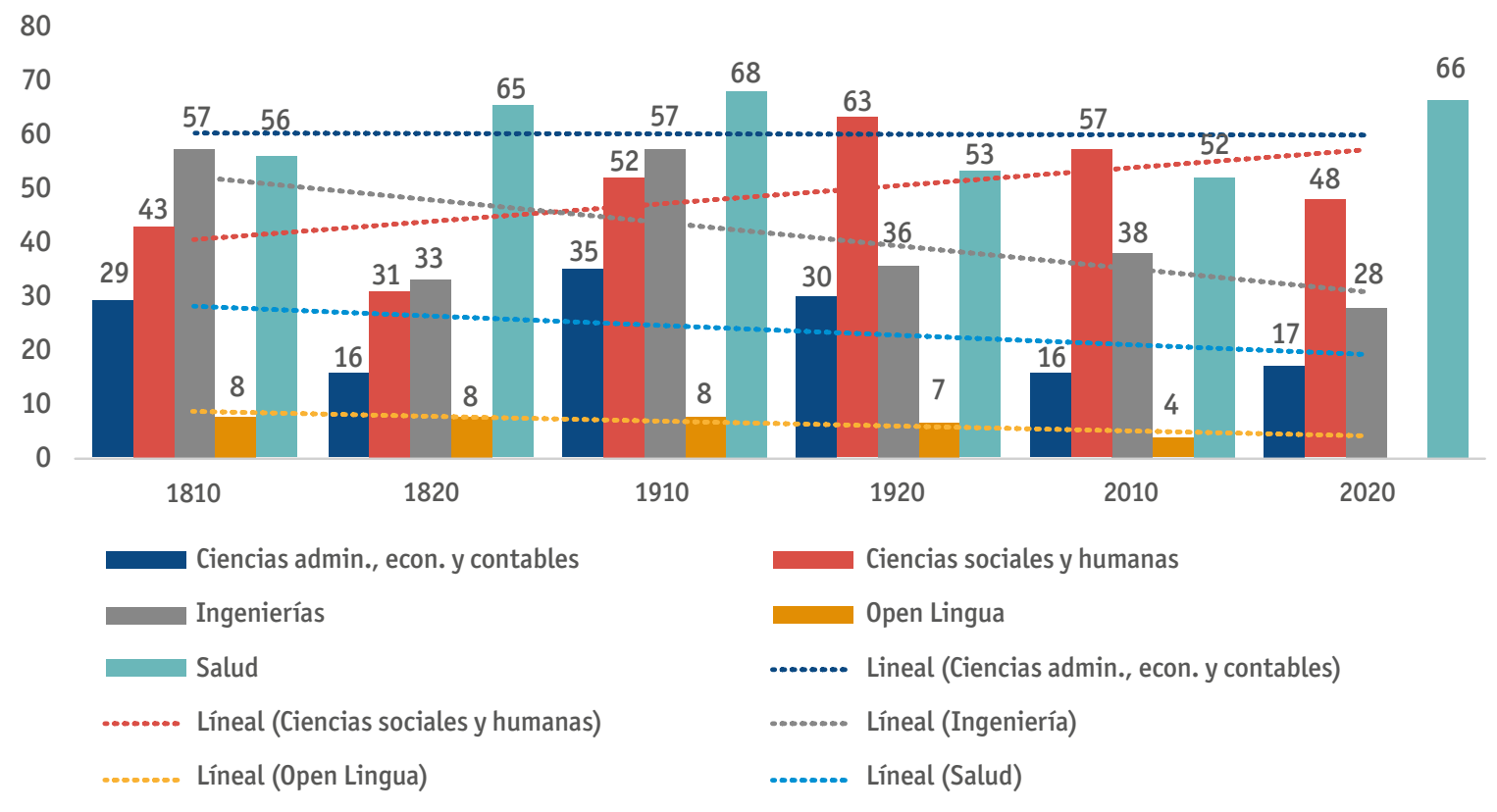

Figura 23. Comportamiento por áreas de conocimiento, cursos cancelados. Elaboración propia con base en información suministrada por la Dirección de Gestión de Proyectos Especiales, UCC, 2021.

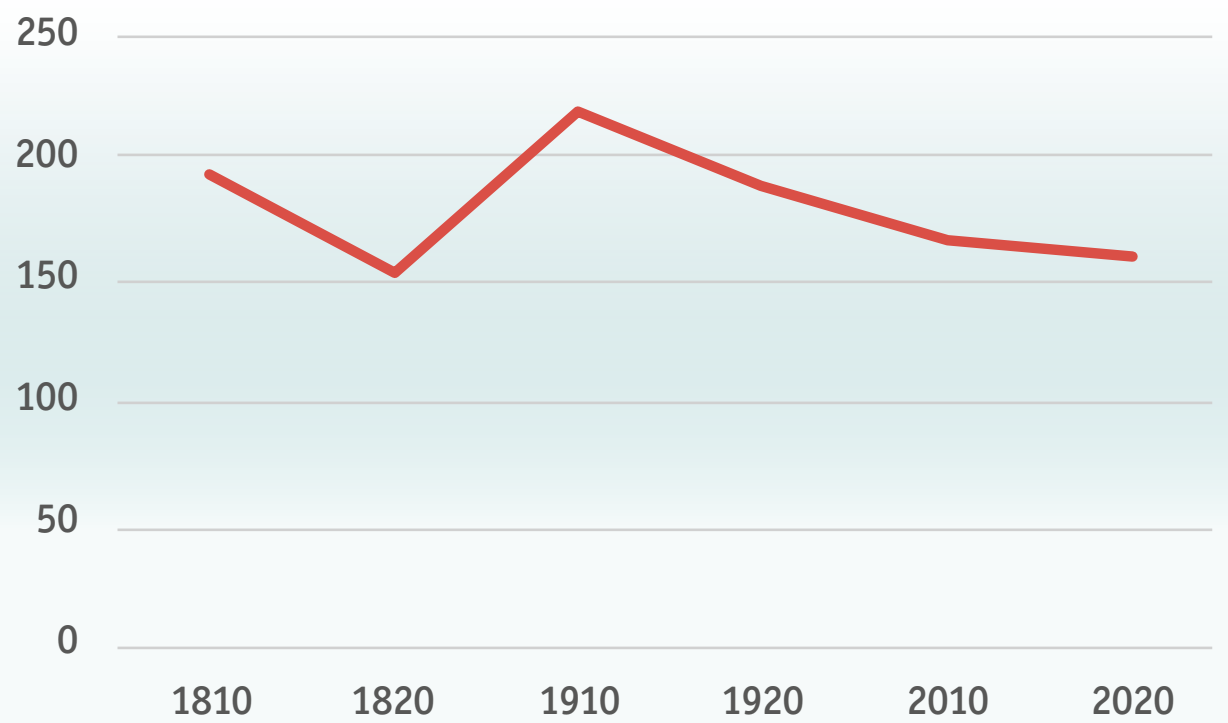

Figura 24. Tendencia de los cursos cancelados, campus Medellín. Elaboración propia con base en información suministrada por la Dirección de Gestión de Proyectos Especiales, UCC, 2021. 
Tabla 6. Comportamiento de los cursos cancelados por programas académicos, campus Medellín

\begin{tabular}{|c|c|c|c|c|c|c|c|}
\hline \multicolumn{8}{|c|}{ Cantidad de cursos cancelados } \\
\hline PROGRAMAS ACADÉMICOS & 1810 & 1820 & 1910 & 1920 & 2010 & 2020 & Total general \\
\hline Administración de Empresas & 1 & 1 & & & & & 2 \\
\hline Administración de Empresas (C) & 12 & 7 & 18 & 16 & 7 & 12 & 72 \\
\hline Comunicación Social & 1 & 1 & & & & & 2 \\
\hline Comunicación Social (C) & & & 2 & 6 & 5 & & 13 \\
\hline Contaduría Pública & 9 & 6 & 3 & & & & 18 \\
\hline Contaduría Pública (C) & 7 & 2 & 14 & 14 & 9 & 5 & 51 \\
\hline Derecho & 7 & 3 & 3 & 2 & 2 & & 17 \\
\hline Derecho $(\mathrm{C}) \quad \Delta$ & 4 & 4 & 16 & 23 & 16 & 21 & 84 \\
\hline Diseño Crossmedia (C) & 5 & & 3 & 1 & 3 & 8 & 20 \\
\hline Humanidades & 3 & 3 & 3 & 3 & 3 & & 15 \\
\hline Ingeniería Civil & 26 & 11 & 22 & 9 & 11 & 1 & 80 \\
\hline Ingeniería Civil (C) & 23 & 17 & 24 & 21 & 22 & 18 & 125 \\
\hline Ingeniería de Software (C) & 3 & 4 & 3 & 3 & & & 13 \\
\hline Ingeniería Mecánica (C) & & 1 & 5 & 2 & 2 & 1 & 11 \\
\hline Lic. Matemáticas e Informática & 6 & 2 & 4 & 2 & 9 & 11 & 34 \\
\hline Licenciatura en Matemática (C) & & & & & 6 & & 6 \\
\hline Medicina $\quad \Delta$ & 26 & 35 & 26 & 16 & 13 & 21 & 137 \\
\hline Medicina $(\mathrm{C}) \quad \Delta$ & 12 & 8 & 16 & 20 & 17 & 29 & 102 \\
\hline Odontología & 12 & 3 & 6 & 5 & 8 & & 34 \\
\hline Odontología (C) & 6 & 19 & 20 & 12 & 14 & 16 & 87 \\
\hline Open Lingua & 8 & 8 & 8 & 7 & 4 & & 35 \\
\hline Psicología & 21 & 7 & 17 & 14 & 10 & 3 & 72 \\
\hline Psicología (C) & 1 & 11 & 7 & 13 & 6 & 13 & 51 \\
\hline Total general & 193 & 153 & 220 & 189 & 167 & 159 & 1081 \\
\hline
\end{tabular}

Fuente: elaboración propia con base en información suministrada por la Dirección de Gestión de Proyectos Especiales, UCC, 2021. 
A nivel de programas académicos, se evidencia que Medicina, por objetivos y competencias; Ingeniería civil, por objetivos y competencias, y Derecho, por competencias, son aquellos que mayor número de cancelaciones reportan de manera regular en cada semestre académico.

Otra manera de realizar seguimiento al rendimiento académico de los estudiantes es identificar cuáles son aquellos cursos que mayor número de cancelaciones realizan los estudiantes. La tabla 7 muestra el comportamiento con mayor incidencia.

Tabla 7. Comportamiento de cursos con mayor incidencia de cancelaciones por programa académico, campus Medellín

\begin{tabular}{|c|c|c|c|c|c|c|}
\hline Cantidad de cursos cancelados & 1810 & 1820 & 1910 & 1920 & 2010 & 2020 \\
\hline \multicolumn{7}{|l|}{ PROGRAMA ACADÉMICO } \\
\hline HUMANIDADES & 20 & 17 & 27 & 34 & 19 & \\
\hline Humanidades I & 9 & 12 & 13 & 14 & 13 & \\
\hline Humanidades II & 4 & 4 & 5 & 5 & 2 & \\
\hline Humanidades III & 7 & 1 & 9 & 15 & 4 & \\
\hline MEDICINA & 131 & 109 & 147 & 35 & 24 & 50 \\
\hline Bioquímica IV & 10 & 12 & 0 & 3 & 0 & 1 \\
\hline Clínica del Adulto & 0 & 0 & 13 & 11 & 0 & \\
\hline Electiva I & 5 & 13 & 51 & 3 & 0 & 1 \\
\hline MEDICINA (c) & 28 & 28 & 56 & 65 & 66 & 124 \\
\hline Procesos Bioquímicos & 6 & 11 & 11 & 4 & 3 & 2 \\
\hline Procesos Inmunológicos & 0 & 0 & 10 & 3 & 24 & 18 \\
\hline OPEN & 132 & 60 & 70 & 85 & 45 & \\
\hline Inglés I & 87 & 19 & 27 & 28 & 17 & \\
\hline Inglés II & 15 & 19 & 12 & 29 & 14 & \\
\hline Inglés III & 15 & 4 & 21 & 20 & 9 & \\
\hline Inglés IV & 14 & 12 & 7 & 6 & 5 & \\
\hline Total general por semestre & 561 & 433 & 627 & 508 & 411 & 351 \\
\hline
\end{tabular}

Fuente: elaboración propia con base en información suministrada por la Dirección de Gestión de Proyectos Especiales, UCC, 2021. 


\section{Gestión en el después}

En esta última etapa juega un papel fundamental el egresado como veedor del resultado formativo y como evidencia de la calidad educativa brindada por la Universidad, pero también se busca ofrecerle una ruta formativa a lo largo de la vida. Los indicadores de desempeño en esta dimensión son:

1. Estudios sobre ocupación y ubicación profesional de los graduados del programa.

2. Estudios sobre correspondencia entre la ocupación y ubicación profesional de los graduados y el perfil de formación del programa.

3. Estudio de reputación.

4. Estudio de percepción de empleadores.

5. Observatorio Laboral para la Educación (OLE).

6. Aporte relativo.

7. Valor agregado.

8. Tasa de graduación.

Descripción de las estrategias adelantadas por el campus Medellín

Durante sus 47 años de existencia, el campus Medellín cuenta, al 2020, con 30686 egresados en diferentes áreas del conocimiento. De estos, el 43\% son hombres y el 57\% mujeres. La gestión de egresados se realiza a través del modelo de gestión "Alumni" a partir de acciones centradas en:

- Comunicación a partir de la implementación de medios físicos, virtuales y de voz a voz, que ha permitido mantener una comunicación efectiva con 12784 egresados, que corresponde al 43\% del total de graduandos, fortaleciendo el relacionamiento desde una perspectiva integral. 
- Reconocimiento del desempeño profesional, logros alcanzados y aportes de los egresados al desarrollo social, académico/científico y económico del país. Este reconocimiento está reglamentado por medio del Acuerdo Superior 159 de 2013. Anualmente, se exalta al egresado destacado de la Universidad en las siguientes categorías:

- Exaltación al mérito por servicio.

- Exaltación al mérito por vida y obra.

- Exaltación al mérito investigativo.

- El programa acceso, permanencia y fomento a la graduación Enlace, se ha venido desarrollando en la seccional Medellín desde su creación en 2013 y se ha ejecutado desde 2014, impactando de manera importante el acceso, la permanencia y graduación de los estudiantes. La siguiente figura muestra que el promedio anual de matrículas de estudiantes nuevos en los últimos cinco años es de 788 (figura 25). A su vez, la tasa de graduación para los últimos cinco años es del $81,8 \%$.

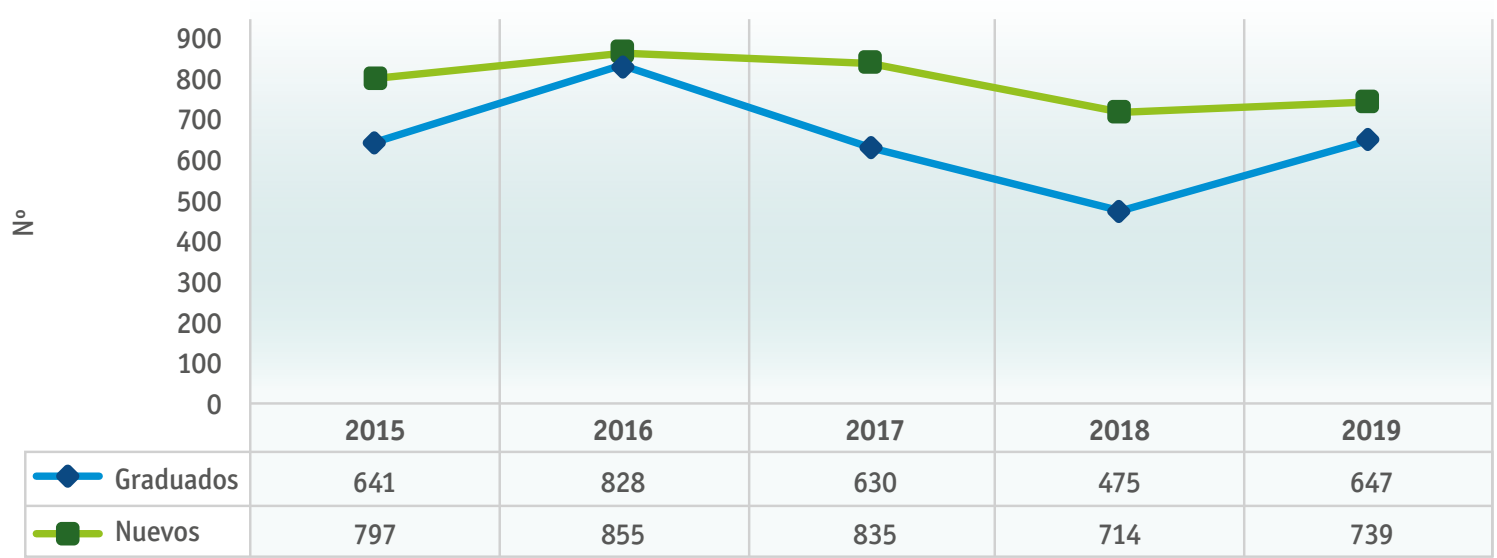

Figura 25. Estudiantes graduados-estudiantes nuevos entre 2015-2019. Elaboración propia con base en información suministrada por la Subdirección Académica, campus Medellín, UCC, 2020. 
Desde 2014, mediante los estudios de impacto y de la dinámica ocupacional de los egresados (EIDO), se evalúa el impacto social y académico de los programas del campus Medellín, mediante el conocimiento de las trayectorias laborales, académicas y sociales de sus egresados. El último estudio se realizó en 2019, contó con una muestra de 535 egresados graduados entre el 20142018 y 117 empleadores. Algunos de los indicadores obtenidos se muestran en la figura 26.

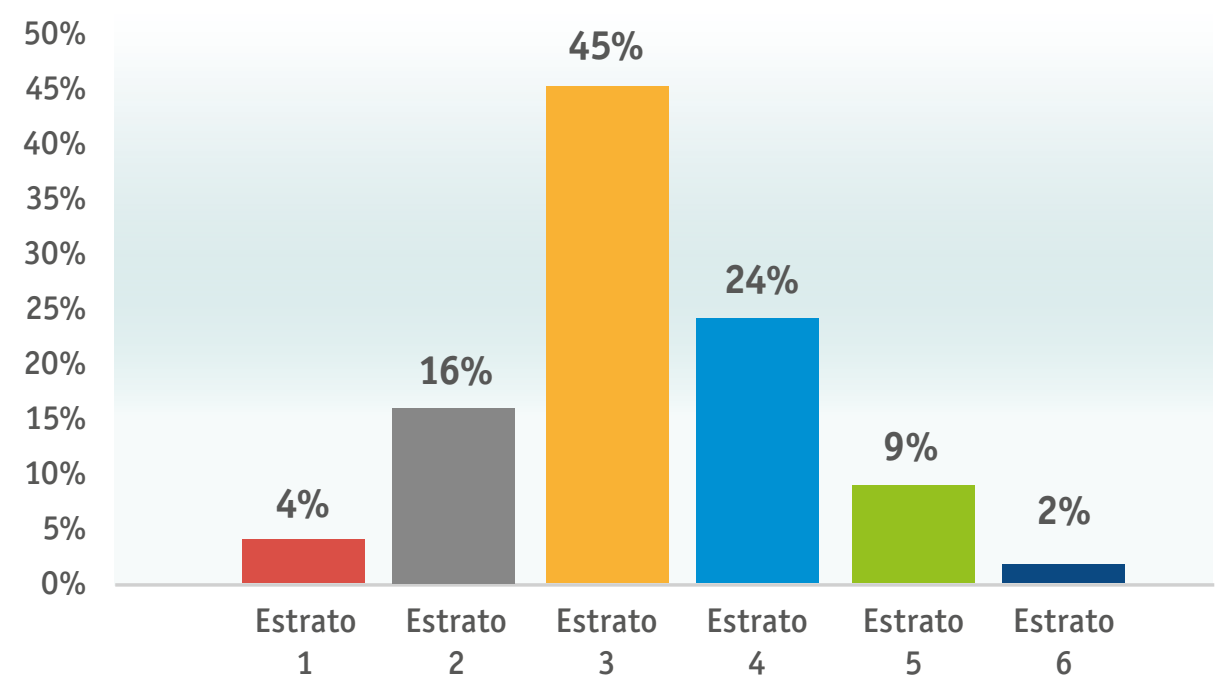

Figura 26. Nivel socioeconómico de egresados, campus Medellín. Elaboración propia con base en información suministrada por EIDO, 2020.

El campus Medellín está generando movilidad social, principalmente, en los estratos socioeconómicos 1 y 2 , pues aproximadamente, el $32 \%$ ha ascendido de nivel. Además, se está formando capital humano que se queda en la región, lo cual se evidencia en un $76 \%$ que aún permanece en ella (figura 26). La información relacionada con la edad de los egresados se muestra en la figura 27.

En general, se encuentra que:

- El 88\% de los encuestados refieren que la formación recibida satisface las necesidades de la empresa. 
- El 85\% de los egresados afirman satisfacción con la formación recibida y con la calidad general de los programas.

- El 86\% de los egresados recomendaría estudiar el programa estudiado en la UCC.

- El 83\% de los empleadores refiere satisfacción con el desempeño laboral y profesional de los egresados del campus Medellín.

- El 91\% de los empleadores recomendarían la contratación de un egresado del campus Medellín.

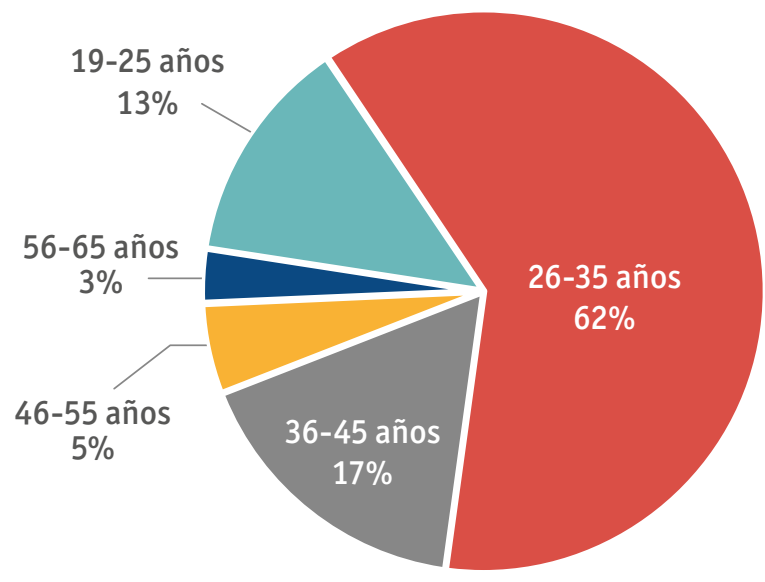

Figura 27. Edad de egresados, campus Medellín. Elaboración propia con base en información suministrada por EIDO, 2020.

Las cinco competencias más fuertes en los egresados son el conocimiento y la formación académica, la comunicación, la calidad profesional, el desempeño, la calidez humana y el carisma.

De acuerdo con el estudio, la seccional Medellín ha logrado posicionar a sus egresados en el medio, logrando los siguientes resultados: un $57 \%$ son empleados, un 24\% trabajadores independientes, $4 \%$ empresarios dueños de empresa y un $13 \%$ está desempleado y un $1 \%$ está desempleada, pero no le interesa conseguir empleo. 


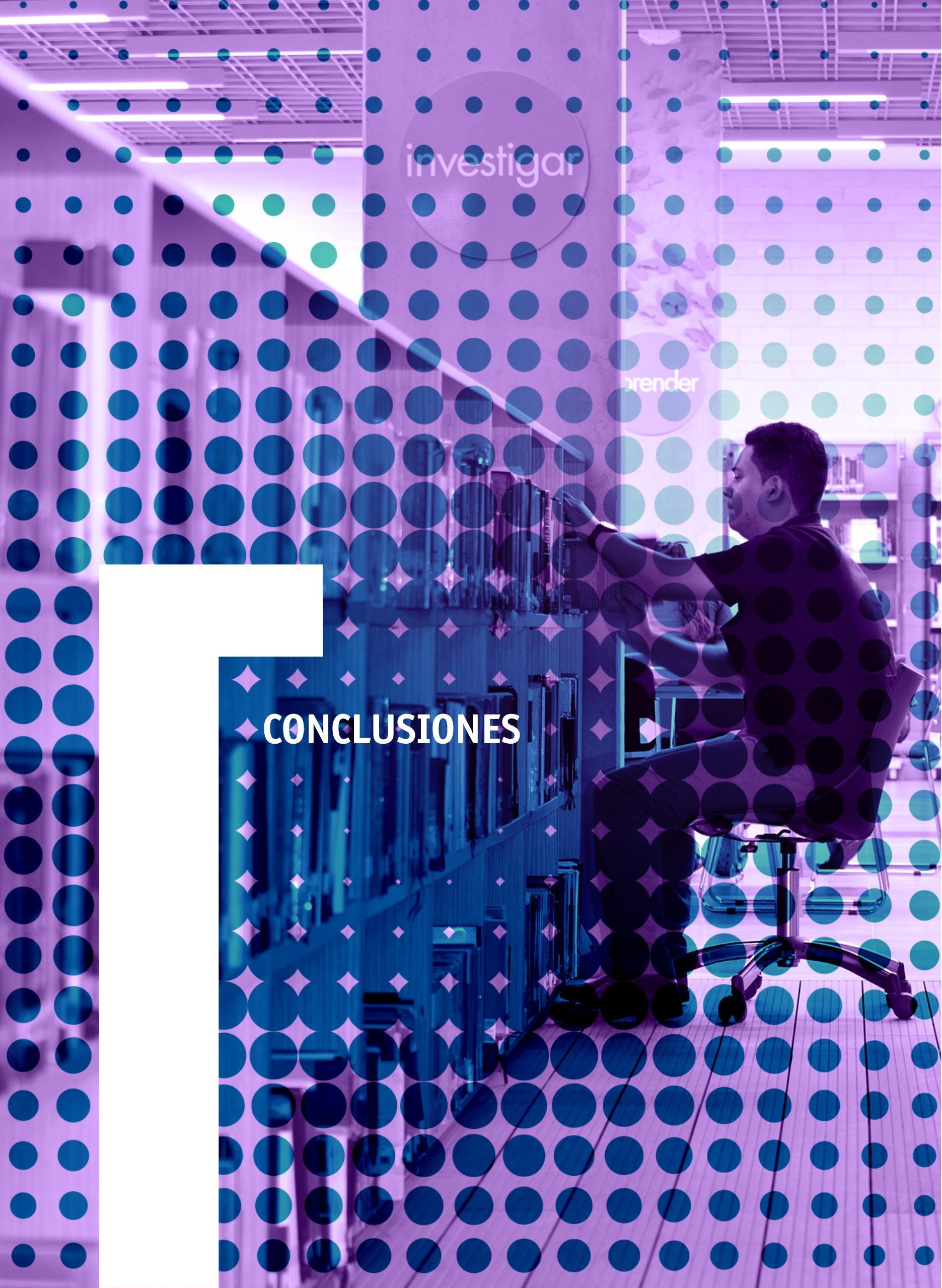


T a implementación del Centro de Monitoreo del Aprendizaje a lo Largo de la Vida para Todos ha permitido mejorar la calidad educativa a partir del proceso sistemático de recolectar, analizar y utilizar información para hacer seguimiento y medición permanente a las variables e indicadores, que intervienen en el desarrollo del modelo educativo y la calidad del Proyecto Educativo Institucional. Ha permitido proveer información de carácter estratégico, tanto para el personal académico administrativo, como para el profesor y el estudiante, que se refleja en indicadores de eficacia como por ejemplo:

En el ANTES:

- Implementación de un sistema de reconocimiento de competencias y saberes previos que ha posibilitado el acceso, la movilidad y la continuidad de estudios superiores y posgraduales. Entre el 2015-2020, en el campus se han realizado 1418 validaciones, 348 suficiencias y 504 homologaciones. En el mismo periodo, por transferencias internas provenientes de otros campus, se han admitido 360 estudiantes y por transferencias externas 470 estudiantes.

- La caracterización sociodemográfica de la población estudiantil admitida ha permitido la formulación y el desarrollo de un acompañamiento permanente en los órdenes financiero, académico y psicosocial, impactando de manera positiva la permanencia estudiantil.

- La evaluación prescriptiva de las pruebas Saber 11 de estudiantes admitidos, ha permitido identificar el valor académico agregado, que permite aislar lo aprendido en la institución, de las condiciones iniciales con el fin de medir más precisamente el aporte institucional al aprendizaje del estudiante y la calidad en la formación académica. Además, ha fortalecido la actualización 
permanente de los procesos curriculares y planes de estudio con acciones como, por ejemplo, la inclusión de cursos de formación humanística cuyas competencias se enfocan en el desarrollo de la lectura crítica, escritura y razonamiento cuantitativo. También, la inclusión de al menos cuatro niveles de inglés para el desarrollo de competencias en segunda lengua y el desarrollo de un portafolio permanente de actividades enfocadas en la promoción de la lectura y la escritura.

En el DURANTE:

El monitoreo del aprendizaje, en este momento, ha permitido fortalecer las acciones de acompañamiento académico, que busca propender por la permanencia y el buen desempeño académico de los estudiantes a partir del desarrollo de las competencias requeridas a nivel disciplinar. Algunos indicadores de eficacia de este proceso son:

- Implementación módulo "Mis Asesorados" con un registro de 3496 procesos de tutorías, asesorías, consejerías, que han fortalecido el acompañamiento y soporte académico a los estudiantes, acompañado de la implementación del programa de salud positiva y el fortalecimiento del programa Enlace para el acompañamiento psicosocial, logrando una disminución del 75\% en el número de estudiantes en condición de semestre especial durante los últimos cinco años.

- Disminución en la tasa de deserción por periodo en los últimos cinco años y una tendencia por debajo de los indicadores a nivel nacional e institucional. Esto es evidencia el impacto favorable de las acciones de monitoreo, acompañamiento y seguimiento mediante el programa Enlace.

- Implementación del siec, permitiendo la evaluación periódica de las competencias genéricas y algunas específicas, lo cual ha permitido establecer una cultura de evaluación formativa y alarmas tempranas para intervenir 
de manera oportuna el aprendizaje y el desarrollo de las competencias. Con el seguimiento al valor académico agregado, se ha podido estimar la variación en el desarrollo cognitivo de los estudiantes, entre el momento inicial y el momento final del proceso educativo, evidenciando un valor académico positivo de 2,54 puntos para el caso de la seccional Medellín en el periodo comprendido entre 2014-2018.

- El seguimiento y monitoreo de las evaluaciones a profesores por parte de los estudiantes ha permitido incrementar la cultura de la evaluación de los profesores y sus clases, con un incremento del $57,5 \%$ de clases evaluadas y el número de profesores con planes de mejora ha disminuido en un $5 \%$.

- Las cancelaciones de cursos evidencian una tendencia a la disminución, fruto del fortalecimiento de los procesos de acompañamiento académico a los estudiantes.

En el DESPUÉS:

El monitoreo y seguimiento a los egresados, se constituye en un insumo fundamental para el establecimiento de acciones de mejora al modelo educativo, los procesos educativos y formativos. Mediante el EIDo que se realiza de manera bianual se evidencia que la graduación de profesionales en el campus Medellín está generando movilidad social, está formando capital humano que se queda en la región, lo que indica que hay pertinencia en los planes de formación. Es fundamental continuar con el fortalecimiento del proceso de vinculación laboral, pues un 13\% de los egresados reportan estar desempleados. 


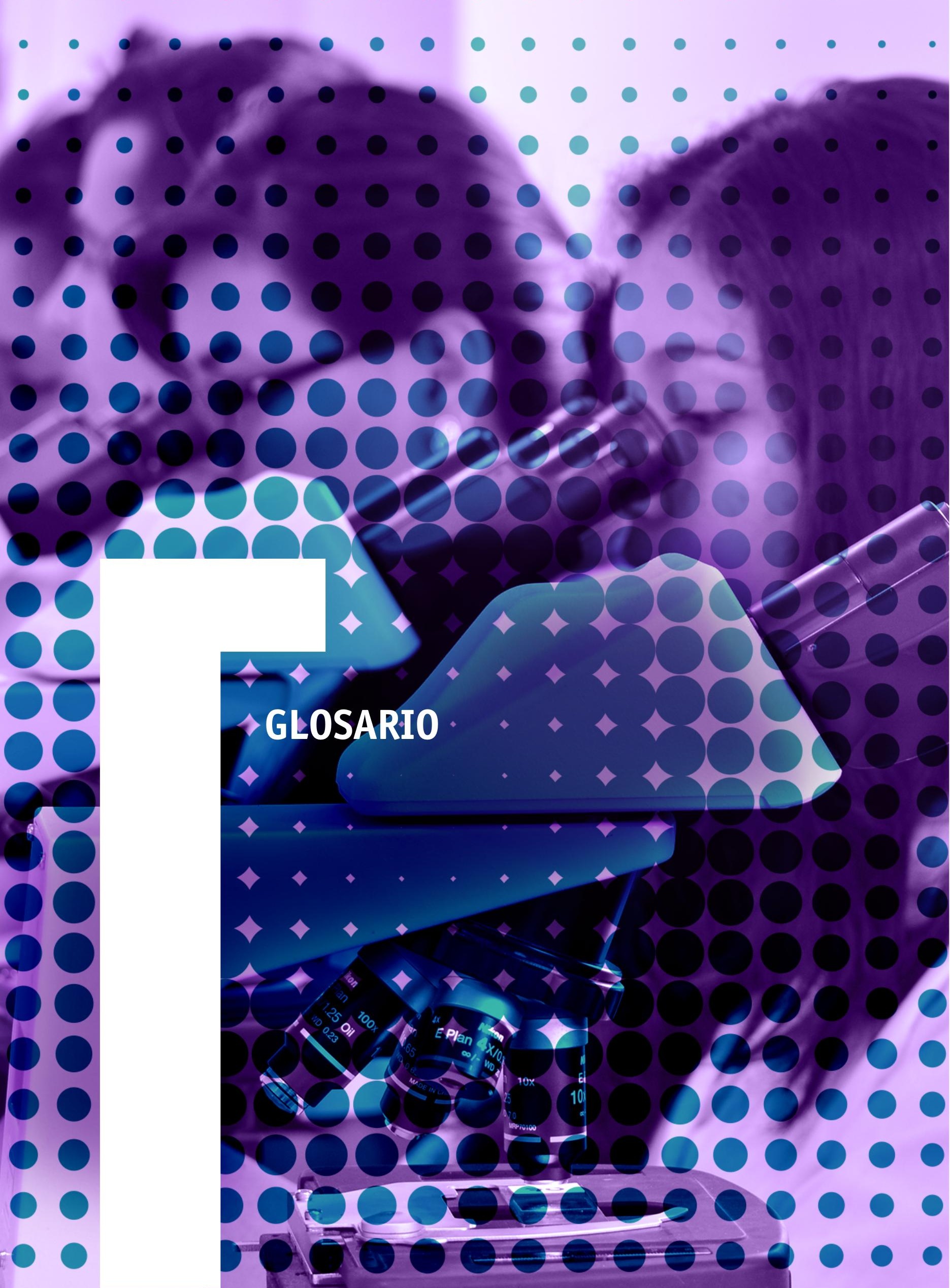


APORTE RELATIVO (AR): el ejercicio de aporte relativo es un refinamiento del ejercicio Valor Agregado, que busca medir qué tanto aportó una institución en términos de aprendizaje en comparación con otra institución, debido únicamente a un mayor esfuerzo o mejores prácticas educativas de la institución. De esta manera se cuenta con un ejercicio más preciso, en el cual se aísla del cálculo de Valor Agregado, aquellos factores que no están directamente relacionados con la educación impartida por las instituciones. De esta forma, el ICFES reconoce que las condiciones de entrada de los estudiantes admitidos a las instituciones de educación superior, difieren entre ellas y establece una premisa de "comparar comparables", analizando las diferencias en el va de las IEs que cuentan con estudiantes con resultados similares en la prueba Saber 11 (ICFES, 2018).

APRENDIZAJE: "el aprendizaje es un proceso y a la vez resultado. Es una práctica individual y una construcción colectiva que se da en un contexto, en una realidad multidimensional" (OEI, 2017, p. 4). Desde el enfoque de aprendizaje profundo, con base en los planteamientos de Jhon Biggs, se concibe como una forma de interactuar con el mundo; caracterizada por la producción de cambios transferibles a nuevas situaciones como consecuencia directa de las prácticas realizadas. La producción de cambios se relaciona con la mutación de conocimientos y conductas anteriores. Para que haya aprendizaje, se requiere desaprender, reconstruir o resignificar aprendizajes previos. La transferencia a nuevas situaciones permite el enfrentamiento a circunstancias novedosas, asimilándolas a lo ya conocido.

\section{APRENDIZAJE A LO LARGO DE LA VIDA: según la UNesco (s. f.):}

Es un principio organizativo de todas las formas de educación (formal, no formal e informal) con componentes mejor integrados e interrelacionados. Se basa en la 
premisa de que el aprendizaje no está confinado a un periodo específico de la vida, sino que va "de la cuna a la tumba" (sentido horizontal), considera todos los contextos en los que conviven las personas como familia, comunidad, trabajo, estudio, ocio, (sentido vertical), y supone valores humanísticos y democráticos como la emancipación y la inclusión (sentido profundo). Enfatiza el aseguramiento de los aprendizajes relevantes (y no sólo la educación) más allá del sistema escolar. (p. 2)

El aprendizaje a lo largo de la vida como un nuevo enfoque y principio orientador de los sistemas educativos y de los procesos de aprendizaje, surge en un contexto fuertemente impactado por cambios vertiginosos en el conocimiento, las tecnologías, en la forma de comunicación, en el comportamiento demográfico, en un mundo del trabajo que exige una actualización continua.

APRENDIZAJES PREVIOS: "son aquellos obtenidos a lo largo de la vida, de manera formal, no formal o informal. Incluye los aprendizajes empíricos y autónomos adquiridos en el lugar de trabajo, en la comunidad y como parte del vivir diario. Es un aprendizaje no necesariamente institucionalizado" (Ministerio de Educación Nacional, s. f.).

ANALÍTICAS DE APRENDIZAJE: el término analítica se aplica a los esfuerzos en la explotación de datos de diversas fuentes para ayudar a las organizaciones a ser más eficaces. Ayuda a evaluar las acciones pasadas para estimar el potencial de las acciones futuras, con las cuales tomar mejores decisiones y adoptar estrategias más eficaces, ya sea a nivel organizacional o individual (García Peñalvo, 2014). Siemens (2010) señala que las analíticas de aprendizaje, más allá de ser una simple herramienta análisis de datos, permiten apoyar el sistema educativo porque posibilitan la adecuación del currículo, la personalización, la adaptación y la predicción. Las analíticas consisten en la medición, recopilación, análisis y presentación de datos sobre los estudiantes, sus contextos y las interacciones que allí se generan, con el fin de comprender los procesos de enseñanza y de aprendizaje que se están desarrollando y optimizar los entornos educativos. 
CENTRO DE MONITOREO DEL APRENDIZAJE: "herramienta de medición permanente a las variables e indicadores cuantitativos y cualitativos, que intervienen en el desarrollo del modelo educativo, la evolución y desempeño académico de los estudiantes, generando alarmas tempranas para la toma de decisiones oportunas y efectivas a nivel institucional" (UCC, 2017, p. 10).

COHORTE: "conjunto de estudiantes que ingresaron a primer curso en el mismo período (año y semestre), en un programa académico de una institución de educación superior" (sNIEs, s. f.).

COMPETENCIA: “es la integración armónica de conocimientos, actitudes y habilidades para facilitar el desempeño flexible, eficaz y con sentido de una tarea o actividad en contexto" (Unigarro, 2017, p. 49). Según el Marco Nacional de Cualificaciones (MNC), es la capacidad demostrada para poner en acción conocimientos, habilidades, destrezas y actitudes que hacen posible su desempeño en diversos contextos sociales. Se evidencia a través del logro de los Resultados de Aprendizaje (Ministerio de Educación Nacional, 2020, art. 2.7.2.1).

\section{CONSEJERÍA:}

Orientación que se realiza al estudiante cuando se encuentre ante dificultades académicas, psicosociales o financieras, brindando asesoría en: orientación, en métodos y hábitos de estudio, formulación y realización de proyecto de vida, asesoría en financiación para el pago de la matrícula, seguimiento de calificaciones. Se atiende así mismo la dimensión humana, contemplando las dificultades de interacción, emocionales, afectivas, familiares y de adaptación sociocultural que puedan estar afectando al estudiante. De esta forma, se apoyan los procesos pedagógicos, trabajando en forma conjunta con estudiantes, monitores, docentes, administrativos y directivos. (UCC, Programa Enlace)

CUALIFICACIÓN: "es el reconocimiento formal que otorga una institución autorizada después de un proceso de evaluación a una persona que ha demos- 
trado las competencias expresadas en términos de Resultados de Aprendizaje definidos y vinculados a un nivel de cualificación" (Ministerio de Educación Nacional, s. f.).

DESEMPEÑO ACADÉMICO: puede ser entendido como la capacidad del sujeto de responder a las exigencias del currículo. El mismo estará influido por múltiples variables relativas al alumno (temperamento, recursos cognitivos, conocimiento previo, estrategias de aprendizaje), variables asociadas al docente (personalidad, estrategias pedagógicas y didácticas utilizadas, etc.), variables relativas al entorno familiar, factores referidos a las características del ambiente escolar (Stelzer y Cervigni, 2011).

\section{DESERTOR:}

Estudiante que de manera voluntaria o forzosa no registra matrícula por dos o más períodos académicos consecutivos del programa en el que se matriculó; y no se encuentra como graduado, o retirado por motivos disciplinarios. La deserción es el resultado del efecto de diferentes factores como individuales, académicos, institucionales y socioeconómicos. (Ministerio de Educación Nacional, s. f.)

EDUCACIÓN: en su Proyecto Institucional, la UCC asume la educación como una acción comunicativa que se da de manera procesual y que tiene como intención la formación. La acción comunicativa remite a la relación de diálogo, en contexto, que se da entre profesores y estudiantes. A partir del intercambio de argumentos entre enseñantes y aprendices, $\mathrm{y}$ entre aprendices mismos es que opera lo educativo (UCC, 2013).

EDUCACIÓN FORMAL: es aquella estructurada jerárquicamente, ordenada de manera cronológica dentro del sistema educativo y que se extiende desde la escuela primaria hasta la universidad. Incluye, además, los programas o cursos destinados a una formación técnica y profesional. En Colombia, se define 
desde la Ley 115 de 1994, como "aquella que se imparte en establecimientos educativos aprobados, en una secuencia regular de ciclos lectivos, con sujeción a pautas curriculares progresivas, y conducente a grados y títulos" (MEN, 1994, art. 10).

EDUCACIÓN NO FORMAL: es toda aquella actividad educativa organizada fuera del sistema formal establecido. Es:

la que se ofrece con el objeto de complementar, actualizar, suplir conocimientos y formar en aspectos académicos o laborales sin sujeción al sistema de niveles y grados establecidos en la educación formal (artículo 11 de esta Ley). La educación no formal se rige por los principios y fines generales de la educación establecidos en la presente Ley. Promueve el perfeccionamiento de la persona humana, el conocimiento y la reafirmación de los valores nacionales, la capacitación para el desempeño artesanal, artístico, recreacional, ocupacional y técnico, la protección y aprovechamiento de los recursos naturales y la participación ciudadana y comunitaria. (MEN, 1994, cap. 2)

EDUCACIÓN INFORMAL: es el proceso vital en que, cada individuo, adquiere actitudes, valores, habilidades y conocimientos. Lo hace a través de la experiencia diaria y de las influencias o recursos de su entorno, que incluye desde familia o amigos hasta los medios de comunicación. La Ley 115 de 1994, la define como "todo conocimiento libre y espontáneamente adquirido, proveniente de personas, entidades, medios masivos de comunicación, medios impresos, tradiciones, costumbres, comportamientos sociales y otros no estructurados" (MEN, 1994, art. 43).

ENLACE: programa que fomenta la permanencia estudiantil y la graduación de los estudiantes de los programas de pregrado y posgrado de la Universidad Cooperativa de Colombia, a través de estrategias de acompañamiento académico, psicosocial y financiero, que permitan apoyar el proceso de formación integral del estudiante y la finalización de su programa académico (UCC, 2011). 
EVALUACIÓN DE DESEMPEÑO: la evaluación del desempeño en un Modelo Educativo Crítico con Enfoque de Competencias permite la valoración de las acciones y productos que realiza el estudiante durante su proceso de aprendizaje, permite la retroalimentación y validación del desarrollo de las competencias. Evaluar es "medir y comparar el grado de refinamiento de las competencias, para: 1) construir sentido, es decir, orientar los mundos posibles, vislumbrar nuevos contextos; 2) criticar y discriminar, separando lo deseable de lo no deseable; 3 ) tomar decisiones para corregir oportunamente; 4) acreditar" (Unigarro, 2017, p. 86).

GRADUADO: "persona natural que curso y aprobó el plan de estudios reglamentado por la Institución para un programa de educación superior, cumplió los requisitos de grado que establece la ley y la Institución respectiva, y obtuvo el título que otorga la Institución para el programa realizado, conforme lo aprobado en el registro calificado expedido por el MEN" (Ministerio de Educación Nacional, s. f.).

MARCO NACIONAL DE CUALIFICACIONES (MNC): "es el instrumento que permite estructurar y clasificar las cualificaciones en función de un conjunto de criterios, ordenados por niveles y expresados en términos de Resultados de Aprendizaje alcanzables por las personas" (Ministerio Nacional de Educación, 2020c, art. 2.7.2.1).

MÓDULO “MIS ASESORADOS”: funcionalidad del sistema de información académico de la ucc que permite a los estudiantes solicitar asesorías con el fin reforzar los conocimientos en los que considere que tiene falencias. Además, facilita a los profesores el seguimiento de los estudiantes, para así identificar situaciones relacionadas con el rendimiento académico, lo cual permite un mejoramiento continuo en los procesos académicos. 
NIVEL DE FORMACIÓN: “etapas de los niveles académicos del sistema de educación superior con unos objetivos y tipo de estudios que las caracterizan. Estas etapas son: Técnica Profesional, Tecnológica y Universitaria que corresponden al nivel académico de pregrado; y Especialización, Maestría y Doctorado que pertenecen al nivel académico de posgrado" (Ministerio de Educación Nacional, s. f.).

\section{OBSERVATORIO DE IMPACTO Y DINÁMICA OCUPACIONAL (OIDO):} es una unidad de carácter técnico que estudia y analiza la situación, comportamiento y tendencias del mercado de trabajo en los aspectos más relevantes, así como las necesidades y oportunidades del territorio, a fin de contribuir al aseguramiento de la pertinencia de la oferta educativa, enfoques y metodologías, en congruencia con la evolución de la disciplina y, las dinámicas de los diferentes sectores y exigencias de los mismos. Es fuente de consulta y proposición en temas relacionados con el seguimiento y medición de impacto de los graduados a partir del desempeño laboral, profesional, académico y social (UCC, s. f.).

OBSERVATORIO LABORAL PARA LA EDUCACIÓN (OLE): es un sistema creado, principalmente, para hacer seguimiento a los graduados de la educación superior: mantiene información sobre sus condiciones laborales y sobre qué tipo de profesionales necesita el mercado (Ministerio de Educación Nacional, s. f.).

RECONOCIMIENTO DE COMPETENCIAS: es el proceso mediante el cual se establecen procedimientos, instrumentos y criterios para identificar las competencias obtenidas por un aspirante a lo largo de la vida, de manera formal, obtenidas de programas de educación para el trabajo y el desarrollo humano o informal, que incluyen los aprendizajes empíricos y autónomos adquiridos en el lugar de trabajo, en la comunidad y como parte del vivir 
diario y que pueden ser aprendizajes o competencias no necesariamente institucionalizadas. El proceso de Reconocimiento de Competencias en la UCC se llevará a cabo mediante la convalidación de competencias, las homologaciones y las validaciones.

RENDIMIENTO ACADÉMICO: rendimiento es un término que hace referencia a efecto (logro). Alude a una producción o utilidad que rinde o da alguien o algo. En el entorno educativo se refiere al resultado cuantitativo o cualitativo que se obtiene en el proceso de aprendizaje, al "producto de la asimilación del contenido de los programas de estudio, expresado en calificaciones dentro de una escala convencional" (García, 2013, p. 34). Conjunto de transformaciones operadas en el educando a través de los procesos ensenanza-aprendizaje. Síntesis del proceso educativo. Permite al estudiante y a la institución tomar las medidas de mejoramiento requeridas para cumplir los resultados de aprendizaje propuestos.

RESULTADOS DE APRENDIZAJE: "son las declaraciones expresas de lo que se espera que un estudiante conozca y demuestre en el momento de completar su programa académico" (MEN, 2019). Deben ser coherentes con las necesidades de formación integral y con las dinámicas propias de la formación a lo largo de la vida necesarias para un ejercicio profesional y ciudadano responsable. Deben estar alineados con los campos de desempeño planteados por la Institución y por el Programa específico.

\section{SISTEMA INSTITUCIONAL DE EVALUACIÓN DE COMPETENCIAS} (SIEC): sistema institucional de la UCC diseñado para diagnosticar y evaluar el estado de las competencias de los estudiantes que ingresan a la institución, el desempeño y rendimiento académico de los estudiantes durante su ciclo de vida académica y con los resultados, implementar estrategias de mejoramiento. Está compuesto por cuatro programas: pruebas de competencias 
(genéricas, transversales y específicas), valor académico agregado, rúbrica institucional y reconocimiento de competencias previas.

TASA DE DESERCIÓN POR COHORTE: "número acumulado de estudiantes de una cohorte que no ha registrado matricula por dos o más periodos consecutivos en un programa académico de una Institución de Educación Superior hasta un semestre determinado, sobre los primíparos de esa cohorte" (Ministerio de Educación Nacional, s. f.).

TASA DE DESERCIÓN ANUAL: porcentaje de estudiantes desertores identificados en el período t que estuvieron matriculados en el periodo $t-2$.

TUTORÍA: las tutorías académicas individuales o grupales, aclaran dudas sobre los contenidos de los cursos, trabajos o actividad en particular. La tutoría obedece al desarrollo de un plan estructurado, entre tutor y tutorado, de manera sistemática, bajo los lineamientos de un programa determinado (UCC, Programa Enlace).

VALOR AGREGADO: el Valor Agregado Académico consiste en el proceso de aprendizaje, crecimiento y rendimiento por parte del estudiante a través del tiempo debido a la acción formativa que apropia durante su permanencia en la Institución de Educación. El valor agregado mide cuánto aporta una institución a las competencias de sus estudiantes. El valor agregado en el ámbito de la educación superior consiste en la variación global del resultado alcanzado en pruebas externas aplicadas a los estudiantes (Saber 11), al iniciar sus estudios superiores (como línea de base) y al terminarlos como condición o estado de salida.

VARIABLE: propiedad no constante que cambia o puede cambiar en un individuo o entre varios individuos dentro de un grupo o entre varios grupos. Es 
cada una de las características o cualidades que poseen los individuos de una población, puede ser cualitativa y cuantitativa. Cualitativa cuando el interés se centra sobre una propiedad no numérica. Cuantitativa cuando la observación que se hace de la variable puede ser expresada en términos numéricos. 

A.G 0.0

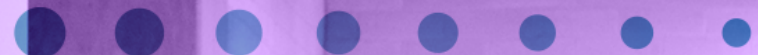

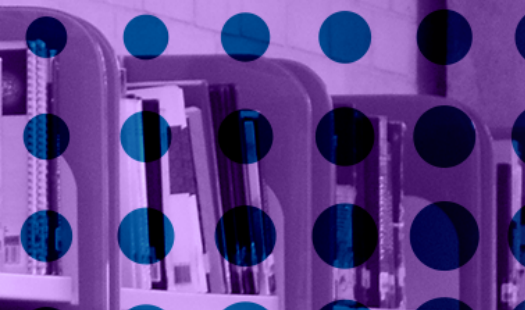

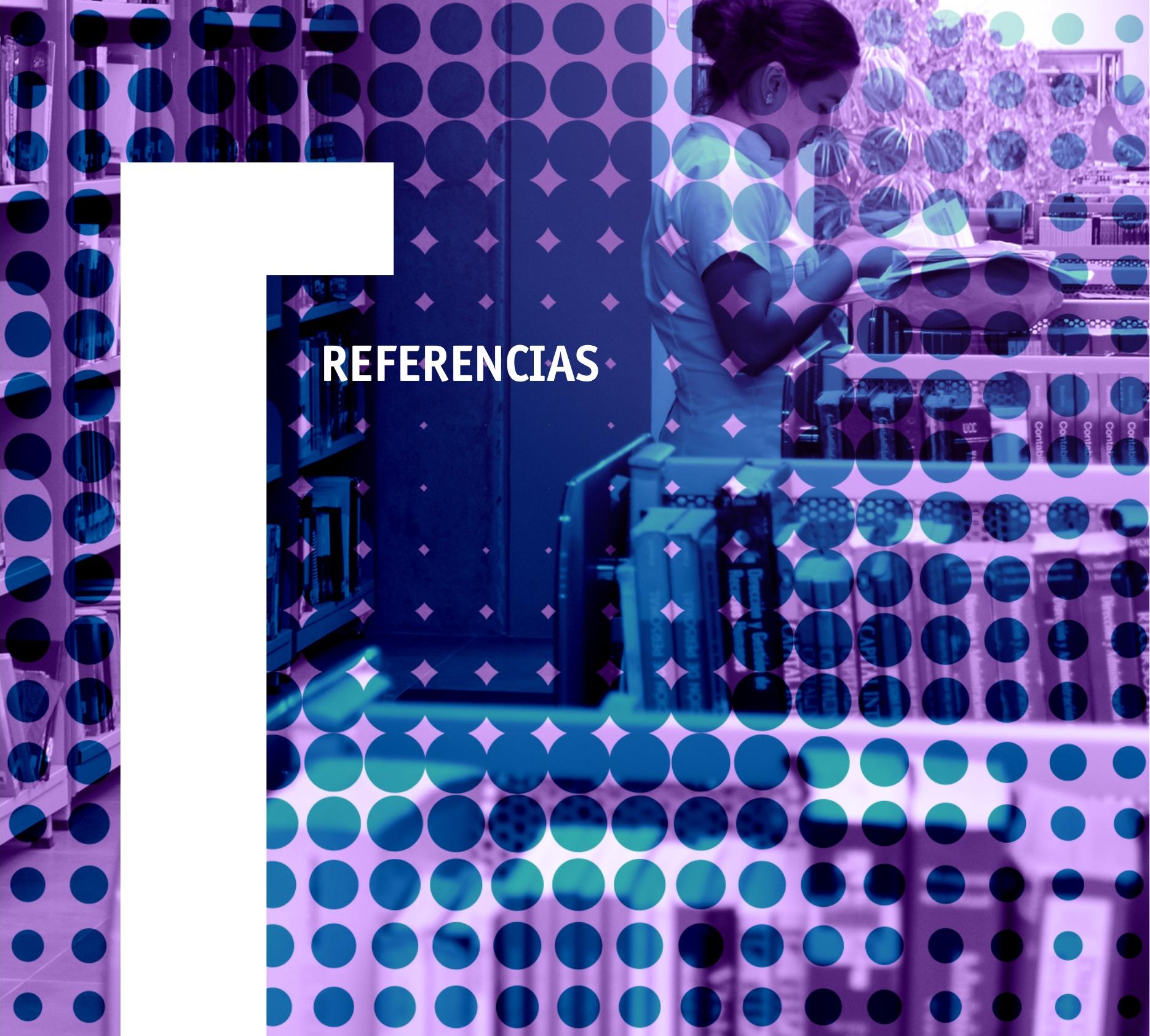


Biggs, J. (2005). Calidad del aprendizaje universitario. Narcea.

Celis Giraldo, J. (2013). El futuro del sistema de asegurameinto de la calidad de la educación superior en Colombia. Acevedo Impresores.

Construyendo Futuro (s. f.). Inicio. https://bit.ly/3CwxvAF

Eurydice. (2013). Recognition of Prior Non-Formal and Informal Learning in Higher Education. European Commission. https://bit.ly/2Zic9bZ

Faure, E., Herrera, F., Kaddoura, A., Lopes, H. Petrovski, A., Rahnema, M. y Champion, F. (1972). Aprender a ser. La educación del futuro. unesco.

Figel, J. (2009). Competencias clave para el aprendizaje permanente. Al Tablero, 52. https://bit.ly/3nShwJe

García, R. (2013). Un acercamiento al rendimiento académico de los estudiantes de la Licenciatura en Sociología de la Universidad de Guadalajara. Vínculos: Sociología, análisis y opinión, (4), 33-57. https://bit.ly/2Zg3iYm

García Peñalvo, F. J. (2014). Formación en la sociedad del conocimiento, un programa de doctorado con una perspectiva interdisciplinar. Educación y Cultura en la Sociedad de la Información, 15(1), 4-9.

Instituto Colombiano para la Evaluación de la Educación. (ICFEs). (2018). Valor agregado y aporte relativo. ICFEs. https://bit.ly/30F5Cmm

Congreso de la República de Colombia. (2019). Ley 1955. Por el cual se expide el Plan Nacional de Desarrollo 2018-2022 "Pacto por Colombia, pacto por la equidad". Congreso de la República de Colombia. https://bit.ly/3LILQTN

Ministerio de Educación de Perú. (2016). Guía para la formulación del Plan de Monitoreo (Local/Regional). Ministerio de Educación de Perú. https://bit. ly/39pCNBE 
Ministerio de Educación Nacional de Colombia. (MEN). (2020a). Resolución 015224. Por la cual se establecen los parámetros de autoevaluación, verificación y evaluación de las condiciones de calidad de carácter institucional reglamentadas en el Decreto 1075 de 2015, modificado por el Decreto 1330 de 2019, para la obtención y renovación del registro calificado. MEN. https://bit.ly/2ZilmB6

Ministerio de Educación Nacional de Colombia. (men). (2020b). Resolución 021795. Por la cual se establecen los parámetros de autoevaluación, verificación y evaluación de las condiciones de calidad de programa reglamentadas en el Decreto 1075 de 2015, modificado por el Decreto 1330 de 2019, para la obtención, modificación y renovación del registro calificado. mEN. https://bit. ly/3EAJCOS

Ministerio de Educación Nacional de Colombia. (MEN). (2020c). Decreto por el cual se adopta y reglamenta el Marco Nacional de Cualificaciones (MNC), se dictan otras disposiciones y se adiciona el Decreto 1075 de 2015, Único Reglamentario del Sector Educación. MEN. https://bit.ly/3EEDLYT

Ministerio de Educación Nacional de Colombia. (men). (2019). Decreto 1330 de julio 25 de 2019. Por el cual se constituye el Capítulo 7 del Título 3 de la Parte 5 del Libro 2 del Decreto 1075 de 2015 - Único Reglamentario del Sector Educación. men. https://bit.ly/3AucYfp

Ministerio de Educación Nacional de Colombia. (MEN). (1994). Ley 115 de febrero 08 del 1994. Por la cual se expide la ley general de educación. MEN. https://bit. ly/3pQiabg

Ministerio de Educación Nacional de Colombia. (MEN). (s. f.). Glosario. MEN. https://bit.ly/3koZnjR

Ministerio de Educación Nacional de Colombia. (MEN). (s. f.). Diseño Universal para el Aprendizaje. men. https://bit.ly/3u0nmcC

Organización de Estados Iberoamericanos para la Educación, la Ciencia y la Cultura. (0ЕI). (2017). Módulo: aprendizaje a o largo de la vida. 0EI. https://bit. ly/3hR520s 
Organización de las Naciones Unidas para la Educación, la Ciencia y la Cultura. (unESCO). (2019). La promesa de las evaluaciones de aprendizaje a gran escala. Reconocer los límites para generar oportunidades. unEsco.

Organización de las Naciones Unidas para la Educación, la Ciencia y la Cultura. (unESco). (s. f.). Aprendizaje a lo largo de la vida. https://bit.ly/3kre0jG Organización de las Naciones Unidas para la Educación, la Ciencia y la Cultura. (UNESCO) (s.f.). Fichas prácticas. https://bit.ly/3FybJiu

Organización para la Cooperación y el Desarrollo Económicos. (OCDE). (2016). Educación en Colombia: aspectos destacados. oCDE. https://bit.ly/3nQw00Y

Pontificia Universidad Javeriana. (s. f.). Seguimiento de aprendizajes. https:// bit.ly/3iKjsQm

Sarria, J. A. (s. f.). Evaluación educativa: planteamientos teóricos básicos. Monografías.com. https://bit.ly/2VXBoPz

Santiago, R., Díez, A. y Andía, L. (2017). The Flipped Classroom. Editorial uoc.

Siemens, G. (2010). What Are Learning Analytics? https://bit.ly/2YzR5gY

Stelzer, F. y Cervigni, M. (2011). Desempeño académico y funciones ejecutivas en infancia y adolescencia. Una revisión de la literatura. Revista de investigación en educación, 9(1), 148-156.

Universidad Cooperativa de Colombia. (Ucc). (2021). Acuerdo Superior 012. Por el cual se crea el Centro de Monitoreo del Aprendizaje a lo Largo de la Vida, para Todos en la Universidad Cooperativa de Colombia. ucc. https://bit.ly/3j0z70W

Universidad Cooperativa de Colombia. (UCC). (2019). Acuerdo Superior 459. Por el cual se actualizan los lineamientos para el reconocimiento de la competencia dentro del programa de formación Open Lingua de la Universidad Cooperativa de Colombia. ucc. https://bit.ly/3oStVx0

Universidad Cooperativa de Colombia. (UCC). (2018). Acuerdo Superior 366. Por el cual se actualiza el régimen de preparatorios de la Universidad Cooperativa de Colombia. ucc. https://bit.ly/3AuNX3E 
Universidad Cooperativa de Colombia. (ucc). (2017a). Acuerdo Superior 312. Por el cual se crea el Sistema Institucional de Evaluación por Competencias. ucc. https://bit.ly/3EzA0sB

Universidad Cooperativa de Colombia. (UCc). (2017b). Cartilla Proyecto Centro de monitoreo del aprendizaje a lo largo de toda la vida. Documento de trabajo.

Universidad Cooperativa de Colombia. (Ucc). (2013a). Acuerdo Superior 147. Por el cual se actualiza el Proyecto Institucional. ucc. https://bit.ly/3zwCU8N

Universidad Cooperativa de Colombia. (UCc). (2013b). Resolución Rectoral 432. Por el cual se modifica y reglamenta la política de beneficios y estímulos para estudiantes y egresados de la Universidad Cooperativa de Colombia y entidades en convenio. ucc. https://bit.ly/3LMLrzR

Universidad Cooperativa de Colombia. (ucc). (2011). Acuerdo Superior 044. Por medio del cual se crea el programa Enlace. ucc. https://bit.ly/3EuiQHY

Universidad Cooperativa de Colombia. (ucc). (s. f.). Acompañamiento académico. ucc. https://bit.ly/3lHJXXu

Universidad Cooperativa de Colombia. (ucc). (s. f.). Observatorio de impacto y dinámica ocupacional. ucc. https://bit.ly/3EDEB8g

Universidad del Norte. (s. f.). Centro de recursos para el éxito estudiantil. Universidad del Norte. https://bit.ly/3hNknPG

Valenzuela, C. y Pérez, S. (2012). Diseño e implementación de Sistema de Seguimiento de Estudiantes y Titulados de la Universidad Diego Portales. Revista Calidad en la Educación, 37. http://dx.doi.org/10.31619/caledu.n37.91 
